\title{
Issues in the Use of Weapons-Grade MOX Fuel in VVER-1000 Nuclear Reactors: Comparison of $\mathrm{UO}_{2}$ and MOX Fuels
}

October 2004

\author{
Prepared by \\ J.C. Gehin \\ J.J. Carbajo \\ R.J. Ellis
}




\section{DOCUMENT AVAILABILITY}

Reports produced after January 1, 1996, are generally available free via the U.S. Department of Energy (DOE) Information Bridge:

Web site: http://www.osti.gov/bridge

Reports produced before January 1, 1996, may be purchased by members of the public from the following source:

National Technical Information Service

5285 Port Royal Road

Springfield, VA 22161

Telephone: 703-605-6000 (1-800-553-6847)

TDD: 703-487-4639

Fax: 703-605-6900

E-mail: info@ntis.fedworld.gov

Web site: http://www.ntis.gov/support/ordernowabout.htm

Reports are available to DOE employees, DOE contractors, Energy Technology Data Exchange (ETDE) representatives, and International Nuclear Information System (INIS) representatives from the following source:

Office of Scientific and Technical Information

P.O. Box 62

Oak Ridge, TN 37831

Telephone: 865-576-8401

Fax: 865-576-5728

E-mail: reports@adonis.osti.gov

Web site: http://www.osti.gov/contact.html

This report was prepared as an account of work sponsored by an agency of the United States Government. Neither the United States government nor any agency thereof, nor any of their employees, makes any warranty, express or implied, or assumes any legal liability or responsibility for the accuracy, completeness, or usefulness of any information, apparatus, product, or process disclosed, or represents that its use would not infringe privately owned rights. Reference herein to any specific commercial product, process, or service by trade name, trademark, manufacturer, or otherwise, does not necessarily constitute or imply its endorsement, recommendation, or favoring by the United States Government or any agency thereof. The views and opinions of authors expressed herein do not necessarily state or reflect those of the United States Government or any agency thereof. 
ORNL-2004/223

ISSUES IN THE USE OF MOX FUEL IN VVER-1000

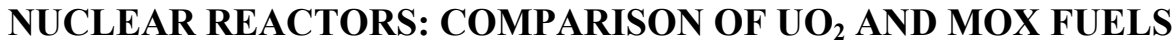

\author{
J. C. Gehin \\ J. J. Carbajo \\ R. J. Ellis
}

Date Published: October 2004

\author{
Prepared by \\ OAK RIDGE NATIONAL LABORATORY \\ P.O. Box 2008 \\ Oak Ridge, Tennessee 37831-6283 \\ managed by \\ UT-Battelle, LLC \\ for the \\ U.S. DEPARTMENT OF ENERGY \\ under contract DE-AC05-00OR22725
}





\section{CONTENTS}

Page

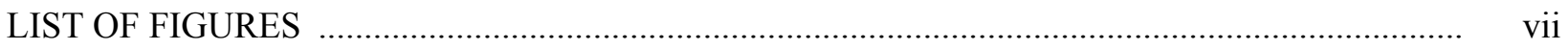

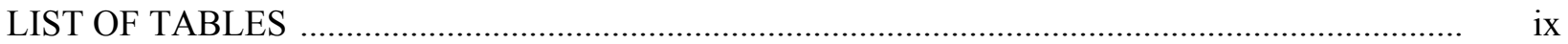

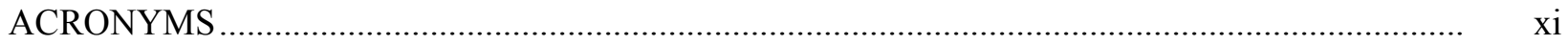

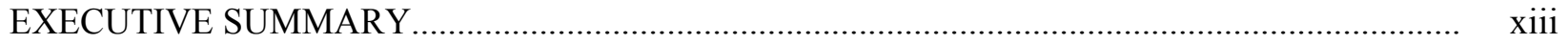

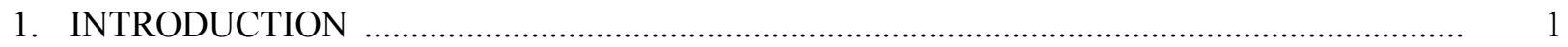

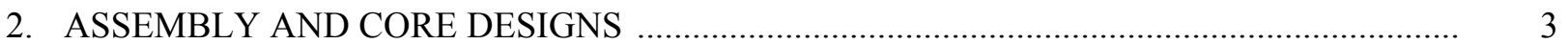

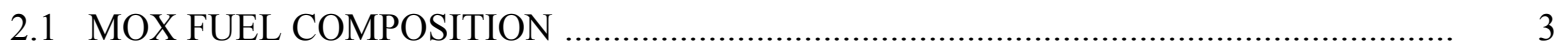

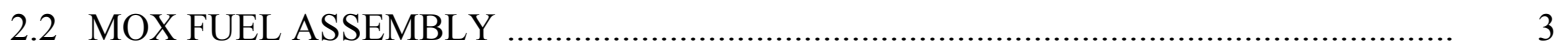

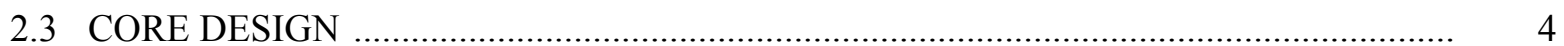

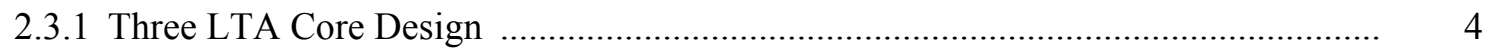

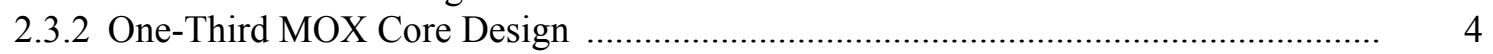

2.3.3 Increased Disposition Rate Cores …..................................................................... 7

2.3.3.1 Evaluation of the Increase in the MOX Core Fraction ............................... 7

2.3.3.2 Increase in the Plutonium Content of the MOX Fuel ................................... 8

2.3.3.3 Reduction in the MOX Fuel Residence Time.............................................. 8

2.3.4 Core Designs with Increased Disposition Rates .................................................. 10

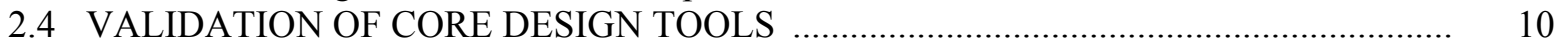

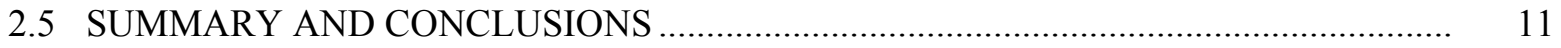

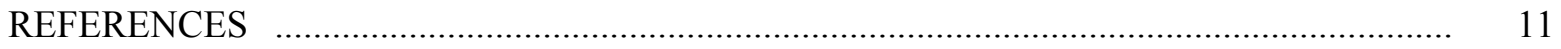

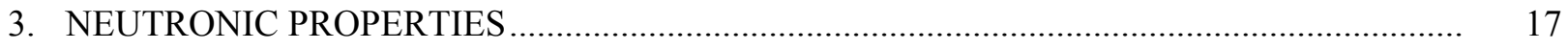

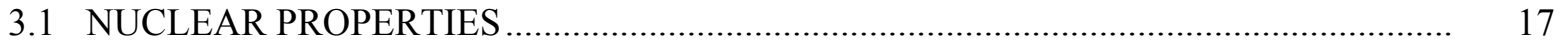

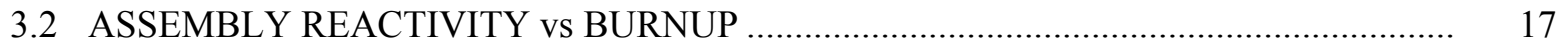

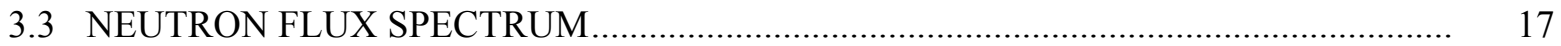

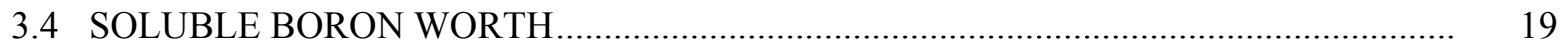

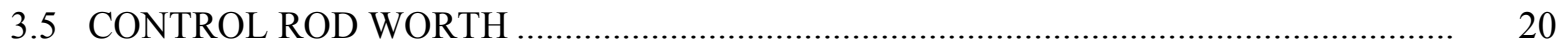

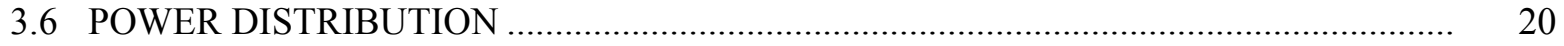

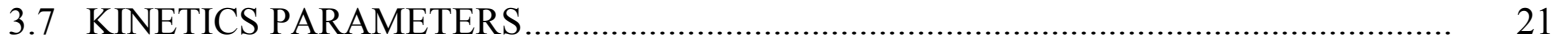

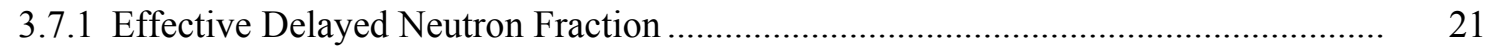

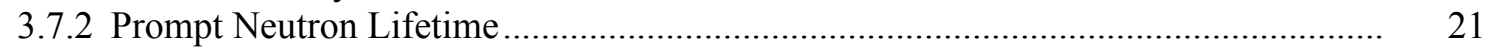

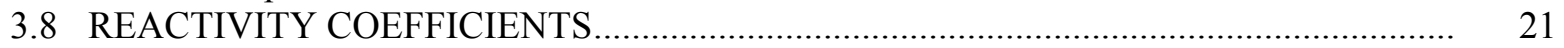

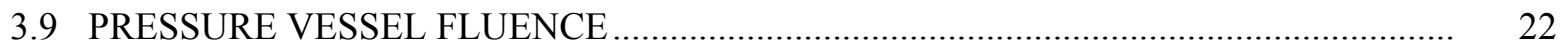

3.10 SUMMARY AND CONCLUSIONS …......................................................... 23

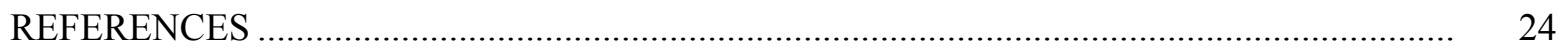

4. MOX AND UO $\mathrm{UO}_{2}$ THERMOPHYSICAL PROPERTIES .................................................... 27

4.1 MOX AND UO $\mathrm{U}_{2}$ PROPERTY DIFFERENCES ............................................................ 27

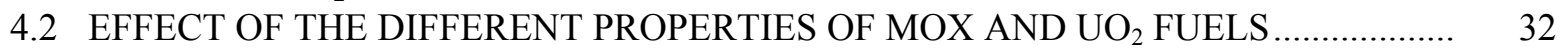

4.3 SUMMARY AND CONCLUSIONS …...................................................................... 34

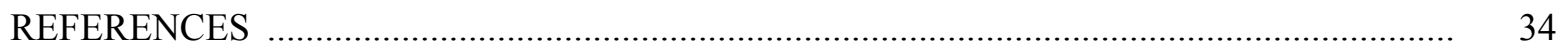




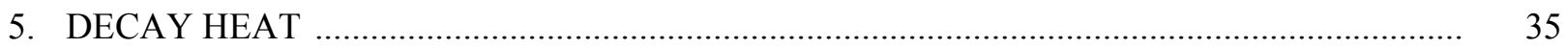

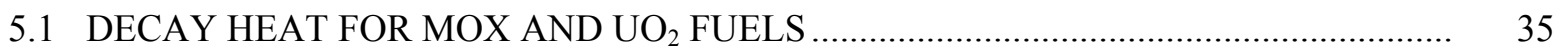

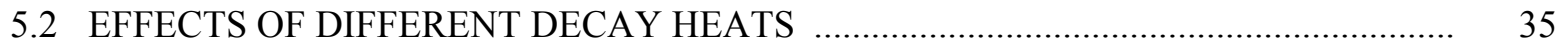

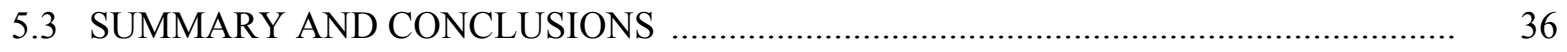

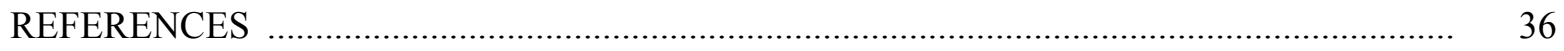

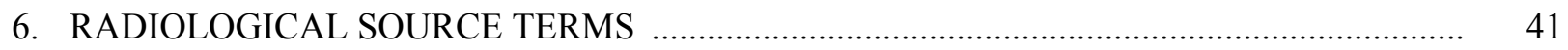

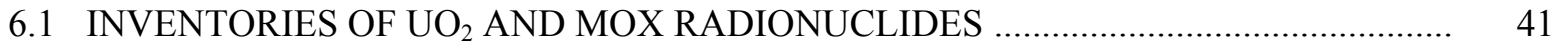

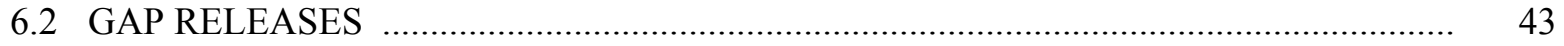

6.3 EFFECTS OF THE DIFFERENT SOURCE TERMS …..............................................

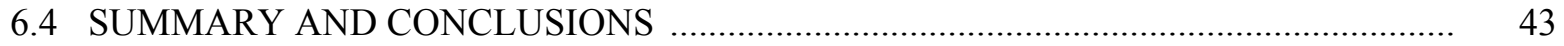

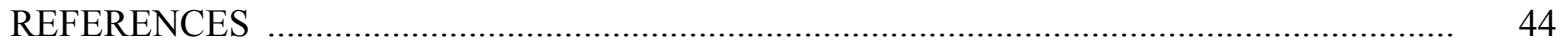

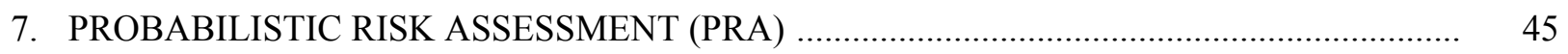

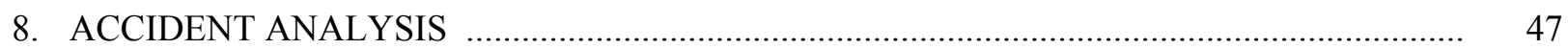

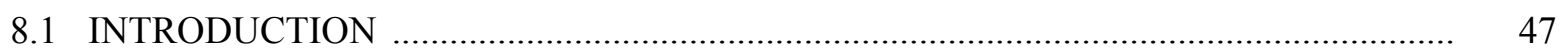

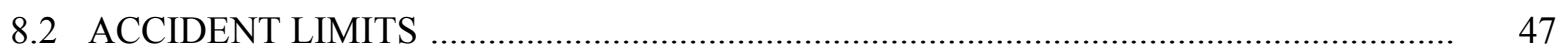

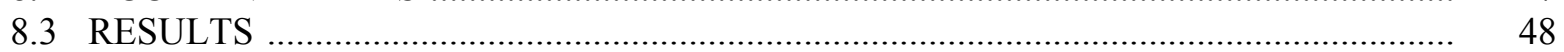

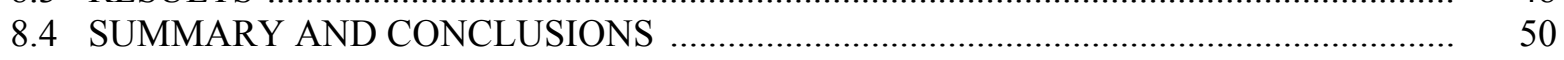

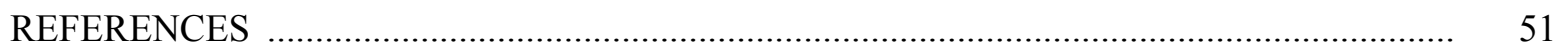

9. FRESH FUEL CRITICALITY AND DOSE PROPERTIES ............................................... 55

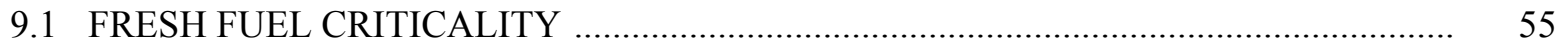

9.1.1 Criticality of $\mathrm{UO}_{2}$ and MOX Assemblies in Package Sets ................................. 55

9.1.2 Criticality of $\mathrm{UO}_{2}$ and MOX Assemblies in Fresh Fuel Depository .......................... 56

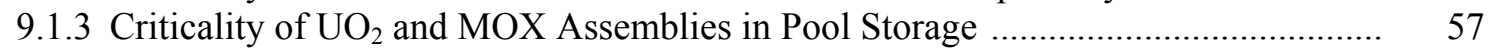

9.1.4 Criticality of $\mathrm{UO}_{2}$ and MOX Assemblies in Fuel Transfer Container ..................... 59

9.1.5 Conclusions on Criticality of Fresh MOX Fuel …............................................ 59

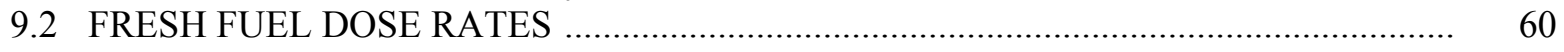

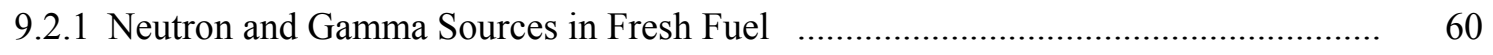

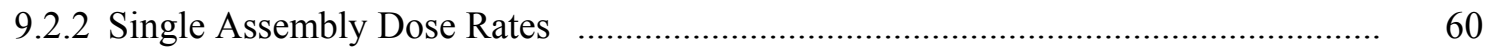

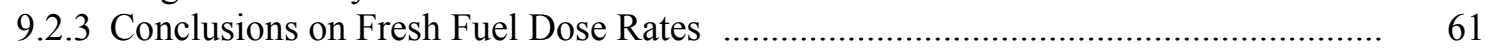

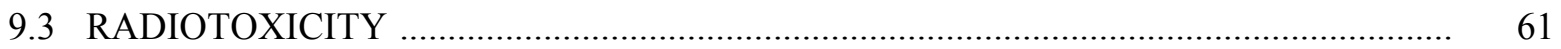

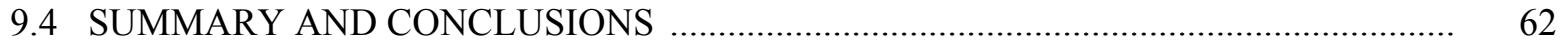

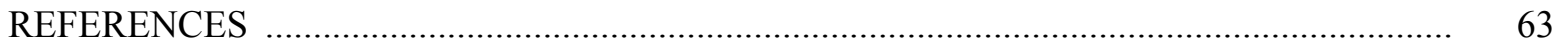

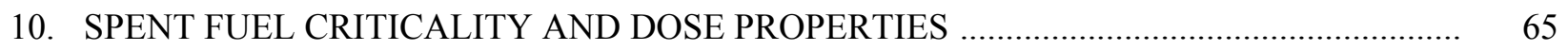

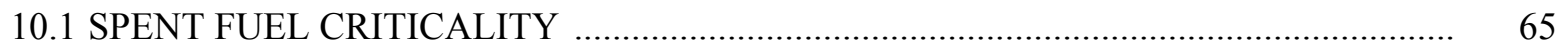

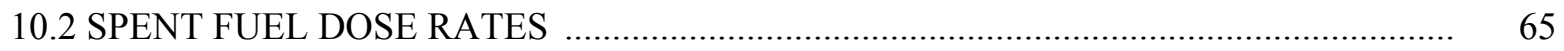

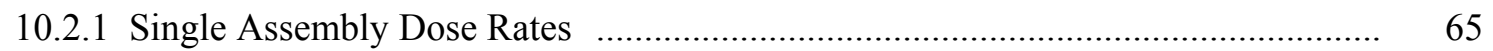

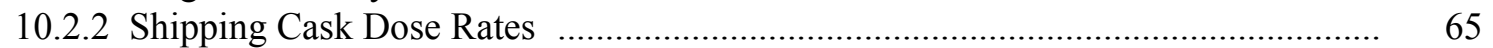

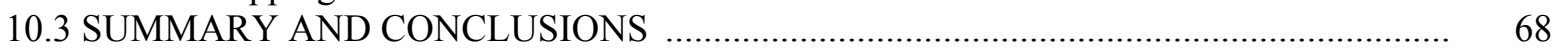

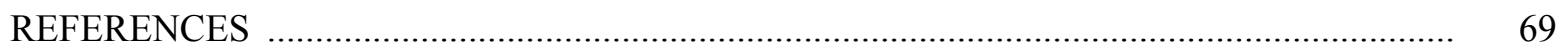

11. SECURITY AND MATERIAL PROTECTION CONTROL AND ACCOUNTABILITY

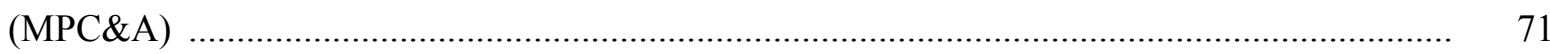

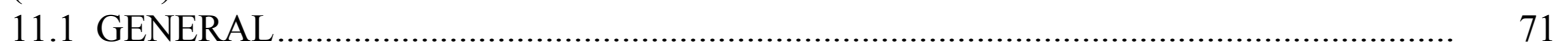

11.2 NONPROLIFERATION AND INTERNATIONAL SAFEGUARDS ............................. 71

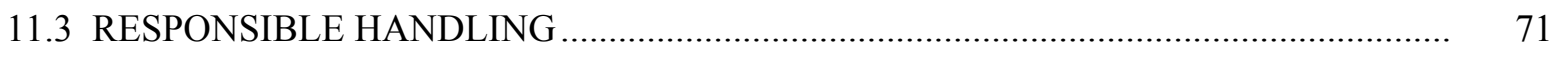




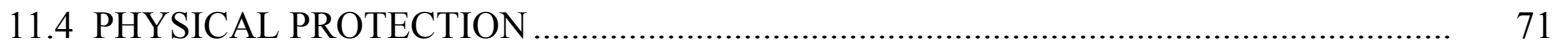

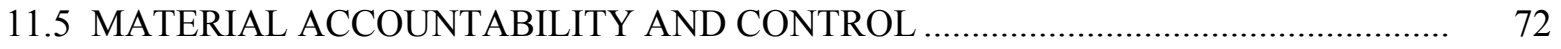

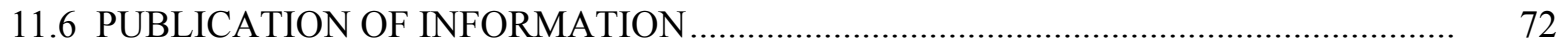

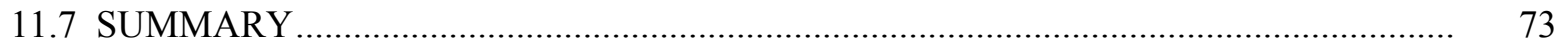

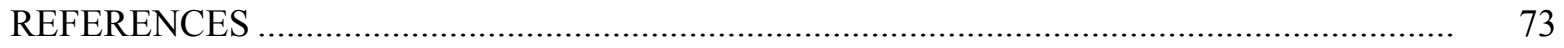

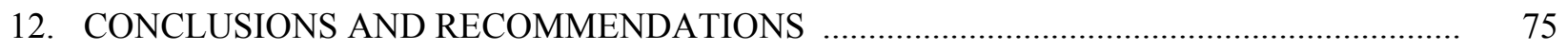

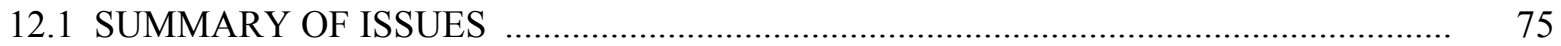

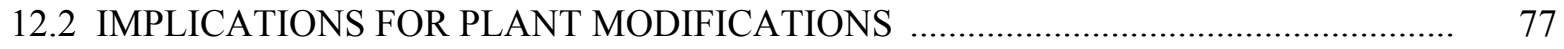




\section{LIST OF FIGURES}

Figure $\quad$ Page

2.1 U41G6n uranium fuel assembly design ............................................................... 5

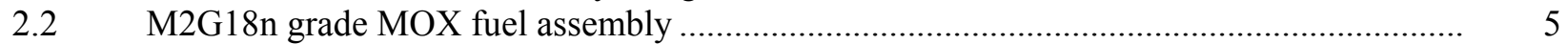

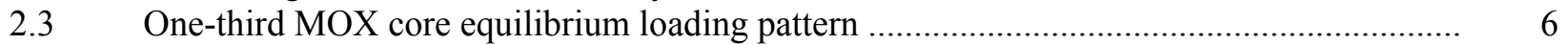

2.4 Key core parameters as a function of MOX core fraction............................................... 9

3.1 Comparison of infinite multiplication factor for $\mathrm{MOX}$ and $\mathrm{UO}_{2}$ assemblies ....................... 18

3.2 Azimuthal variation of the fast neutron flux near core midplane...................................... 25

3.3 Axial variation in the fast neutron flux at 10.3 degrees (azimuthal maximum) .................. 26

4.1 Variation of fuel melting temperature as a function of mole fraction (y) of $\mathrm{PuO}_{2} \ldots \ldots \ldots \ldots \ldots . . . . .29$

4.2 Influence of burnup on fuel melting temperature ......................................................... 30

4.3 Thermal expansion of $\mathrm{UO}_{2}$ and $\mathrm{PuO}_{2}$ fuels................................................................ 31

4.4 Variation of the heat capacity as a function of temperature and fuel composition............... 31

4.5 Thermal conductivity of $\mathrm{UO}_{2}$ and $\mathrm{MOX}$ fuel for different burnups....................................... 32

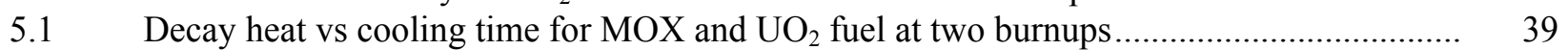

5.2 Ratio of MOX and $\mathrm{UO}_{2}$ decay heats during the first $20 \mathrm{~d}$ of cooling time .......................... 40

5.3 Ratio of MOX and $\mathrm{UO}_{2}$ decay heats up to $10,000 \mathrm{~d}$ of cooling time................................. 40

6.1 Fission gas releases from European fuels.........................................................................

8.1 Relative power calculated for the control rod ejection with three different

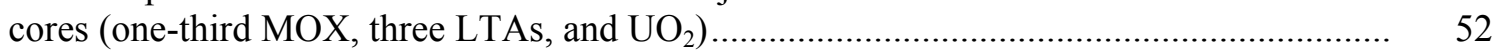

8.2 Relative power calculated by OKB-Gidropress for the control rod ejection. ...................... 53

8.3 Cladding temperatures calculated for the one-third core MOX after control rod ejection..... 54

9.1 Cross section view of a package set for VVER-1000 FA transportation............................. 56

9.2 Single assembly models used for calculational analysis of compact and noncompact cooling pool arrangements ...................................................................................... 57

9.3 Dependency of the effective multiplication factor on FA placement pitch in compact and noncompact cooling pools .................................................................................... 58

9.4 Dependency of the effective multiplication factor on water density in FA for compact and noncompact cooling pools .................................................................................. 58

9.5 Cross-sectional view of fuel transfer container.............................................................. 59

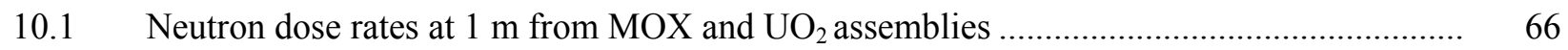

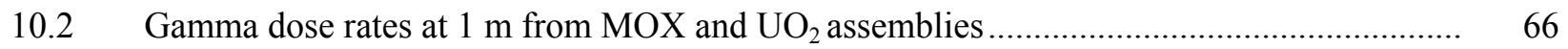

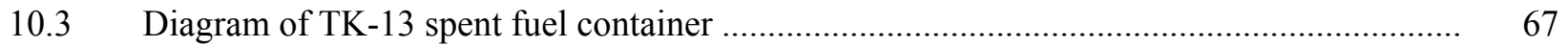




\section{LIST OF TABLES}

Table

Page

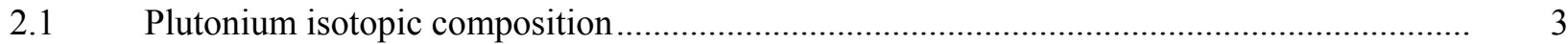

2.2 Comparison of performance of uranium (V-320 core design) and one-third MOX cores ..... 6

2.3 Parameters of the $\mathrm{UO}_{2}$ and MOX core designs with increased disposition rates ................. 12

2.4 Database for validation of Russian neutronics codes .....................................................

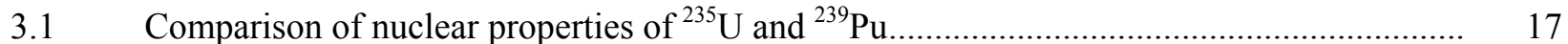

3.2 Comparison of the thermal and fast neutron fluxes in $\mathrm{MOX}$ and $\mathrm{UO}_{2}$ fuel assemblies ......... 18

3.3 Comparison of boron concentrations for $\mathrm{UO}_{2}$ and increase-disposition-rate MOX cores ..... 19

3.4 Comparison of the pin peaking factors and linear heat rates between

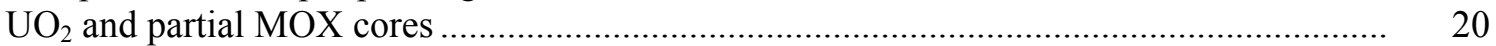

3.5 Comparison of the effective delayed neutron fraction for $\mathrm{UO}_{2}$ and partial MOX cores ........ 21

3.6 Comparison of reactivity coefficients for $\mathrm{UO}_{2}$ and $\mathrm{MOX}$ core designs............................... 22

3.7 Results of fast neutron flux $\left(\mathrm{E}>0.5 \mathrm{MeV}, 10^{9} \mathrm{n} / \mathrm{cm}^{2} \mathrm{~s}\right)$ at the pressure vessel

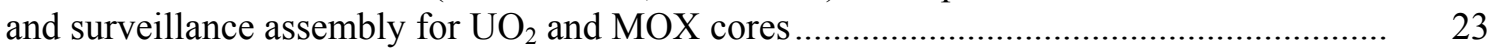

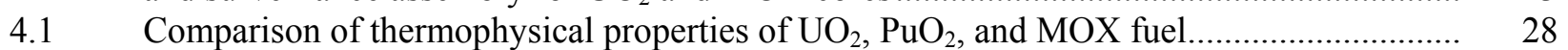

5.1 MOX and LEU fuel assembly decay heat as a function of discharge burnup..................... 37

5.2 Ratio of decay heat — MOX to LEU fuel assemblies ...................................................... 38

6.1 Actinide activity source terms for discharged $\mathrm{MOX}$ and $\mathrm{UO}_{2}$ fuel .....................................

6.2 FP nuclide source terms for discharged $\mathrm{MOX}$ and $\mathrm{UO}_{2}$ fuel ..........................................

9.1 Multiplication factors in infinite grid of package set cells with $\mathrm{UO}_{2}$ and $\mathrm{MOX}$ FA ............ 55

9.2 Comparison of the neutron and gamma sources (relative units) for fresh $\mathrm{UO}_{2}, \mathrm{WG} \mathrm{MOX}$, and RG MOX

9.3 Neutron and gamma dose rates at FA surface and total dose as a function of distance from the FA.

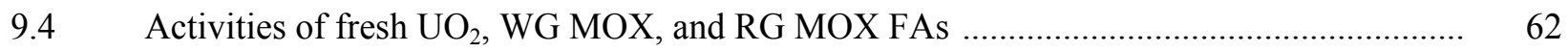

10.1 Comparison of neutron and gamma sources for spent $\mathrm{UO}_{2}$, WG MOX, and RG MOX

10.2 Neutron and gamma dose rates at transportation cask surface and total dose as a function of distance from the cask 


\section{ACRONYMS}

\begin{tabular}{|c|c|}
\hline B & burnup (at. \%) or boron \\
\hline BFS & zero power facility at IPPE \\
\hline $\mathrm{BN}$ & fast reactor in Russia \\
\hline $\mathrm{BOC}$ & beginning of cycle \\
\hline BWR & boiling-water reactor \\
\hline BV & noncompact cooling pool \\
\hline $\mathrm{CDF}$ & core damage frequency \\
\hline $\mathrm{CPC}$ & control protection system \\
\hline DNB & departure from nucleate boiling \\
\hline DOE & Department of Energy \\
\hline EFPD & effective full-power day \\
\hline $\mathrm{EOC}$ & end of cycle \\
\hline ESADA & Empire State Atomic Development Associates \\
\hline FA & fuel assembly \\
\hline FP & fission product \\
\hline Fr & France \\
\hline Frag & fragment \\
\hline Germ & Germany \\
\hline Hex & hexagonal \\
\hline HL & high leakage \\
\hline HM & heavy metal \\
\hline HPSIS & high-pressure safety injection system \\
\hline IAEA & International Atomic Energy Agency \\
\hline ICSBEP & international criticality safety benchmark evaluation project \\
\hline INEEL & Idaho National Engineering and Environmental Laboratory \\
\hline IPPE & Institute for Physics and Power Engineering \\
\hline ISTC & International Scientific and Technical Center \\
\hline $\mathrm{L}$ & liquid \\
\hline LEU & low-enriched uranium \\
\hline LL & low leakage \\
\hline LOCA & loss-of-coolant accident \\
\hline LTA & lead test assembly \\
\hline MECR & most efficient control rod \\
\hline MPC\&A & material protection control and accountability \\
\hline MOX & mixed oxide \\
\hline MSLB & main steam line break \\
\hline MT & metric ton \\
\hline MTC & moderator temperature coefficient \\
\hline NEA & Nuclear Energy Agency \\
\hline NPP & nuclear power plant \\
\hline NPT & nonproliferation treaty \\
\hline NRC & Nuclear Regulatory Commission \\
\hline OECD & Organization for Economic Cooperation and Development \\
\hline OKB-GP & OKB-Gidropress \\
\hline ORNL & Oak Ridge National Laboratory \\
\hline PCMI & pellet-to-cladding mechanical interaction \\
\hline PLL & partial low leakage \\
\hline QA & quality assurance \\
\hline PRA & probabilistic risk assessment (or analysis) \\
\hline PSA & probabilistic safety assessment (or analysis) \\
\hline
\end{tabular}




$\begin{array}{ll}\text { PV } & \text { pressure vessel } \\ \text { PWR } & \text { pressurized-water reactor } \\ \text { R\&D } & \text { research and development } \\ \text { RFGS } & \text { zero power facility at IPPE } \\ \text { RG } & \text { reactor grade } \\ \text { RIA } & \text { reactivity insertion accident } \\ \text { RRC-KI } & \text { Reactor Research Center-Kurchatov Institute } \\ \text { RU } & \text { Russia } \\ \text { SLL } & \text { super low leakage } \\ \text { S } & \text { solid } \\ \text { SG } & \text { steam generator } \\ \text { SGT } & \text { safeguards transport } \\ \text { Sq } & \text { square } \\ \text { SST } & \text { safe and secure trailer } \\ \text { SUPR } & \text { Russian facility with uranium and plutonium lattices } \\ \text { TD } & \text { theoretical density } \\ \text { UBV } & \text { compact cooling pool } \\ \text { U.S. } & \text { United States } \\ \text { VVER (WWER) } & \text { water-moderated water-cooled energy reactor } \\ \text { WG } & \text { weapons grade }\end{array}$




\section{EXECUTIVE SUMMARY}

The purpose of this report is to quantify the differences between mixed oxide (MOX) and lowenriched uranium (LEU) fuels and to assess in reasonable detail the potential impacts of MOX fuel use in VVER-1000 nuclear power plants in Russia. This report is a generic tool to assist in the identification of plant modifications that may be required to accommodate receiving, storing, handling, irradiating, and disposing of MOX fuel in VVER-1000 reactors.

The report is based on information from work performed by Russian and U.S. institutions. The report quantifies each issue, and the differences between LEU and MOX fuels are described as accurately as possible, given the current sources of data.

The VVER-1000 reactor has a total of 163 assemblies in the core. Before mission fuel is loaded in the core, three MOX assemblies, called the lead test assemblies (LTAs) will be loaded and burned for two or three cycles. Mission fuel will be loaded depending on the fueling scheme from one-third core MOX up to $45 \%$ core MOX. The remaining core will be regular $\mathrm{UO}_{2}$ fuel assemblies. The final fueling scheme has not been determined yet.

The issues that have been analyzed are assembly and core design, neutronic properties, thermophysical properties, decay heat, source terms, probabilistic risk analysis, accident analysis, fresh fuel criticality and doses, spent fuel criticality and doses, and security and accountability.

The overall physical configuration of MOX fuel assemblies will be identical to $\mathrm{UO}_{2}$ fuel assemblies. Power peaking factors for MOX fuel will be very similar to $\mathrm{UO}_{2}$ fuel. The plutonium contents in a MOX assembly must be profiled to reduce $\mathrm{MOX} / \mathrm{UO}_{2}$ assembly discontinuities. The neutronic properties of both fuels are different, with different kinetic parameters that result in faster reactions to power changes in MOX fuel compared to $\mathrm{UO}_{2}$ fuel. MOX fuel also absorbs more thermal neutrons than $\mathrm{UO}_{2}$ fuel and reduces the worth of the control rods, and the worth of the boron dissolved in the coolant is greatly reduced. Thus, control rod worth and boron concentration in the coolant may need to be increased. Some analyses have already been performed with $80 \%$ enriched boron in the control rods. Additional investigation of the safety systems, particularly the boron injection system, is necessary to determine the need for enriched soluble boron.

MOX fuel has a number of properties that are different from $\mathrm{UO}_{2}$ fuel. It has a lower thermal conductivity than $\mathrm{UO}_{2}$ fuel, resulting in higher centerline temperatures and more energy stored than $\mathrm{UO}_{2}$ fuel at comparable power levels. MOX fuel has more inhomogeneities, lower heat of fusion, and lower melting temperature than $\mathrm{UO}_{2}$ fuel. Irradiated $\mathrm{MOX}$ fuel has a lower decay heat in the short term (days) but a larger decay heat in the long term than $\mathrm{UO}_{2}$ fuel. Irradiated $\mathrm{MOX}$ and $\mathrm{UO}_{2}$ fuels have different source terms, with more MOX actinides and larger inventories of some fission products (e.g., $\left.{ }^{131} \mathrm{I}\right)$ than $\mathrm{UO}_{2}$ fuel. MOX fuel may have larger gap releases than $\mathrm{UO}_{2}$ fuel that may result in larger pressures inside the gap. Fresh MOX fuel has also larger neutron and gamma sources than fresh $\mathrm{UO}_{2}$ fuel, resulting in doses about eight times larger. MOX fuel has higher radiotoxicity than $\mathrm{UO}_{2}$ fuel. This is an important consideration in transportation and handling of MOX fuel. 
Fuel assembly criticality with MOX fuel is comparable to $\mathrm{UO}_{2}$ fuel values. Pressure vessel fluence with MOX fuel is not an issue with appropriate fuel loadings (no MOX loaded in the core periphery). Similarly, design accident calculations completed with cores with one-third MOX appear to be within safety margins and comparable to calculations performed with $100 \% \mathrm{UO}_{2}$ fuel. Calculations with $41 \%$ MOX fuel will be completed in the future.

Because MOX fuel contains weapons-grade plutonium that can be diverted to weapons use, additional security and control accountability measures must be implemented. The control rods of cores with $30-40 \%$ MOX need to be upgraded by increasing the enrichment of ${ }^{10} \mathrm{~B}$ to $80 \%$ (from the natural concentration of $19.8 \%$ ). The need of other modifications or upgrades cannot be decided until more studies and calculations are completed. 


\section{INTRODUCTION}

In July 1998 the Presidents of the United States and Russian Federation signed the Agreement on Scientific and Technical Cooperation in the Management of Plutonium that has been withdrawn from Nuclear Military Programs ("July 1998 Agreement"). Each country is pledged to the disposition of no less than 34 metric tons (MT) of this plutonium, according to roughly parallel timetables, at an average annual rate of approximately 2 MT following the construction and/or modification of the requisite facilities. The agreement provides for the prioritization, coordination, review, and approval of cooperative projects to evaluate and initiate research and development (R\&D) tasks to support the use of mixed-oxide (MOX) fuel in water-moderated, water-cooled energy reactors (VVER) and fast reactors $(\mathrm{BN})$ in Russia and pressurized-water reactors (PWR) in the United States.

There are nine completed VVER-1000 reactors in Russia, of which the newest units are the best candidates for using MOX fuel. These reactors are located at the following stations: Balakovo (four units commissioned in the late 1980s/early 1990s), Kalinin (three units commissioned in 1985, 1987, and 2004), Rostov (commissioned in 2001) and Novovoronezh (one unit commissioned in 1974). Two additional reactors are scheduled to come online in the near future; Rostov 2 (2007) and Balakovo 5 (2008). In 1998 the Balakovo-4 unit was designated as the lead unit for lead test assembly (LTA) testing and initial mission fuel use.

The purpose of the report is to quantify the differences between MOX and low-enriched uranium (LEU) fuels and to assess in reasonable detail the potential impacts of MOX fuel use in VVER-1000 nuclear power plants in Russia. The report is a tool to assist in the identification of any plant modifications that may be required to accommodate receiving, storing, handling, irradiating, and disposing of MOX fuel in VVER-1000 reactors.

The information contained in this report has been collected from previous work performed in this program by Russian and U.S. institutions and supplemented as necessary to provide additional information. The report quantifies each issue and the differences between LEU and MOX fuels are described as accurately as possible, given the current sources of data. As more data and additional studies are completed in the near future, the report will be upgraded and completed in the areas where there is incomplete information at the present time. 


\section{ASSEMBLY AND CORE DESIGNS}

The goal in the introduction of the MOX fuel into VVER-1000 reactors is to change the assembly and core designs as little as possible to provide physical compatibility with the existing assemblies and core design as well as nuclear compatibility in terms of reactivity and power peaking. This chapter will present the MOX assembly and core designs based on activities during the past several years.

\subsection{MOX FUEL COMPOSITION}

The MOX fuel used in the assembly and core designs requires the specification of the isotopic composition of the uranium and weapons plutonium used $\left(\mathrm{UO}_{2}\right.$ and $\mathrm{PuO}_{2}$ powders $)$ in the manufacturing process. The uranium used in the MOX fuel is depleted with a ${ }^{235} \mathrm{U}$ content of $0.2 \mathrm{wt} \%$. The weaponsgrade (WG) plutonium will be mixed with other reactor-grade (RG) plutonium to arrive at a final isotopic specification to be used in the manufacture of MOX fuel. In early studies, an isotopic vector was assumed to be $93 \%{ }^{239} \mathrm{Pu}, 6 \%{ }^{240} \mathrm{Pu}$, and $1 \%{ }^{241} \mathrm{Pu}$ (Ref. 1). For analysis purposes, the precise specification for the plutonium isotopes has been declared and is provided in Table 2.1. The values are slightly different than those assumed in early analysis, but this small difference will have no impact on the analysis results. The quantity of $\mathrm{PuO}_{2}$ mixed with the $\mathrm{UO}_{2}$ varies depending upon the specific assembly design. Values range from $2.5-5 \mathrm{wt} \%$.

Table 2.1 Plutonium isotopic composition

\begin{tabular}{|l|c|c|c|c|c|c|}
\hline Isotope & ${ }^{238} \mathrm{Pu}$ & ${ }^{239} \mathrm{Pu}$ & ${ }^{240} \mathrm{Pu}$ & ${ }^{241} \mathrm{Pu}$ & ${ }^{242} \mathrm{Pu}$ & ${ }^{241} \mathrm{Am}$ \\
\hline Content, wt \% & 0.13 & 91.72 & 6.55 & 1.17 & 0.43 & 0.0 \\
\hline
\end{tabular}

Source: Ref. 2.

\subsection{MOX FUEL ASSEMBLY}

The design of the MOX fuel assembly is based on that of the standard $\mathrm{UO}_{2}$ assembly designs currently in use in Russia. This assembly design has evolved from using stainless steel cladding and grid spacers to zirconium-niobium alloy cladding to reduce the parasitic neutron absorption in the assembly structures. The physical geometry of the MOX assembly is identical to that of the $\mathrm{UO}_{2}$ assembly and therefore has the same flow area and geometric compatibility to provide arbitrary placement in the reactor core.

The $\mathrm{UO}_{2}$ assemblies generally consist of a single fuel enrichment, or at most two enrichments to minimize power peaking near the water gaps at the edge of the assemblies. The MOX assemblies require three different plutonium loading zones to minimize power peaking that occurs at interfaces between $\mathrm{MOX}$ and $\mathrm{UO}_{2}$ assemblies as a result of the larger fission and absorption cross sections of ${ }^{239} \mathrm{Pu}$ than ${ }^{235} \mathrm{U}$. Current $\mathrm{UO}_{2}$ and MOX assembly designs use $\mathrm{UO}_{2} / \mathrm{Gd}_{2} \mathrm{O}_{3}$ as burnable absorbers to control core reactivity at the beginning of cycle (BOC). The $\mathrm{UO}_{2}$ assemblies typically have six such pins with a nominal loading of 5\% gadolinium. The MOX fuel assemblies, however, require more pins, ranging from 8 to 27 pins depending on the core design because the effectiveness of the gadolinium absorber is lower as a result of the harder neutron spectrum in the MOX fuel assembly. In addition, the gadolinium loading is typically lower than $\mathrm{UO}_{2}$ assemblies, $\sim 3-4 \%$, because the gadolinium burns out more slowly. Typical $\mathrm{UO}_{2}$ and MOX fuel assemblies are shown in Figs. 2.1 and 2.2, respectively. These diagrams show typical configurations that are used for the $\mathrm{UO}_{2}$ and $\mathrm{MOX}$ assemblies with different assembly types differing in the ${ }^{235} \mathrm{U}$ enrichment and plutonium loadings. 


\subsection{CORE DESIGN}

The design of the MOX core has developed during the past several years to meet several program goals. This section discusses the one-third MOX core design and follow-on core designs to increase the plutonium disposition rate and extend the cycle length from 12 months to 18 months.

\subsubsection{Three LTA Core Design}

Evaluations of the performance of the three cycles with the three LTA assemblies have been analyzed and compared to the performance of the $\mathrm{UO}_{2}$ assemblies (Ref. 3). In general, the insertion of three MOX assemblies has no significant impact on the performance and behavior of the reactor core. Safety analysis of the LTA core configuration is discussed in Chap. 8.

\subsubsection{One-Third MOX Core Design}

The current baseline core design is a one-third MOX core configuration, which has similar performance to the advanced $\mathrm{UO}_{2}$ core design, $\mathrm{V}-320^{1}$. A diagram of this core design is presented in Fig. 2.3, and an overview of the core parameters is presented in Table 2.2. In Fig. 2.3, each hexagon represents a fuel assembly showing the fuel assembly type (U42G6 is a uranium assembly with $4.2 \mathrm{wt} \%$ enriched fuel and six uranium-gadolinium absorber rods, and P39G8 is a MOX assembly with 3.9 wt \% plutonium and eight uranium-gadolinium absorber rods) and the number of cycles that the assembly has been burned. The colors are chosen such that shades of blue represent uranium assemblies, and shades of red represent MOX assemblies. This core operates on annual cycles with a plutonium disposition rate of

$270 \mathrm{~kg} / \mathrm{year}$. The basis of this core design was to stay well within the MOX core technology developed in Europe during the past several decades. Regarding this core design there are several particular features to note:

- The MOX and $\mathrm{UO}_{2}$ bundles are arranged in a checkerboard fashion with the uranium bundles located in the periphery of the core and highly-burned bundles (four-times burned uranium assemblies) located close to the vessel to minimize the vessel fluence.

- In this design the MOX assemblies are burned for three annual cycles, and the $\mathrm{UO}_{2}$ assemblies are burned for three and four cycles.

- The number and location of control rods is unchanged from $\mathrm{UO}_{2}$ core design, but the enrichment of the $\mathrm{B}_{4} \mathrm{C}$ section has been increased to $80 \%$ to improve the control rod effectiveness.

- The power peaking factors in the MOX core are essentially the same as the power peaking factors in the $\mathrm{UO}_{2}$ core design.

- The effective delayed neutron fraction in the MOX core is about $10 \%$ lower than that of the $\mathrm{UO}_{2}$ core.

Further discussions of the neutronics issues that affect the design choices outlined above for this core design are discussed in Chap. 3. 


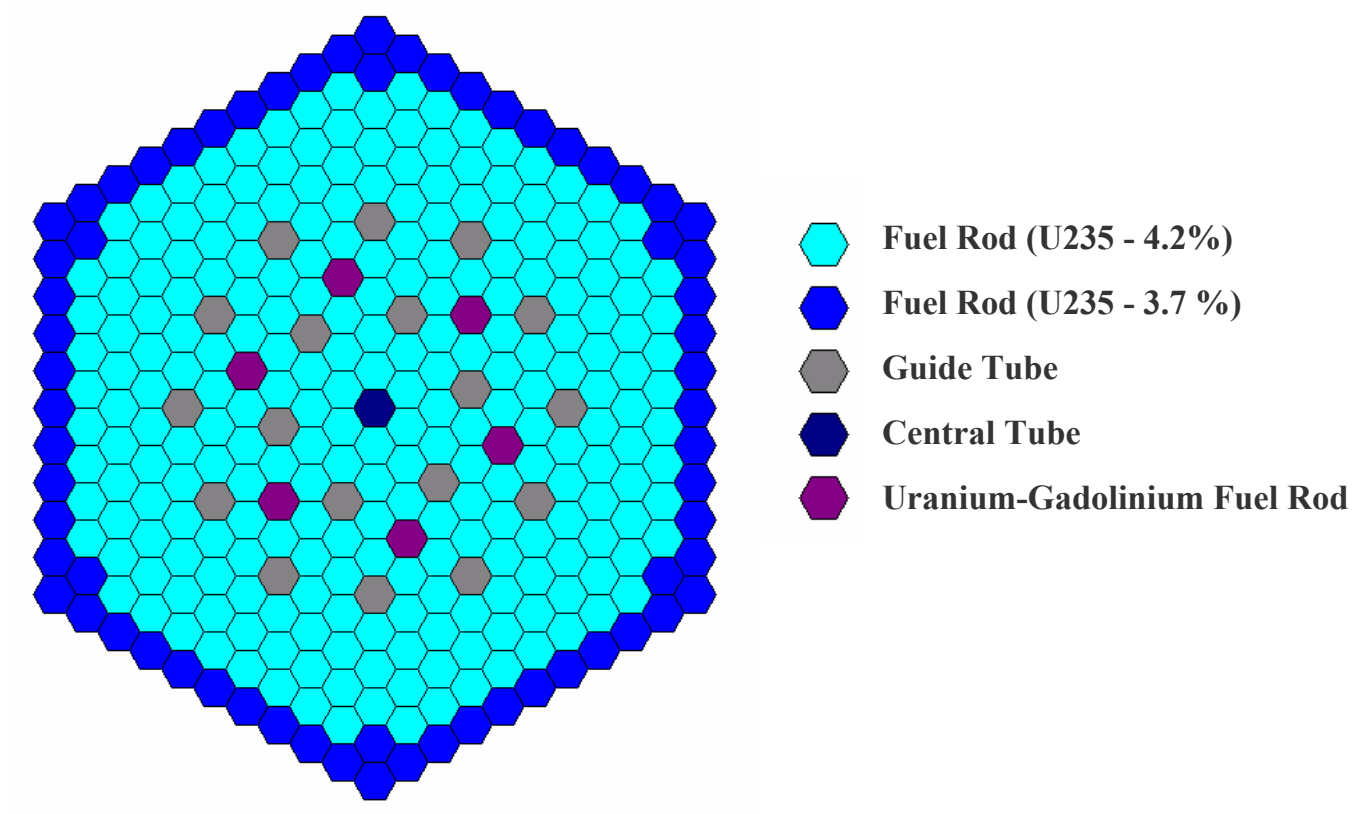

Fig. 2.1 U41G6n uranium fuel assembly design. Source: Ref. 2.

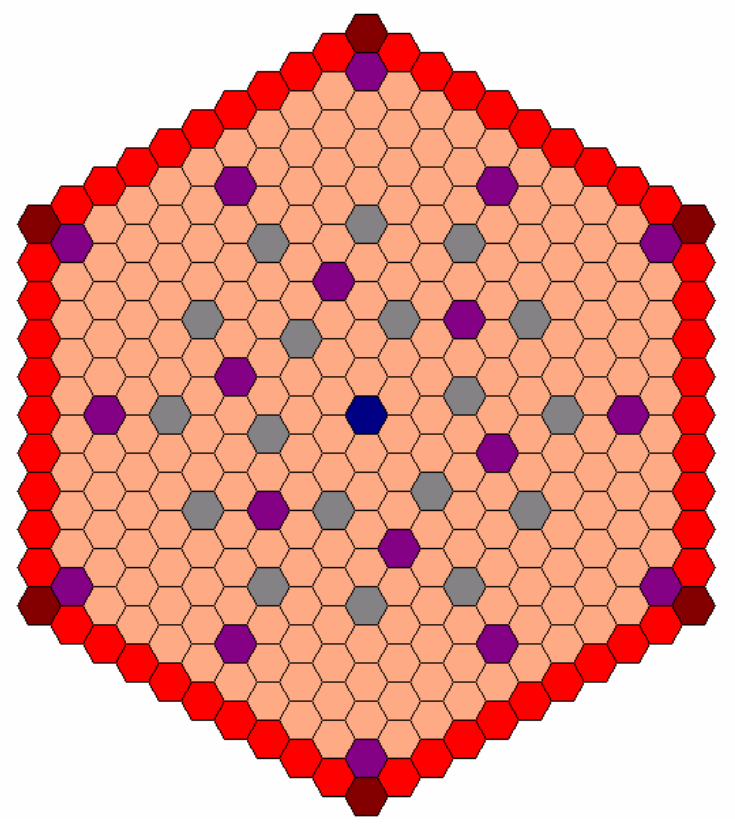

Guide Tube

Central Tube

Fuel Rod (Pu - 3.9\%)

Fuel $\operatorname{Rod}(\mathrm{Pu}-2.9 \%)$

Fuel Rod, (Pu- $2.6 \%)$

Uranium-Gadolinium Fuel Rod

Fig 2.2 M2G18n grade MOX fuel assembly. Source: Ref. 2. 


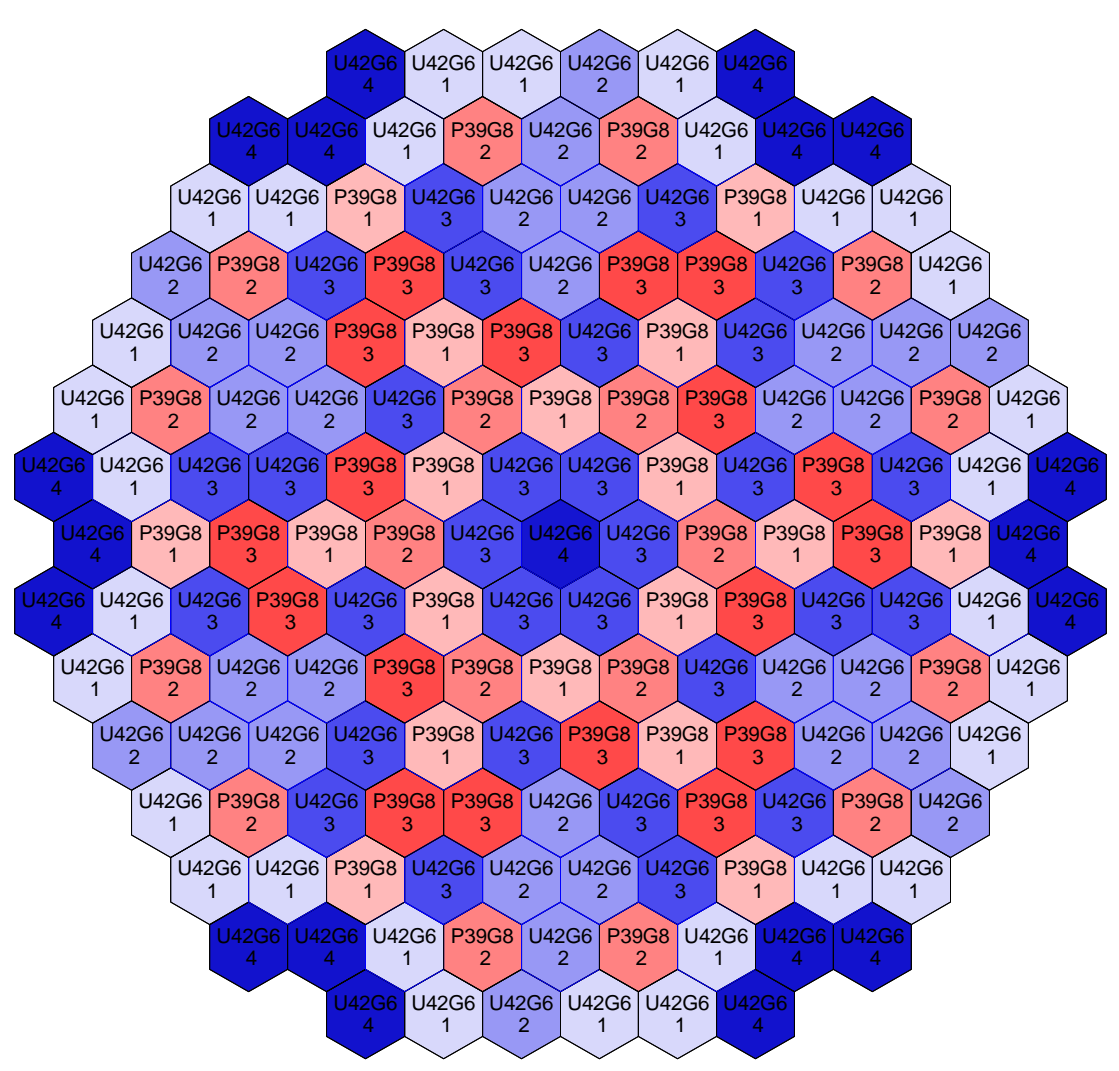

Figure 2.3 One-third MOX core equilibrium loading pattern. Source: Ref. 2.

Table 2.2 Comparison of performance of uranium (V-320 core design) and one-third MOX cores.

\begin{tabular}{|c|c|c|}
\hline & $\mathrm{UO}_{2}(\mathrm{~V}-320)$ & 1/3 MOX \\
\hline Number of assemblies loaded per cycle & $\begin{array}{l}30\left(\mathrm{UO}_{2}, 4.23 \mathrm{wt} \%{ }^{235} \mathrm{U}\right) \\
24\left(\mathrm{UO}_{2}, 4.40 \mathrm{wt} \%{ }^{235} \mathrm{U}\right)\end{array}$ & $\begin{array}{l}30\left(\mathrm{UO}_{2}, 4.08 \%{ }^{235} \mathrm{U}\right) \\
18(\mathrm{MOX}, 3.65 \% \mathrm{Pu})\end{array}$ \\
\hline MOX core fraction & - & $33 \%$ \\
\hline Annual plutonium utilization $(\mathrm{kg})$ & - & 270 \\
\hline $\begin{array}{l}\text { Average/maximum } \mathrm{UO}_{2} \text { discharge burnup } \\
(\mathrm{MWd} / \mathrm{kg})\end{array}$ & $41.2 / 48.1$ & $42.1 / 49$ \\
\hline $\begin{array}{l}\text { Average/maximum MOX discharge burnup } \\
(\mathrm{MWd} / \mathrm{kg})\end{array}$ & - & $39.1 / 39.6$ \\
\hline Cycle length (EFPD) & 298 & 283 \\
\hline Critical $\mathrm{H}_{3} \mathrm{BO}_{3}$ concentration $(\mathrm{ppm})$ & 6720 & 6910 \\
\hline Effective delayed neutron fraction & $\begin{array}{l}\text { BOC: } 0.0064 \\
\text { EOC: } 0.0056\end{array}$ & $\begin{array}{l}\text { BOC: } 0.0053 \\
\text { EOC: } 0.0051\end{array}$ \\
\hline Moderator temperature coefficient $(\mathrm{pcm} / \mathrm{C})$ & $\begin{array}{l}\text { BOC: }-23 \\
\text { EOC: }-61\end{array}$ & $\begin{array}{l}\text { BOC: }-33 \\
\text { EOC: }-68\end{array}$ \\
\hline $\begin{array}{l}\text { Shutdown reactivity margin, \% } \\
\text { (EOC, } 280^{\circ} \mathrm{C} \text {, most effective control rod } \\
\text { out) }\end{array}$ & 3.1 & 4.2 \\
\hline $\begin{array}{l}\text { Maximum assembly power over cycle } \\
\text { (relative) }\end{array}$ & 1.29 & $\begin{array}{l}\mathrm{UO}_{2}: 1.31 \\
\mathrm{MOX}: 1.26\end{array}$ \\
\hline $\begin{array}{l}\text { Maximum power of fuel pin over cycle } \\
\text { (relative) }\end{array}$ & 1.46 & $\begin{array}{l}\mathrm{UO}_{2}: 1.47 \\
\mathrm{MOX}: 1.44\end{array}$ \\
\hline
\end{tabular}

Source: Ref. 2. 


\subsubsection{Increased Disposition Rate Cores}

The baseline one-third MOX core configuration, as described previously, is able to achieve a plutonium disposition rate of $270 \mathrm{~kg} /$ year. However, to meet the required disposition rate with fewer reactors, an increase in this disposition rate is needed. The disposition rate can be increased by

- increasing the fraction of MOX assemblies in the core,

- increasing the plutonium content in the MOX fuel,

- reducing the residence time of the MOX assemblies in the reactor.

A combination of these approaches can be used to optimize the core performance and the disposition rate. The variation of each of these parameters was considered in parametric calculations to consider the impacts and limits of pursuing each approach4. Four basic core designs were considered:

- High leakage (HL) - fresh fuel placed on the periphery of the core,

- Partial low leakage (PLL) - 18 burned fuel assemblies placed at the periphery of the core,

- Low leakage (LL) - 30 burned assemblies placed at the periphery of the core, and

- Super low leakage (SLL) - only burned fuel assemblies placed at the periphery of the core.

These basic designs cover the range of possible core configurations that can be utilized in the disposition mission. The analysis performed in Ref. 4 did not optimize the various core designs, but was intended to investigate the general performance features of the various core designs.

\subsubsection{Evaluation of the Increase in the MOX Core Fraction}

For each of the possible core loading patterns the variation in key core performance properties were computed and compared as a function of the fraction of the core loaded with MOX ranging from an alluranium core to a full MOX core. Figure 2.4 shows the variation in cycle length, mass of plutonium loaded in the core, normalized pin power, delayed neutron fraction, critical boron concentration, and moderator temperature coefficient at BOC and end of cycle (EOC). These results show that the plutonium disposition rate increased from $270 \mathrm{~kg} /$ year in the one-third MOX core case to approximately $1000 \mathrm{~kg} / \mathrm{year}$ in the full MOX core. The cycle lengths decrease only slightly as the MOX fraction is increased. The basic neutron characteristics of the core changes are described as follows for an increase in the MOX core fraction from 0 to $100 \%$ :

- The critical concentration of boric acid at the BOC increases significantly with increased MOX core fraction. This increase is the result of the reduction in the worth of the boron absorber. The decrease in the boron reactivity worth may therefore require the use of enriched boron to maintain the concentration within an acceptable range.

- Without grading the MOX fuel assemblies, a significant increase in the pin power peaking occurs with fuel loadings in the $20-80 \%$ core fraction because of the $\mathrm{UO}_{2}$ and MOX assembly interfaces. Results, as shown in Table 2.2 for the one-third MOX core, show that with graded assembly designs, the power peaking in the MOX cores is similar to that of the $\mathrm{UO}_{2}$ cores.

- The moderator temperature coefficient decreases with increased MOX loading in almost a linear fashion. Therefore, the introduction of MOX fuel may affect the core behavior in overcooling accidents such as a steam line break. 
- The effective delayed neutron fraction decreases from about $0.55 \%$ to $0.36 \%$. This decrease will have an impact on the core behavior in transient conditions, and therefore safety analyses will have to be performed with these lower values.

- Both the scram efficiency and the shutdown margin decrease with increased MOX loadings as a result of the reduced worth of the control rods. Therefore, to maintain the scram reactivity and the shutdown margin to the values for the $\mathrm{UO}_{2}$ core, it will be necessary to increase the reactivity worth of the control rods.

- The use of core loading patterns with reduced core leakage can increase the effectiveness of the control systems in the higher MOX fraction cores. However, these core designs, particularly the SLL core leads to the addition of more burnable absorbers and assembly profiling, which may offset some of this gain. The current approach for core designs in VVER-1000 reactors is the use of low-leakage core configurations to maximize the fuel utilization and to minimize the neutron fluence to the pressure vessel. This is demonstrated in the one-third MOX core design shown in Fig. 2.3.

While these parametric studies have considered MOX core fractions up to $100 \%$, the worldwide experience is limited to core fractions less than about $45 \%$. Increases above this value would likely require substantial modifications to the reactor control, safety, and protection systems resulting from the large reductions in the control rod reactivity worth, soluble boron reactivity worth, and effective delayed neutron fraction.

\subsubsection{Increase in the Plutonium Content of the MOX Fuel}

The plutonium disposition rate can be increased by increasing the amount of plutonium used in the MOX fuel. This will result in an increase in the overall MOX fuel loading, but it will require a reduction in the uranium enrichment to maintain the same cycle length and the addition of burnable absorbers to maintain the BOC core reactivity. The relative increase in the plutonium loading to that of the uranium loading will lead to larger power peaking in the MOX assemblies as well as higher burnups. In addition, because more of the fissions will occur in plutonium, this has a similar impact on core parameters as increasing the MOX core fraction. Based on calculational analysis, it is possible to increase the disposition rate by $20 \%$ without having a large impact on the core parameters. This option results in a less efficient utilization of plutonium in comparison to optimized core design.

\subsubsection{Reduction in the MOX Fuel Residence Time}

In the one-third MOX core presented above, the MOX fuel assemblies reside in the core for three annual cycles. The overall disposition rate can be increased by irradiating the fuel assemblies for only two cycles to increase the throughput. In this case the MOX fuel burnups are significantly reduced, and similar to the increase in the plutonium content in the fuel, results in a less efficient use of the plutonium. A variant of the one-third MOX cycle has been analyzed with an irradiation of the MOX fuel assemblies for two cycles. In this core design the disposition rate increased from $270 \mathrm{~kg} / \mathrm{year}$ to $450 \mathrm{~kg} / \mathrm{year}$. The number of MOX fuel assemblies loaded per year increased from 18 to 30. 


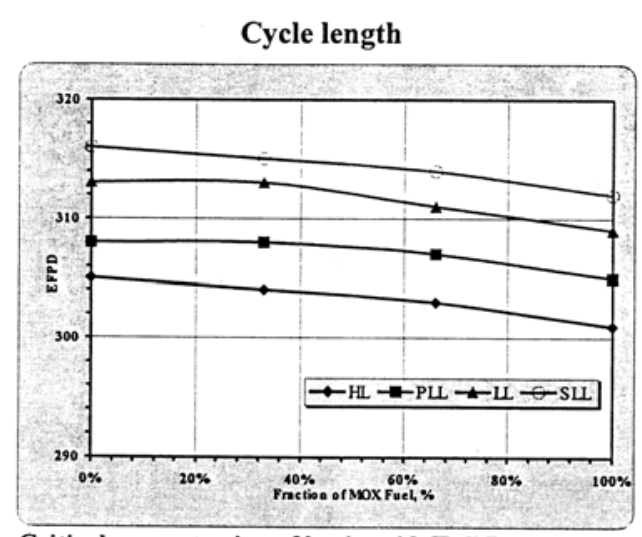

Weight of charged plutonium and uranium-235

Critical concentration of boric acid (Full Power, BOC)
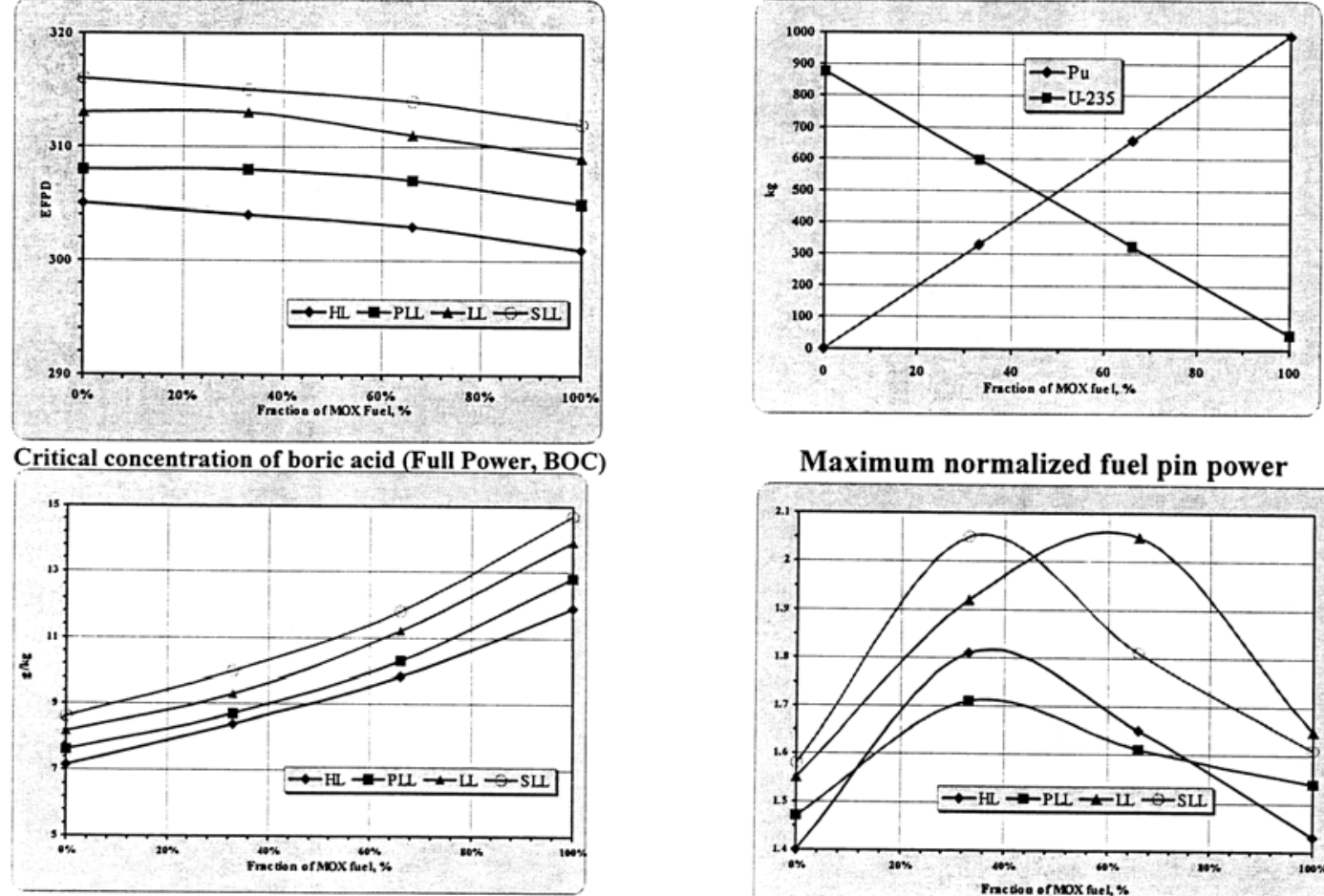

Average effective fraction of delayed neutrons (Full Power, BOC)

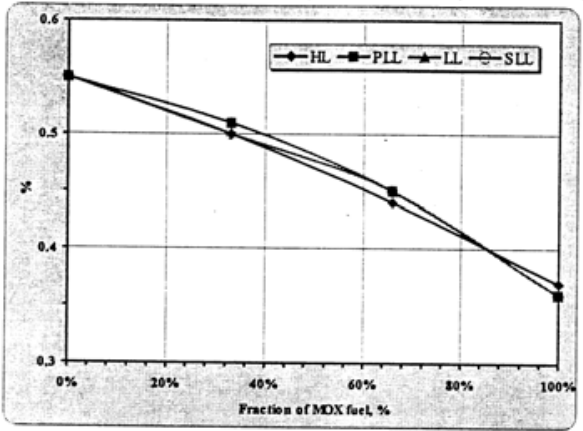

Moderator temperature coefficient of reactivity (Full Power, EOC)
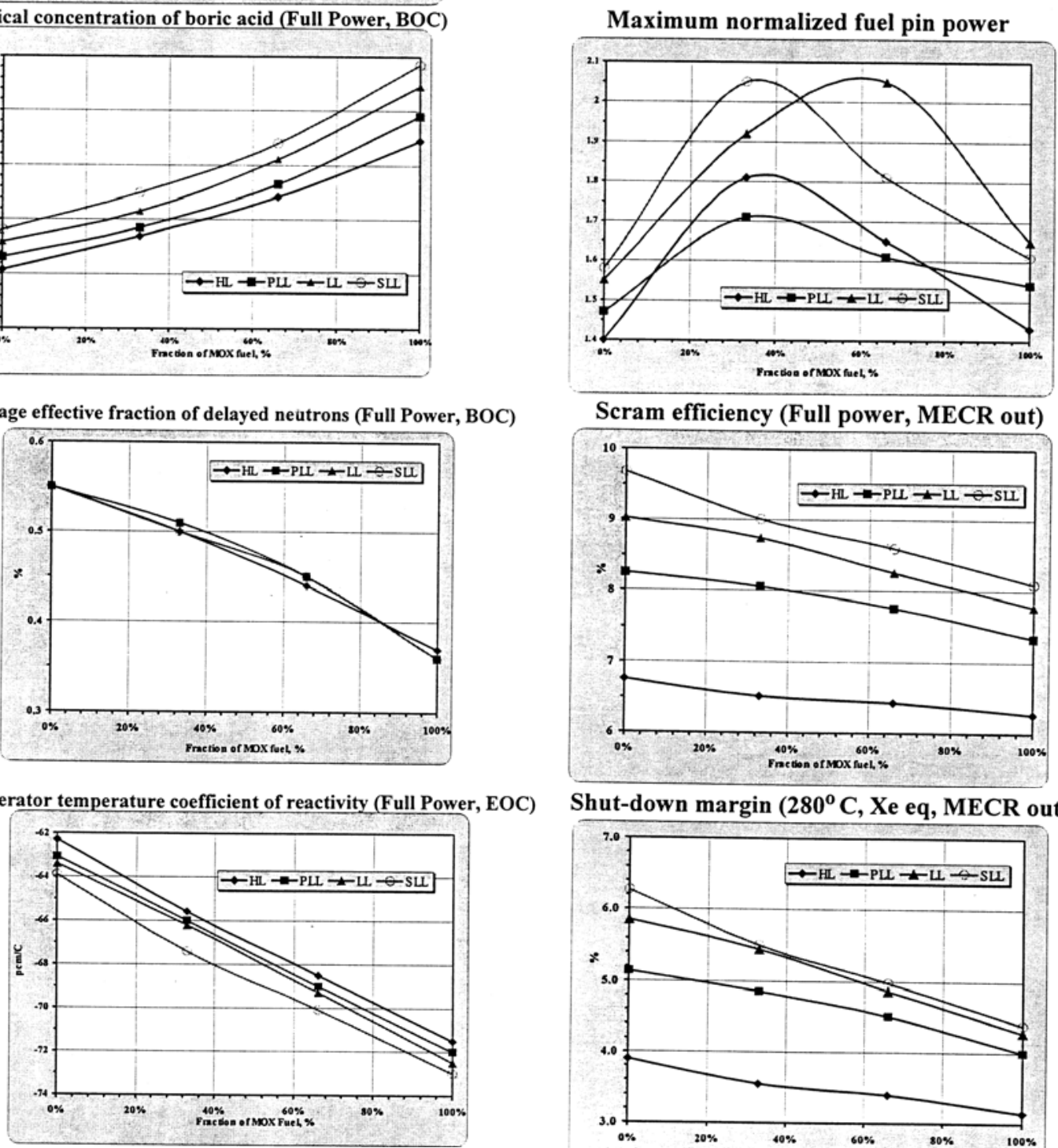

Shut-down margin $\left(280^{\circ} \mathrm{C}, \mathrm{Xe}\right.$ eq, MECR out

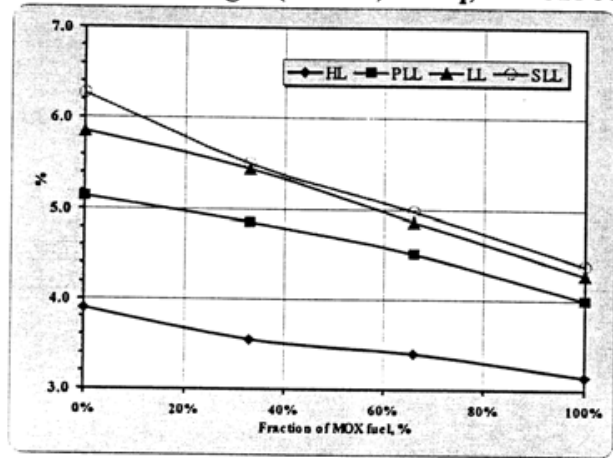

Fig. 2.4 Key core parameters as a function of MOX core fraction. Source: Ref. 4. 


\subsubsection{Core Designs with Increased Disposition Rates}

Several different core configurations have been designed to increase the disposition rate and to also address the Rosenergoatom program of increasing the capacity factors of the VVER-1000 by increasing the cycle lengths from 12- to 18 -months ${ }^{5}$. The specific uranium core configurations to be used for the 18month cycle have not yet been designed, but preliminary work indicates that core designs with similar performance as the V-320 uranium core design with 12-month cycles can be obtained. The longer cycles, however, require increases in fuel enrichment and, therefore, require additional analysis for criticality for transportation and storage. The initial core reactivity is reduced by adding additional uranium-gadolinium rods in the assembly and requires an increase in the soluble boron concentrations.

Based on the uranium fuel cycles for 12- and 18-month cycles, additional core designs were performed in which part of the core was replaced with MOX fuel assemblies. The core designs were obtained to match the performance of the uranium core designs with annual plutonium disposition rates of $\sim 450 \mathrm{~kg}$ and with MOX core fractions less than $45 \%$. To maintain the effectiveness of the control system, the ${ }^{10} \mathrm{~B}$ absorber in the control elements was enriched to $80 \%$. A comparison of the results is given in Table 2.3 for several of the core designs that were obtained. The table gives the key core parameters for each design that covers the range of cycle lengths and disposition rates. Based on these core designs, increased disposition rates can be obtained for cycle durations ranging from 12- to 18months. Note however, that these core designs require further analysis to ensure that they meet all safety requirements.

\subsection{VALIDATION OF CORE DESIGN TOOLS}

The results presented in this chapter, as well as those presented throughout this report, are obtained using calculational tools and corresponding data. To support the insertion of MOX fuel in the VVER1000, the Russian Research Center "Kurchatov Institute" has been working during the past several years to validate its codes and data to obtain certification from the Russian nuclear regulatory authority. A significant amount of experimental data has been provided by the United States and Europe to perform the validation and obtain certification to support the insertion of the three LTAs into unit 4 of the Balakovo Nuclear Power Plant. A summary of the validation efforts is provided in Table 2.4 covering critical experiments, calculational exercises, plant operation data, and postirradiation examinations.

The critical experiment data available are limited to the data provided by the United States and by the Organization for Economic Cooperation and Development (OECD) Nuclear Energy Agency (NEA). A comparison of the specific areas covered by the MOX experiments in Table 2.4 shows that data are not sufficient in the areas of absorber worth (boron and gadolinium), reactivity coefficients (temperatures), isotopic compositions, and reactor kinetics parameters. In addition, the experimental data provided are generally for square lattices, which do not have a large impact on the applicability of the data to VVER1000, but limit the codes that can be used to analyze the data. The table also lists experiments being performed at the Institute for Physics and Power Engineering (IPPE) zero power facilities (RFGS and BFS). These are recent experiments performed under ISTC support. The usefulness and applicability of this data are yet to be determined. To fill in required experimental data, a comprehensive critical experiment program is planned at the SUPR or BFS facilities at IPPE.

The data shown here are currently being used to support the certification of the design tools for the insertion of the three LTAs and are sufficient for this purpose. However, the amount of experimental data for MOX fuel is significantly less than that available for $\mathrm{UO}_{2}$ fuel. Therefore, because of the lack of data, the calculational uncertainty for analysis of MOX cores may be larger than that of $\mathrm{UO}_{2}$ cores. 


\subsection{SUMMARY AND CONCLUSIONS}

The assembly and core designs as well as the impact of increased disposition rates were presented in this chapter. The MOX fuel assemblies have an overall physical configuration that is identical to the $\mathrm{UO}_{2}$ assemblies; however, the plutonium content in the MOX assembly must be profiled to reduce power peaking at $\mathrm{MOX} / \mathrm{UO}_{2}$ assembly interfaces. Increasing the $\mathrm{MOX}$ core fraction increases the disposition rate, but results in significant reduction in the control rod effectiveness and the effective delayed neutron fraction as well as increases in the required soluble boron concentrations. These impacts on core parameters limit the core fraction to $\sim 45 \%$ MOX for practical core designs and will require the consideration of increases in the boron enrichment in the control rods and soluble boron.

A review of the currently available data for the reactor design code validation and certification shows a need for more experimental data, particularly for absorbers (boron, gadolinium) in MOX fuel. Other needs include temperature reactivity effects and kinetics parameters. The Russians have proposed the SUPR experimental program to provide these additional data. Sufficient data are currently available to support the insertion of the LTAs.

\section{REFERENCES}

1. A. M. Pavlovitchev et al., Mission Fuel Kinetics Input and RELAP-Like Calculations, Russian Research Center “Kurchatov Institute," ORNL/SUB/00-85B99398V-14, Oak Ridge National Laboratory, 2001.

2. S. Alioschin et al., "VVER-1000 Gadolinium Core with 30\% MOX," Presentation at the AmericanRussian Technical Meeting on MOX Fuel Disposition in VVER-1000, Oak Ridge, TN, March 5-9, 2001.

3. A .M Pavolovitchev et al., Kinetics Parameters of VVER-1000 Core with 3 MOX Lead Test Assemblies to be used for Accident Analysis Codes, Russian Research Center "Kurchatov Institute," ORNL/SUB/99-B99398V-2, Oak Ridge National Laboratory, 2000.

4. S. Aleshin et al., "Analysis of Possibilities of Increasing of MOX Fuel Part in VVER-1000 above $30 \%$," Presentation at the American-Russian Technical Meeting on MOX Fuel Disposition in VVER-1000, Moscow, Russia, July 24-28, 2000.

5. A. M. Pavlovitchev et al., Analysis of Alternative In-Core Fuel Core Management with Increased Disposition Pu Rate in VVER-1000, Russian Research Center "Kurchatov Institute," Final Report for Task 2 of Work Release KI-WR13JCG (2004).

6. A. M Pavlovitchev et al., Analysis of Alternative In-Core Fuel Core Management With Increased Disposition Pu Rate in VVER-1000, Russian Research Center "Kurchatov Institute," Moscow, Russia, 2003.

7. A. M Pavlovitchev et al, Justification of the Critical Experiments with MOX Fuel at the Zero Power Facility SUPR, Russian Research Center "Kurchatov Institute," 2004. 
Table 2.3 Parameters of $\mathrm{UO}_{2}$ and MOX core designs with increased disposition rates

\begin{tabular}{|c|c|c|c|c|c|c|}
\hline \multicolumn{3}{|l|}{ Cycle design name } & U42 & U24P30 & U66 & $\mathrm{U} 36 \mathrm{P} 36$ \\
\hline \multirow[t]{3}{*}{ Number of feed assemblies } & \multicolumn{2}{|c|}{ Total } & 42 & 54 & 66 & 72 \\
\hline & \multicolumn{2}{|c|}{ Uranium } & 42 & $24(4)$ & 66 & $36(2-3)$ \\
\hline & \multicolumn{2}{|c|}{ MOX } & - & $30(2-3)$ & - & $36(2)$ \\
\hline \multicolumn{3}{|c|}{ Average enrichment of fresh $\mathrm{UO}_{2} \mathrm{FAs}, \%$} & 4.33 & 4.38 & 4.61 & 4.65 \\
\hline \multicolumn{3}{|c|}{ Average content of plutonium in fresh MOX fuel rods, $\%$} & - & 3.69 & - & 4.63 \\
\hline \multicolumn{3}{|c|}{ Maximal content of plutonium in fresh MOX fuel rods, $\%$} & - & 3.9 & - & 4.95 \\
\hline \multicolumn{3}{|c|}{ Minimal content of plutonium in fresh MOX fuel rods, \% } & - & 2.6 & - & 2.8 \\
\hline \multicolumn{3}{|c|}{ Number of U-Gd rods in fresh MOX FA } & - & 18 & - & 27 \\
\hline \multicolumn{3}{|c|}{ Average content of plutonium in fresh MOX FAs, $\%$} & - & 3.48 & - & 4.23 \\
\hline \multicolumn{3}{|c|}{ MOX FAs in feed FA \% } & - & 55.6 & - & 50.0 \\
\hline \multicolumn{3}{|l|}{ MOX FAs in core, $\%$} & - & 40.5 & - & 44.2 \\
\hline \multicolumn{3}{|c|}{ MOX fuel rods part in core, $\%$} & - & 38.2 & - & 40.3 \\
\hline \multicolumn{3}{|c|}{ Cycle length, EFPD (with coastdown) } & 300 & 307 & 464 & 465 \\
\hline \multicolumn{3}{|c|}{ Duration of the reactor operation at nominal parameters, EFPD } & - & - & 436 & 431 \\
\hline \multicolumn{3}{|c|}{ Load factor, $\%$} & 82.0 & 82.5 & 87.1 & 86.9 \\
\hline \multicolumn{3}{|c|}{ Annual plutonium consumption, $\mathrm{kg}$} & - & 444 & - & 450 \\
\hline \multirow{2}{*}{\multicolumn{2}{|c|}{$\begin{array}{l}\text { Burnup of discharged } \mathrm{UO}_{2} \text { fuel, } \\
\mathrm{MWd} / \mathrm{kgHM}\end{array}$}} & Average & 49.8 & 50.4 & 48.9 & 46.3 \\
\hline & & Maximum over FAs* & 53.3 & 53.3 & 60.4 & 52.8 \\
\hline \multirow{3}{*}{\multicolumn{2}{|c|}{$\begin{array}{l}\text { Burnup of discharged MOX fuel, } \\
\mathrm{MWd} / \mathrm{kgHM}\end{array}$}} & Average & & 31.1 & - & 43.5 \\
\hline & & Maximum over FAs* & & 36.9 & - & 45.5 \\
\hline & & Maximum over fuel rods* & & 41.9 & - & 49.8 \\
\hline
\end{tabular}

* Central FA not included

Source: Ref. 6. 
Table 2.4 Database for validation of Russian neutronics codes.

\begin{tabular}{|c|c|c|c|c|c|c|c|c|c|c|c|c|c|c|}
\hline \multirow[b]{2}{*}{ 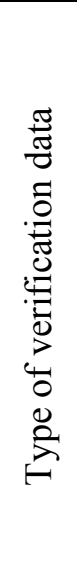 } & \multirow[b]{2}{*}{ Verification data } & \multirow[b]{2}{*}{ 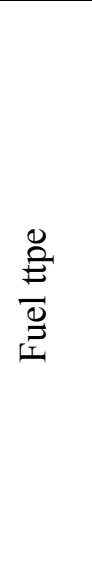 } & \multirow[b]{2}{*}{ 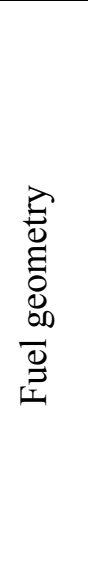 } & \multirow[b]{2}{*}{$\stackrel{\mathscr{L}}{2}$} & \multirow[b]{2}{*}{ 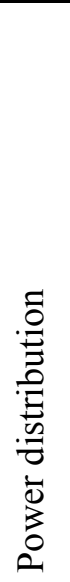 } & \multicolumn{4}{|c|}{ Effects of reactivity } & \multicolumn{3}{|c|}{$\begin{array}{l}\text { Absorption } \\
\text { efficiency }\end{array}$} & \multirow[b]{2}{*}{ 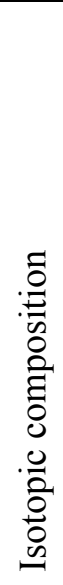 } & \multirow[b]{2}{*}{ 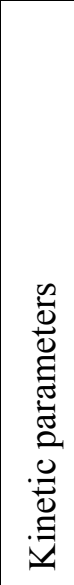 } \\
\hline & & & & & & 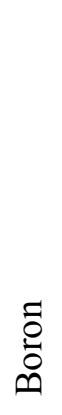 & 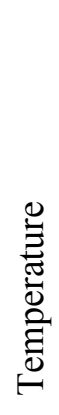 & $\begin{array}{l}\frac{\dot{\vec{d}}}{\frac{2}{a}} \\
\stackrel{0}{0} \\
\stackrel{0}{0}\end{array}$ & 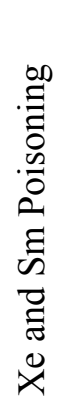 & $\begin{array}{l}\widehat{0} \\
0 \\
0 \\
0 \\
0 \\
0 \\
0 \\
0 \\
0 \\
0\end{array}$ & 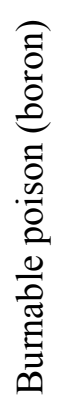 & $\begin{array}{l}\bar{\Xi} \\
\stackrel{D}{D} \\
\bar{D}\end{array}$ & & \\
\hline \multirow{12}{*}{ 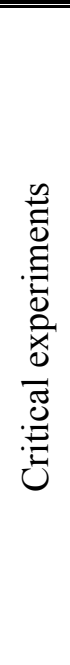 } & RU, RRC KI, “P” (Lattices, FAs) & $\mathrm{U}$ & Hex & $\overline{0}$ & $\overline{0}$ & & & & & 0 & 0 & 0 & & \\
\hline & Hungary-RU, ZR-6, & $\mathrm{U}$ & Hex & $\bullet$ & $\bullet$ & 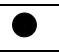 & $\boldsymbol{0}$ & & & 0 & & $\bullet$ & & \\
\hline & Czech Rep.-RU, LR-0, & $\mathrm{U}$ & Hex & $\bullet$ & - & 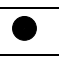 & & & & & & $\bullet$ & & \\
\hline & Int. Handbook of ICSBEP, Lattices & $\mathrm{Pu}$ & $\mathrm{Sq}$ & 0 & & & & & & & & & & \\
\hline & $\begin{array}{l}\text { Int. Handbook of ICSBEP, } \\
\text { Homogeneous. }\end{array}$ & $\mathrm{Pu} / \mathrm{U}$ & Hom & $\bullet$ & & & & & & & & & & \\
\hline & US, $\quad$ ESADA & $\mathrm{Pu} / \mathrm{U}$ & $\mathrm{Sq}$ & $\bullet$ & - & & & & & & & & & \\
\hline & SAXTON & $\mathrm{Pu} / \mathrm{U}$ & $\mathrm{Sq}$ & ? & ? & 0 & & & & & & & & \\
\hline & OECD, $\quad$ VENUS-2 & $\mathrm{Pu} / \mathrm{U}$ & $\mathrm{Sq}$ & $\bullet$ & $\bullet$ & & & & & & ○ & & & \\
\hline & OECD, & $\mathrm{Pu} / \mathrm{U}$ & & 0 & - & & 0 & & & & & & & \\
\hline & RFGS (IPPE) & $\mathrm{Pu} / \mathrm{U}$ & Hex & 0 & 0 & & & & & & & & & \\
\hline & BFS(IPPE) & $\mathrm{Pu} / \mathrm{U}$ & Hex & $\bullet$ & $\bullet$ & & & & & & & & & \\
\hline & $\begin{array}{ll}\text { RU, } \\
\text { performed) }\end{array} \quad$ SUPR(IPPE) (to be & $\mathrm{Pu} / \mathrm{U}$ & Hex & $\bullet$ & - & 0 & 0 & & & 0 & 0 & $\bullet$ & & 0 \\
\hline
\end{tabular}

Source: Ref. 7. 
Table 2.4 continued

\begin{tabular}{|c|c|c|c|c|c|c|c|c|c|c|c|c|c|c|c|}
\hline \multirow{2}{*}{ 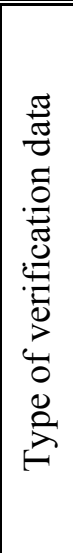 } & \multirow{2}{*}{\multicolumn{2}{|c|}{ Verification data }} & \multirow[b]{2}{*}{ 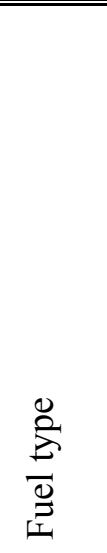 } & \multirow[b]{2}{*}{ 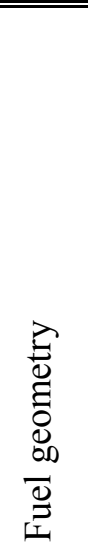 } & \multirow[b]{2}{*}{$\stackrel{4}{4}$} & \multirow[b]{2}{*}{ 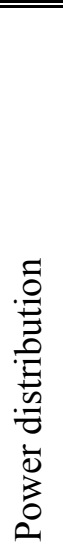 } & \multicolumn{4}{|c|}{ Effects of reactivity } & \multicolumn{3}{|c|}{$\begin{array}{l}\text { Absorption } \\
\text { efficiency }\end{array}$} & \multirow[b]{2}{*}{ 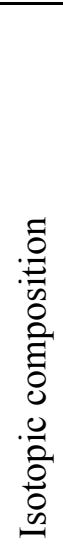 } & \multirow[b]{2}{*}{ 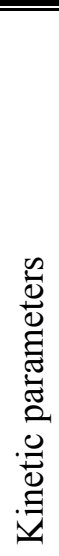 } \\
\hline & & & & & & & 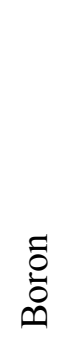 & 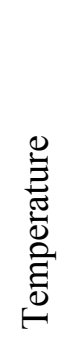 & $\frac{\frac{\dot{\bar{d}}}{2}}{\stackrel{0}{\circ}}$ & 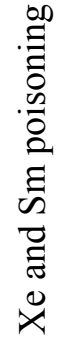 & $\begin{array}{l}\text { Oే } \\
0 \\
0 \\
0 \\
0 \\
0 \\
0 \\
0 \\
0 \\
0\end{array}$ & $\begin{array}{l}\tilde{0} \\
0 \\
0 \\
0 \\
.0 \\
0 \\
0 \\
0 \\
0 \\
0 \\
0 \\
0 \\
0\end{array}$ & 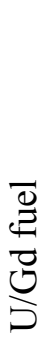 & & \\
\hline \multirow{13}{*}{ 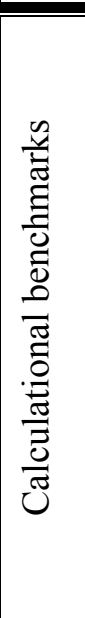 } & RU/US, & Cell & $\mathrm{U}$ & Hex & 0 & & 0 & 0 & 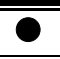 & 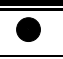 & & & & 0 & 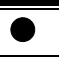 \\
\hline & RU/US, & Cell & $\mathrm{Pu}$ & Hex & 0 & & 0 & - & $\bullet$ & $\bullet$ & & & & - & $\bullet$ \\
\hline & RU/US, & PWR FA & $\mathrm{Pu}$ & $\mathrm{Sq}$ & 0 & 0 & 0 & $\bullet$ & $\bullet$ & 0 & 0 & & & 0 & \\
\hline & RU/US, & VVER FA & $\mathrm{U}$ & Hex & 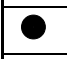 & 0 & 0 & $\bullet$ & $\bullet$ & $\bullet$ & 0 & 0 & & $\boldsymbol{0}$ & \\
\hline & RU/US, & VVER FA & $\mathrm{Pu}$ & Hex & 0 & $\bullet$ & $\bullet$ & $\bullet$ & $\bullet$ & 0 & 0 & 0 & & 0 & \\
\hline & RU/US, & VVER Core Fragm. & $\mathrm{U} / \mathrm{Pu}$ & Hex & 0 & 0 & 0 & $\bullet$ & 0 & 0 & & & & $\boldsymbol{0}$ & 0 \\
\hline & $\mathrm{RU} / \mathrm{Fr} / \mathrm{G}$ & VVER FA & $\mathrm{U}$ & Hex & 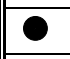 & 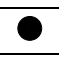 & $\bullet$ & $\bullet$ & $\bullet$ & $\bullet$ & 0 & $\bullet$ & $\bullet$ & $\bullet$ & $\bullet$ \\
\hline & $\mathrm{RU} / \mathrm{Fr} / \mathrm{G}$ & VVER FA & $\mathrm{Pu}$ & Hex & 0 & 0 & 0 & ? & 운 & 0 & 0 & 0 & $\bullet$ & 0 & - \\
\hline & $\mathrm{RU} / \mathrm{Fr} / \mathrm{G}$ & VVER Core Fragm. & $\mathrm{U} / \mathrm{Pu}$ & Hex & 0 & 0 & 0 & $\bullet$ & 0 & 0 & 0 & & & & 0 \\
\hline & OECD, & BWR, FA & $\mathrm{Pu}$ & $\mathrm{Sq}$ & 0 & $\bullet$ & & $\bullet$ & & & & & $\bullet$ & 0 & \\
\hline & OECD, & PWR, Cell, FA & $\mathrm{Pu}$ & $\mathrm{Sq}$ & 0 & 0 & & $\bullet$ & & & & & & $\boldsymbol{0}$ & \\
\hline & RU/US, & Core Fragm. & $\mathrm{U} / \mathrm{Pu}$ & Hex & 0 & 0 & 0 & $\bullet$ & $\bullet$ & 0 & 0 & $\bullet$ & $\bullet$ & $\bullet$ & $\bullet$ \\
\hline & RU/US, & VVER-1000, Core & $\mathrm{U} / \mathrm{Pu}$ & Hex & $\bullet$ & 0 & $\bullet$ & 0 & 0 & 0 & 0 & 0 & 0 & & \\
\hline
\end{tabular}

Source: Ref. 7. 
Table 2.4 continued

\begin{tabular}{|c|c|c|c|c|c|c|c|c|c|c|c|c|c|c|}
\hline \multirow[b]{2}{*}{ 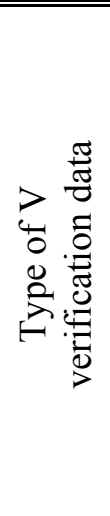 } & \multirow[b]{2}{*}{ Verification data } & \multirow[b]{2}{*}{ 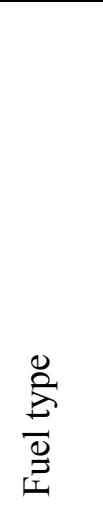 } & \multirow[b]{2}{*}{ 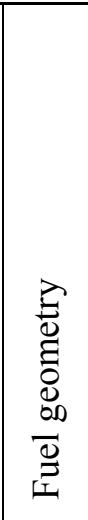 } & \multirow[b]{2}{*}{$\stackrel{\mathscr{\Xi}}{\mathscr{4}}$} & \multirow[b]{2}{*}{ 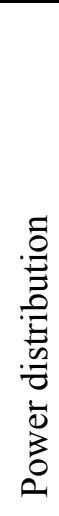 } & \multicolumn{4}{|c|}{ Effects of reactivity } & \multicolumn{3}{|c|}{$\begin{array}{l}\text { Absorption } \\
\text { efficiency }\end{array}$} & \multirow[b]{2}{*}{$\begin{array}{l}\text { :0 } \\
: 0 \\
0 \\
0 \\
0 \\
0 \\
0 \\
.00 \\
0 \\
0 \\
0\end{array}$} & \multirow[b]{2}{*}{ 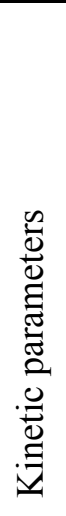 } \\
\hline & & & & & & 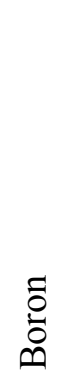 & 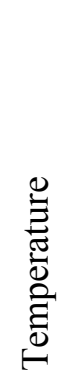 & $\begin{array}{l}\frac{\overline{0}}{0} \\
\stackrel{0}{0} \\
\stackrel{0}{0}\end{array}$ & 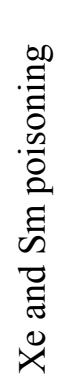 & 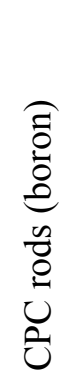 & 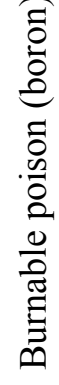 & $\begin{array}{l}\stackrel{\bar{D}}{己} \\
\stackrel{D}{D} \\
D\end{array}$ & & \\
\hline \multirow{4}{*}{ 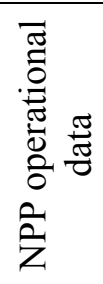 } & RU, VVER-1000 & $\mathrm{U}$ & Hex & 0 & $\bullet$ & - & $\bullet$ & - & - & $\bullet$ & 0 & $\bullet$ & & \\
\hline & RU, VVER-440 & $\mathrm{U}$ & Hex & 0 & 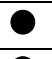 & 0 & $\bullet$ & $\bullet$ & 0 & & & 0 & & \\
\hline & RU, VVER-1000, MOX LTA & $\mathrm{U} / \mathrm{Pu}$ & Hex & 0 & $\bullet$ & & & & & & & & & \\
\hline & RU, VVER-1000, 1/3 MOX & $\mathrm{U} / \mathrm{Pu}$ & Hex & $\bullet$ & $\bullet$ & O & ? & $\bullet$ & O & O & 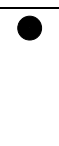 & O & & \\
\hline \multirow{9}{*}{ 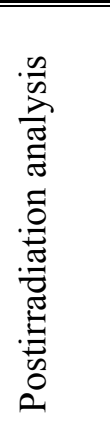 } & US, Yankee & $\mathrm{U}$ & $?$ & & & & & & & & & & $\bullet$ & \\
\hline & RU, VVER-1000, FA & $\mathrm{U}$ & Hex & & $\bullet$ & & & & & & & & $\bullet$ & \\
\hline & RU, VVER-440, FA & $\mathrm{U}$ & Hex & & $\bullet$ & & & & & & & & - & \\
\hline & US, BWR (Quad City), FA & $\mathrm{U} / \mathrm{Pu}$ & $\mathrm{Sq}$ & & & & & & & & & & $\bullet$ & \\
\hline & US, $\quad$ PWR, FA & $\mathrm{U}$ & $\mathrm{Sq}$ & & & & & & & & & & - & \\
\hline & RU, VVER-1000, U/Gd Rods & $\mathrm{U} / \mathrm{Gd}$ & Hex & & $\bullet$ & & & & & & & & - & \\
\hline & RU, "MIR", Experim. Rods & $\mathrm{Pu}$ & - & & & & & & & & & & $\bullet$ & \\
\hline & RU, VVER-1000, MOX LTA & $\mathrm{U} / \mathrm{Pu}$ & Hex & & - & & & & & & & & - & \\
\hline & RU, VVER-1000, 1/3 MOX & $\mathrm{U} / \mathrm{Pu}$ & Hex & & $\bullet$ & & & & & & & & $\bullet$ & \\
\hline
\end{tabular}

Source: Ref. 7 


\section{NEUTRONICS PROPERTIES}

\subsection{NUCLEAR PROPERTIES}

The WG MOX fuel differs from $\mathrm{UO}_{2}$ fuel in that the fissile material is primarily ${ }^{239} \mathrm{Pu}$, and to a lesser extent ${ }^{241} \mathrm{Pu}$, rather than ${ }^{235} \mathrm{U}$. Plutonium and uranium have fundamentally different nuclear cross sections that result in the different performance of the materials in a reactor core. The nuclear properties of these fissile materials are summarized in Table 3.1. Plutonium has a higher thermal absorption cross section and fission cross section, more neutrons per fission, a larger energy per fission, and a smaller delayed neutron fraction. These different nuclear properties have an impact on the neutron spectrum, reactivity coefficients, and absorber effectiveness. The smaller delayed neutron fraction results in changes in the kinetic response of the reactor with the reactor responding more rapidly to reactivity changes.

Table 3.1 Comparison of nuclear properties of ${ }^{235} \mathrm{U}$ and ${ }^{239} \mathrm{Pu}$.

\begin{tabular}{|l|c|c|}
\hline \multicolumn{1}{|c|}{ Parameter } & ${ }^{{ }^{235}} \mathbf{U}$ & ${ }^{239} \mathbf{P u}$ \\
\hline Thermal fission cross section (barns) & 577 & 741 \\
\hline Thermal absorption cross section (barns) & 678 & 1015 \\
\hline Average number of neutrons per fission & 2.43 & 2.87 \\
\hline Delayed neutron fraction & 0.0065 & 0.0020 \\
\hline Energy per fission (MeV) & 192.9 & 198.5 \\
\hline
\end{tabular}

Source: Refs. 1 and 2.

\subsection{ASSEMBLY REACTIVITY vS BURNUP}

The assembly designs as discussed in Chap. 2 provide a reactivity match between the MOX and $\mathrm{UO}_{2}$ assemblies to provide a cycle length that is consistent to the uranium core. A comparison of the infinite multiplication factors for a uranium assembly and a WG MOX assembly (without burnable absorbers) is shown in Fig. 3.1. These profiles show that MOX assembly has a slower reactivity decrease with burnup than for uranium fuel. Therefore, the matching of the MOX and uranium core designs must consider this difference to obtain fuel cycle lengths that are similar. In general this requires that the lifetime-averaged reactivities must match, rather than just the beginning-of-life or end-of-life reactivities. However, for cores that utilize burnable absorbers or have different residence times for the $\mathrm{MOX}$ and $\mathrm{UO}_{2}$ assemblies, reactivity matching will not necessarily be on the lifetime-averaged reactivity. In the case of the VVER1000 MOX core designs, uranium-gadolinium pins are used as the burnable absorber in both the $\mathrm{UO}_{2}$ and MOX assemblies. Because of the neutron spectrum differences, the gadolinium burns out more slowly in the MOX assembly, therefore, it is typical to use lower gadolinium loadings in the MOX assembly.

\subsection{NEUTRON FLUX SPECTRUM}

Because the thermal cross sections are larger for plutonium than for uranium, the thermal flux in the MOX assemblies is significantly lower than that of the $\mathrm{UO}_{2}$ assemblies. Table 3.2 shows values of the thermal flux, fast flux, and flux ratios for typical $\mathrm{MOX}$ and $\mathrm{UO}_{2}$ assemblies. The fast neutron flux is 
Table 3.2 Comparison of the thermal and fast neutron fluxes in $\mathrm{MOX}$ and $\mathrm{UO}_{2}$ fuel assemblies.

\begin{tabular}{|l|c|c|}
\hline & UO $_{\mathbf{2}}$ assembly & MOX assembly \\
\hline Thermal flux $(<0.625 \mathrm{eV})$ & $3.59 \times 10^{13}$ & $2.03 \times 10^{13}$ \\
\hline Fast flux $(>0.625 \mathrm{eV})$ & $2.30 \times 10^{14}$ & $2.47 \times 10^{14}$ \\
\hline Fast/Thermal flux ratio & 6.4 & 12.2 \\
\hline
\end{tabular}

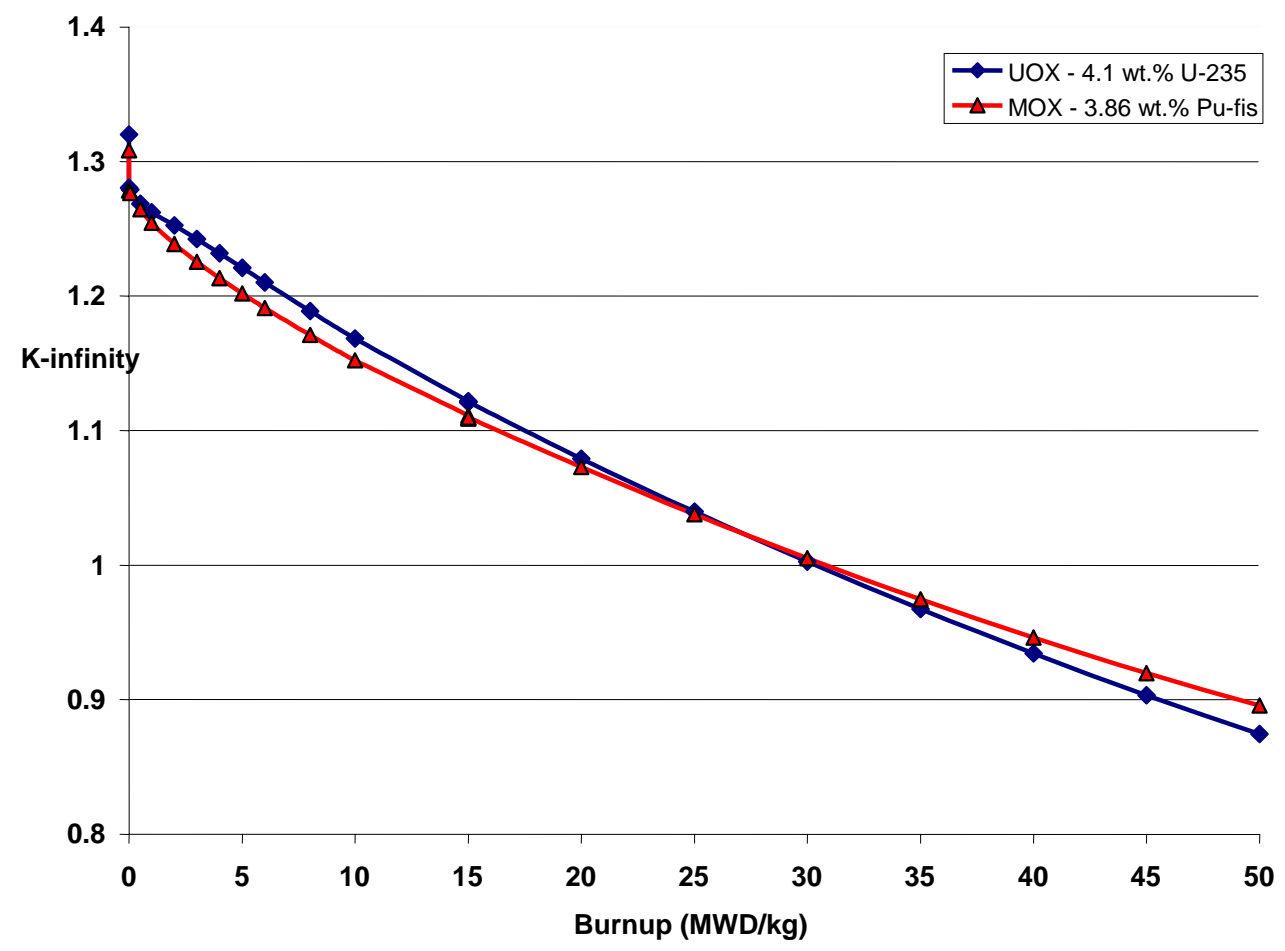

Fig 3.1 Comparison of infinite multiplication factor for $\mathrm{MOX}$ and $\mathrm{UO}_{2}$ assemblies.

slightly larger in the MOX assembly than the $\mathrm{UO}_{2}$ assembly, but the thermal flux is substantially reduced. The fast-to-thermal flux ratio in the MOX assembly is approximately twice that of the $\mathrm{UO}_{2}$ assembly.

The harder neutron flux spectrum in the MOX assembly results in changes in neutronic performance of the fuel assembly. One of the most important impacts is the reduction in the reactivity worth of neutron- absorbing materials, particularly the boron used in the control rods and soluble poison for reactivity control. The leakage of thermal neutrons from $\mathrm{UO}_{2}$ assemblies into a neighboring $\mathrm{MOX}$ assembly leads to power peaking in the peripheral MOX fuel pins. The slight increase in the fast neutron flux can lead to an increased neutron fluence to the reactor vessel. These issues require specific consideration when designing the core and will be discussed in more detail as follows. 


\subsection{SOLUBLE BORON WORTH}

Boric acid $\left(\mathrm{H}_{3} \mathrm{BO}_{3}\right)$ is dissolved in water and is used for reactivity control to offset the burnup of the fuel and burnable absorbers during the fuel cycle, in the emergency response systems to shutdown the reactor, and during refueling operations to ensure subcriticality of the system. Because boron is primarily a thermal neutron absorber, its effectiveness is reduced in MOX assemblies because of the reduction in the thermal neutron flux, as discussed previously. The parametric calculations presented in Fig. 2.4 show the increase in the critical boron concentration that results from an increase in MOX core fraction.

Detailed core design calculations have evaluated the worth of the soluble boron absorber and have been performed for $\mathrm{UO}_{2}$ and one-third-MOX cores ${ }^{3,4}$. For $\mathrm{UO}_{2}$ cores the boron worth ranges from -1.6 to $-1.7 \mathrm{pcm} / \mathrm{ppm} \mathrm{H}_{3} \mathrm{BO}_{3}(-8.9$ to $-9.7 \mathrm{pcm} / \mathrm{ppm} \mathrm{B})$ and for the one-third MOX core design from -1.3 to -1.5 $\mathrm{pcm} / \mathrm{ppm} \mathrm{H}_{3} \mathrm{BO}_{3}(-7.4$ to $-8.6 \mathrm{pcm} / \mathrm{ppm} \mathrm{B})$. Note that the worth is typically expressed in terms of boric acid in Russia rather than in terms of boron concentration. Thus, for this core design there is reduction in the boron worth by about $15 \%$. This lower worth requires an increase in the boron concentration from $5657 \mathrm{ppm} \mathrm{H}_{3} \mathrm{BO}_{3}(992 \mathrm{ppm} \mathrm{B})$ to $6765 \mathrm{ppm}_{3} \mathrm{BO}_{3}(1183 \mathrm{ppm} \mathrm{B})$. For core designs with a higher MOX core, loading the soluble boron concentration will increase further. Results from recent studies with increased plutonium disposition rates are presented in Table 3.3 for 12- and 18-month cycles with disposition rates of $450 \mathrm{~kg} / \mathrm{year}^{5}$. The required boron concentrations at the initial critical conditions and for a $2 \%$ subcritical margin during shutdown increased $25 \%$ for the MOX core over that of the $\mathrm{UO}_{2}$ core. In these designs, there is a substantial use of uranium-gadolinium rods to offset the initial core reactivity and to improve the shutdown margin.

Table 3.3 Comparison of boron concentrations for $\mathrm{UO}_{2}$ and increased-disposition-rate MOX cores

\begin{tabular}{|l|c|c|c|c|}
\hline & \multicolumn{4}{|c|}{ Core design } \\
\hline \multicolumn{1}{|c|}{ Parameter } & $\begin{array}{c}\mathbf{U O}_{2} \\
(\mathbf{U 4 2})\end{array}$ & $\begin{array}{c}\text { MOX } \\
(\mathbf{U 2 4 P 3 0 )}\end{array}$ & $\begin{array}{c}\mathbf{U O}_{2} \\
(\mathbf{U 6 6})\end{array}$ & $\begin{array}{c}\text { MOX } \\
\text { (U36P36) }\end{array}$ \\
\hline Cycle length, (months) & 12 & 12 & 18 & 18 \\
\hline $\begin{array}{l}\text { Annual plutonium } \\
\text { disposition rate, (kg/yr) }\end{array}$ & - & 444 & - & 450 \\
\hline $\begin{array}{l}\text { Critical boron concentration, } \\
\text { ppm } \mathrm{H}_{3} \mathrm{BO}_{3} \text { (ppm B) }\end{array}$ & 6700 & $7700(1346)$ & $8500(1486)$ & 10,700 \\
\hline $\begin{array}{l}\text { Boron concentration for 2\% } \\
\text { subcriticality, ppm } \mathrm{H}_{3} \mathrm{BO}_{3} \\
\text { (ppm B) }\end{array}$ & $(1175)$ & & 13,100 & 16,200 \\
\hline
\end{tabular}

Source: Ref. 5.

The reduced efficiency of the soluble boron can be offset with increases in the boron concentration or enrichment of the boron in the ${ }^{10} \mathrm{~B}$ isotope from the natural content of $19.8 \%$. Significant increases in the boron concentration during operation and refueling can result in difficulties in the adjustment of the boron levels leading to a significant increase in chemical and water volumes that must be processed. These operational issues can be eliminated with the use of enriched boron, which has an increased cost and may require modifications to recover the boron rather than discard it. Either of these options, increased soluble boron levels or use of enriched boron, may require plant modifications to accommodate these operational issues. 


\subsection{CONTROL ROD WORTH}

The VVER-1000 has a total of 61 control clusters, each with 18 absorber elements that are inserted into the guide tube locations in the fuel assemblies. Each of these absorber elements consists of 323-mmlong absorber section with $\mathrm{B}_{4} \mathrm{C}$ and a 30-mm tip with $\mathrm{Dy}_{2} \mathrm{O}_{3}-\mathrm{TiO}_{2}$ as the absorber. The control elements are arranged into 10 control rod groups with group number 10 being used as the regulating group ${ }^{6}$. The control rods are used during startup and shutdown to control the power level and as part of the safety system to scram the reactor. The worth of the control rods is important in the evaluation of the shutdown margins of the reactor as well as the reactivity insertion rates in response to a reactor scram.

Calculations of the shutdown reactivity worth of the control rods with the most effective control rod stuck out of the core were performed for the $\mathrm{UO}_{2}$ core and the one-third-MOX core ${ }^{3,4}$ with the control rod design as described above with natural boron. For the $\mathrm{UO}_{2}$ core, the control rod worth is $-8330 \mathrm{pcm}$ and the MOX core $-7600 \mathrm{pcm}$ at the BOC. As shown in Fig 2.4, the shutdown margin and scram efficiency decreases with increased MOX loading, therefore, in the analysis of the increased disposition rate cores, boron enriched to $80 \%$ was used in the MOX cores to maintain the shutdown margin of the $\mathrm{UO}_{2}$ core.

\subsection{POWER DISTRIBUTION}

Because of the larger fission cross section, the use of MOX assemblies can result in severe power peaking in the fuel pins at the $\mathrm{UO}_{2} / \mathrm{MOX}$ interfaces. Therefore, as was discussed in Chap. 2, the MOX assemblies used pins with different plutonium loadings to minimize this peaking effect. The assembly peaking can be controlled by the overall amount of plutonium in the assembly and by the use of burnable absorbers. The power peaking factors for 12-month and 18-month fuel cycle designs with increased disposition rates are presented in Table 3.4. These results show that with careful design of the assembly and core loading patterns, there is no significant increase in the power peaking and linear heat rates in the partial MOX cores and the pins in the MOX assemblies to do not exhibit higher heating rates.

Table 3.4 Comparison of the pin peaking factors and linear heat rates between $\mathrm{UO}_{2}$ and partial MOX cores (specific core design indicated in parenthesis)

\begin{tabular}{|l|c|c|c|c|}
\hline & \multicolumn{2}{|c|}{ 12-month cycles } & \multicolumn{2}{|c|}{ 18-month cycles } \\
\cline { 2 - 5 } & $\begin{array}{c}\mathbf{U O}_{2} \\
(\mathbf{U 4 2})\end{array}$ & $\begin{array}{c}\text { MOX } \\
\text { (U24P36) }\end{array}$ & $\mathbf{U O}_{2}$ (U66) & $\begin{array}{c}\text { MOX } \\
\text { (U36P36) }\end{array}$ \\
\hline $\begin{array}{l}\text { Maximum pin power in } \mathrm{UO}_{2} \text { pins } \\
\text { (relative) }\end{array}$ & 1.50 & 1.50 & 1.49 & 1.47 \\
\hline $\begin{array}{l}\text { Maximum pin power in } \mathrm{MOX} \text { pins } \\
\text { (relative) }\end{array}$ & - & 1.50 & - & 1.47 \\
\hline $\begin{array}{l}\text { Maximum linear heat rate in } \mathrm{UO}_{2} \\
\text { pins (W/cm) }\end{array}$ & 296 & 298 & 297 & 294 \\
\hline $\begin{array}{l}\text { Maximum linear heat rate in MOX } \\
\text { pins (W/cm) }\end{array}$ & - & 298 & - & 306 \\
\hline
\end{tabular}

Source: Ref. 5. 


\subsection{KINETICS PARAMETERS}

\subsubsection{Effective Delayed Neutron Fraction}

The effective delayed neutron fraction $(\beta)$ is a kinetics parameter that determines the time-dependent response of the reactor. A smaller value of $\beta$ indicates that a larger fraction of the fission neutrons appear as prompt neutrons; therefore, the kinetic response of the reactor is quicker. Conversely, a larger value of $\beta$ indicates that a smaller fraction of the fission neutrons appear as prompt neutrons and the core has a slower response. As shown in Table 3.1 the delayed neutron fraction for ${ }^{239} \mathrm{Pu}$ is significantly less than that of ${ }^{235} \mathrm{U}$. Therefore, MOX cores have a quicker time-dependent response to changes in the core reactivity.

The effective delayed neutron fractions were calculated for the $\mathrm{UO}_{2}$ and $\mathrm{MOX}$ core designs ${ }^{3-5,7}$ and are compared in Table 3.5. These results show a $10-15 \%$ reduction in $\beta$, depending on the MOX core fraction. The larger MOX core fractions show a larger reduction in the delayed neutron fraction. The lowest values of the delayed neutron fraction occur at EOC because the fraction of fissions from plutonium is highest at that time, even for the $\mathrm{UO}_{2}$ cores. The $\mathrm{UO}_{2}$ core safety analysis uses this lower EOC value, but it is still significantly larger than that for the MOX fuel. Therefore, the reduction in the delayed neutron fraction must be considered in the safety analysis and in the evaluation of the core protection system.

Table 3.5 Comparison of the effective delayed neutron fraction for $\mathrm{UO}_{2}$ and partial MOX cores

\begin{tabular}{|l|c|c|c|c|c|c|}
\hline & \multicolumn{3}{|c|}{ 12-month cycle } & \multicolumn{3}{c|}{ 18-month cycle } \\
\cline { 2 - 7 } & $\mathbf{U O}_{\mathbf{2}}$ & $\begin{array}{c}\text { MOX } \\
\mathbf{( 3 0 \% )}\end{array}$ & MOX/UO & $\mathbf{U O}_{\mathbf{2}}$ & MOX (40\%) & MOX/UO $\mathbf{~}_{\mathbf{2}}$ \\
\hline BOC & 0.0065 & 0.0057 & 0.88 & - & - & - \\
\hline EOC & 0.0055 & 0.0051 & 0.92 & 0.0056 & 0.0048 & 0.86 \\
\hline
\end{tabular}

Source: Ref. 3-5, 7.

\subsubsection{Prompt Neutron Lifetime}

The prompt neutron lifetime $(\Lambda)$ is another kinetics parameter that has an impact on the time scale of the reactor core response to reactivity changes. It is related to the neutron generation time and therefore is a measure of the time that it takes for changes in the core multiplication factor to effect the neutron population. Because of the larger thermal absorption cross sections in MOX fuel, the slower neutrons are preferentially absorbed in comparison to MOX fuel resulting in a shorter prompt neutron lifetime. Calculations of the prompt neutron lifetime were performed for the 12-month cycle $\mathrm{UO}_{2}$ and $30 \% \mathrm{MOX}$ cores $^{3-4}$ resulting in a prompt neutron lifetimes of $22.5 \mu$ s and $19.2 \mu$ s for the $\mathrm{UO}_{2}$ and MOX cores, respectively. Therefore, like the value of the effective delayed neutron fraction, this $15 \%$ reduction must be considered in the safety analysis and evaluation of the core protection system.

\subsection{REACTIVITY COEFFICENTS}

The reactivity coefficients are used to relate the change in thermal-hydraulics conditions (temperatures and water densities, for example) to the core neutronics through changes in reactivity. Therefore, the sign and magnitude of these coefficients are very important in determining the behavior of the core operational and accident conditions. The most common reactivity coefficients considered are the Doppler coefficient, which relates reactivity change to fuel temperature change, and the moderator temperature coefficient (MTC), which relates reactivity change to water density and temperature. Previous work has indicated that MOX fuel results in a slightly more negative Doppler coefficient, and a 
significantly more negative $\mathrm{MTC}^{7}$. These more negative coefficients are a concern in accident scenarios where there is an overcooling of the core because MOX fuel will result in a larger increase in reactivity. The steam line break event is one such transient in which cold makeup water results in a reduction in the coolant temperature and the possibility of a significant increase in core power.

The change in the MTC is of most concern in the accident analysis and is generally more negative at BOC than at EOC. Therefore, the use of MOX fuel will result in more significant changes at BOC than EOC. However, the BOC MTC is also sensitive to the soluble boron concentration and its corresponding reactivity worth. The VVER-1000 designs discussed previously rely heavily on the use of uraniumgadolinium absorbers to control BOC reactivity, and therefore the MTC is generally more negative at BOC than in western PWRs. A comparison of the MTC and Doppler coefficient is shown in Table 3.6. These results show only minor changes to the reactivity coefficients when inserting MOX fuel.

Table 3.6 Comparison of reactivity coefficients for $\mathrm{UO}_{2}$ and $\mathrm{MOX}$ core designs.

\begin{tabular}{|l|l|c|c|c|c|}
\hline & Conditions & $\mathbf{U O}_{2}$ (V-320) & $\begin{array}{l}\text { MOX (30\%, } \\
\text { 270 kg/year) }\end{array}$ & $\mathbf{U O}_{2}$ (U42) & $\begin{array}{c}\text { MOX } \\
\text { (U24P30, 40\% } \\
\text { 450 kg/year) }\end{array}$ \\
\hline $\begin{array}{l}\text { Moderator temperature } \\
\text { coefficient }\left(\mathrm{pcm} /{ }^{\circ} \mathrm{C}\right)\end{array}$ & $\begin{array}{l}\text { BOC, full } \\
\text { power }\end{array}$ & -25 & -29 & -31 & -32 \\
\cline { 2 - 6 } & EOC, full power & -60 & -65 & -67 & -69 \\
\hline $\begin{array}{l}\text { Doppler coefficient } \\
\left(\mathrm{pcm} /{ }^{\circ} \mathrm{C}\right)\end{array}$ & $\begin{array}{l}\text { BOC, full } \\
\text { power }\end{array}$ & -2.9 & -2.9 & -2.5 & -2.6 \\
\cline { 2 - 6 } & EOC, full power & -3.1 & -3.1 & -2.8 & -2.8 \\
\hline
\end{tabular}

Source Refs. 3-6.

\subsection{PRESSURE VESSEL FLUENCE}

The harder spectrum in MOX fuel and the increase in the fast neutron flux introduce the potential for increased fast fluence, and therefore embrittlement, of the pressure vessel. The Russian regulatory authority requires an evaluation of the radiation damage and lifetime of the pressure vessel when there is a significant change in the fuel cycle, such as the introduction of MOX fuel. Preliminary studies ${ }^{8}$ were performed to assess the impact of the insertion of MOX fuel on the pressure vessel and more recent studies (Ref. 9) have been performed using the 18-month, higher disposition rate core designs. The fast neutron flux distribution $(>0.5 \mathrm{MeV})$ was calculated on the inner and outer surfaces and inside the pressure vessel wall and for the surveillance specimens of the VVER-1000/320 reactor. Calculations were performed for both the $\mathrm{UO}_{2}$ fuel cycle and MOX fuel cycle using validated computer codes and methods.

The results of the calculations are presented in Figs 3.2 and 3.3 for the fast neutron flux in the pressure vessel wall. The azimuthal variation is presented in Fig. 3.2 in the midsection of the core where there is a plateau in the axial flux distribution at the peak azimuthal location. The axial variation, showing this plateau, is presented in Fig 3.3. These results show an insignificant increase in the neutron flux for the MOX core in comparison with the $\mathrm{UO}_{2}$ core. A summary of these results along with the neutron fluxes in the surveillance specimens is given in Table 3.7. The neutron fluxes at the surveillance assembly are essentially the same for both $\mathrm{UO}_{2}$ and MOX cores.

This minimal change in the fast neutron flux on the pressure vessel is the result of careful design of the core loading patterns. A comparison of the $\mathrm{UO}_{2}$ and $\mathrm{MOX}$ loading patterns for these cases show that the entire outer row of assemblies in the MOX core are uranium assemblies and that the higher burned assemblies are placed at the core locations closest to the pressure vessel. This outer row of assemblies has the most impact on the pressure vessel fluence, and the assemblies occupying this row are essentially the 
same for both the $\mathrm{UO}_{2}$ and MOX cores. Therefore, with careful consideration during the core design process, there is no impact on the pressure vessel fluence as a result of the insertion MOX assemblies.

Table 3.7 Results of fast neutron flux $\left(\mathrm{E}>0.5 \mathrm{MeV}, 10^{9} \mathrm{n} / \mathrm{cm}^{2} \mathrm{~s}\right)$ at the pressure vessel and surveillance assembly for $\mathrm{UO}_{2}$ and $\mathrm{MOX}$ cores

\begin{tabular}{|l|c|c|c|c|c|c|c|c|c|c|}
\hline & \multicolumn{4}{|c|}{ Pressure vessel } & \multicolumn{3}{c|}{ Surveillance assembly } \\
\cline { 2 - 11 } & \multicolumn{2}{|c|}{ Inner surface } & $\begin{array}{c}\text { One fourth of } \\
\text { Thickness }\end{array}$ & \multicolumn{2}{c|}{ Outer surface } & \multicolumn{2}{c|}{ Lower level } & \multicolumn{2}{c|}{ Upper level } \\
\cline { 2 - 11 } & $\mathrm{UO}_{2}$ & $\mathrm{MOX}$ & $\mathrm{UO}_{2}$ & $\mathrm{MOX}$ & $\mathrm{UO}_{2}$ & $\mathrm{MOX}$ & $\mathrm{UO}_{2}$ & $\mathrm{MOX}$ & $\mathrm{UO}_{2}$ & $\mathrm{MOX}$ \\
\hline Maximum & 31.1 & 31.7 & 22.7 & 23.1 & 3.90 & 3.98 & 287 & 285 & 104 & 104 \\
\hline Minimum & 16.4 & 16.8 & 12.3 & 12.6 & 2.67 & 2.73 & 164 & 163 & 64.6 & 64.2 \\
\hline
\end{tabular}

Source: Ref. 9.

\subsection{SUMMARY AND CONCLUSIONS}

The results presented in this chapter cover the impact on the core neutronic behavior from the insertion of MOX fuel in the VVER-1000 reactor. The results indicate the following:

- $\quad{ }^{239} \mathrm{Pu}$ has significantly different nuclear properties than ${ }^{235} \mathrm{U}$ that impact the neutronic behavior of the reactor core.

- The assembly reactivity vs burnup is different for $\mathrm{MOX}$ fuel than $\mathrm{UO}_{2}$ fuel; but with proper design, this difference does not affect the operation of the core in terms of fuel cycle length.

- The neutron spectrum resulting from MOX fuel is harder than that from $\mathrm{UO}_{2}$ fuel. This harder spectrum reduces the worth of the soluble boron and control rod absorbers.

- The worth of absorber materials (boron and gadolinium) used in the soluble boron, burnable absorbers, and control rods is lower in MOX cores. This results in the increase in the soluble boron concentration, increased use of burnable absorbers, and a modification to the control rods to use enriched boron.

- The power distribution and linear heating rates in MOX cores are comparable to that of $\mathrm{UO}_{2}$ cores.

- The delayed neutron fraction and prompt neutron lifetime are smaller in MOX cores and will require analysis to determine any impacts on the reactor safety analysis.

- The moderator temperature coefficient of reactivity is more negative in MOX cores, particularly at $\mathrm{BOC}$, than $\mathrm{UO}_{2}$ cores. The Doppler coefficient of reactivity is also slightly more negative.

- The fast flux at the pressure vessel is not significantly increased in MOX cores if a low-leakage loading pattern with $\mathrm{UO}_{2}$ assemblies on the core periphery is used.

While differences in the core behavior are caused by the insertion of MOX fuel, with careful design the overall core performance is comparable to the operation with $\mathrm{UO}_{2}$ fuel. 


\section{REFERENCES}

1. James J. Duderstadt and Louis J. Hamilton, Nuclear Reactor Analysis, Wiley Text Books (1976).

2. G. Robert Keepin, Physics of Nuclear Kinetics, Addison-Wesley (1965).

3. S. Alioschin et al., "VVER-1000 Gadolinium Core with 30\% MOX," Presentation at the AmericanRussian Technical Meeting on MOX Fuel Disposition in VVER-1000, Oak Ridge, Tennessee, March 5-9, 2001.

4. A.M. Pavlovitchev et al., Kinetics Parameters of VVER-1000 Core with 3 MOX Lead Test Assemblies to be used for Accident Analysis Codes, Russian Research Center "Kurchatov Institute," ORNL/SUB/99-B99398V-2, Oak Ridge National Laboratory, 2000.

5. A. M. Pavlovitchev et al., Analysis of Alternative In-Core Fuel Core Management with Increased Disposition Pu Rate in VVER-1000, Russian Research Center “Kurchatov Institute," Final Report for Task 2 of Work Release KI-WR13JCG, 2004.

6. A.M. Pavlovitchev et al., Fuel Assembly and Core Model for Neutronics Calculations of VVER1000, Russian Research Center "Kurchatov Institute," 1998.

7. A. M. Pavlovitchev et al., Mission Fuel Kinetics Input and RELAP-Like Calculations, Russian Research Center "Kurchatov Institute," ORNL/SUB/00-85B99398V-14, Oak Ridge National Laboratory, 2001.

8. B. Bodkin et al., "Variation of Fast Neutron Fluence Rate on the WWER-1000 Pressure Vessel Due to the Implementation of MOX Fuel Cycle," Presentation at the French-German-Russian meeting on Studies of the Feasibility of Weapons-Grade Plutonium Disposition in WWER-1000, July $15,2000$.

9. S. M. Zaritsky et al., Results of RPV Fluence Calculations, Russian Research Center "Kurchatov Institute," 2004. 


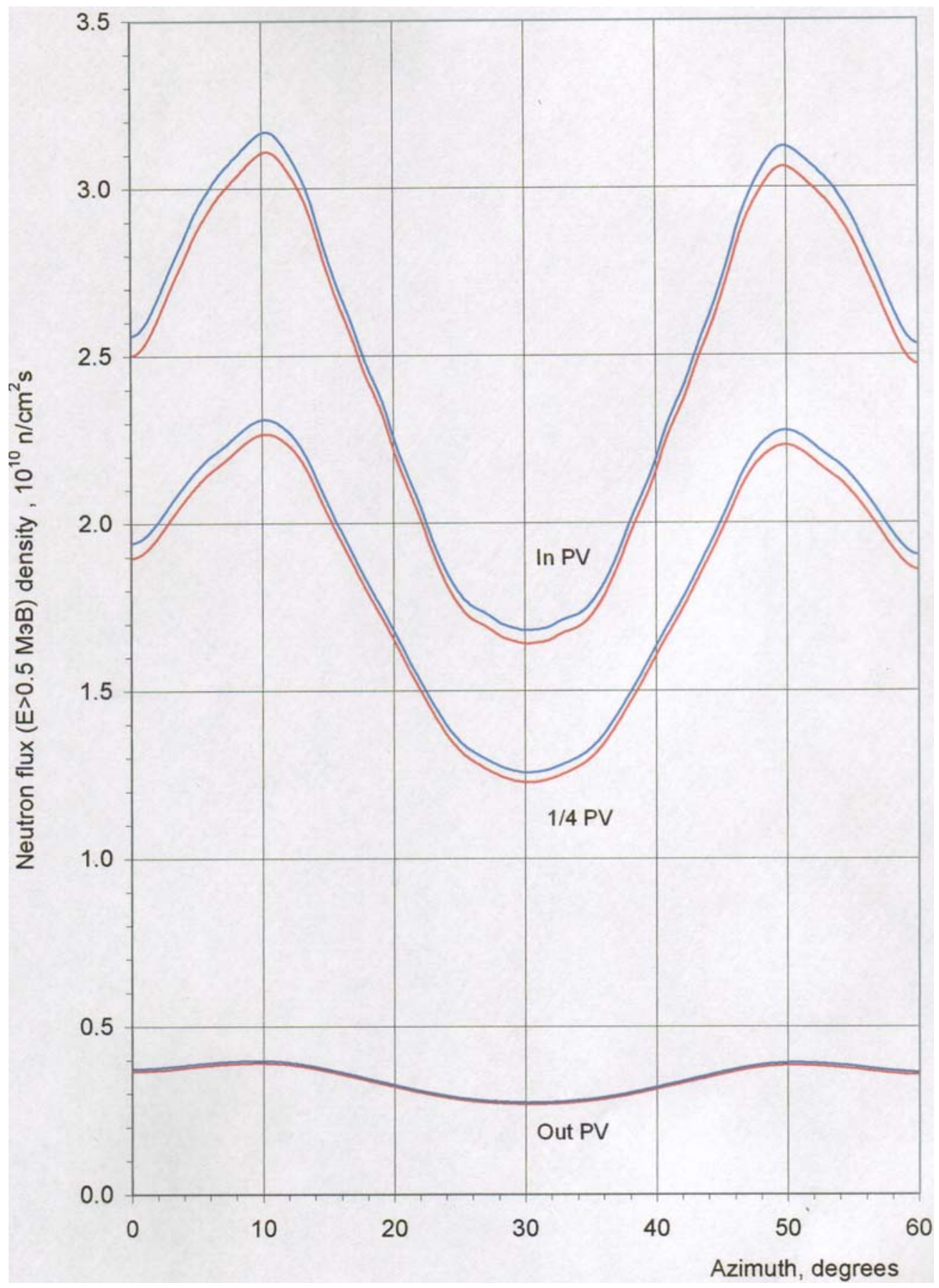

Fig. 3.2 Azimuthal variation of the fast neutron flux near core midplane (red line is $\mathrm{UO}_{2}$; blue line is MOX). Source: Ref. 9. 


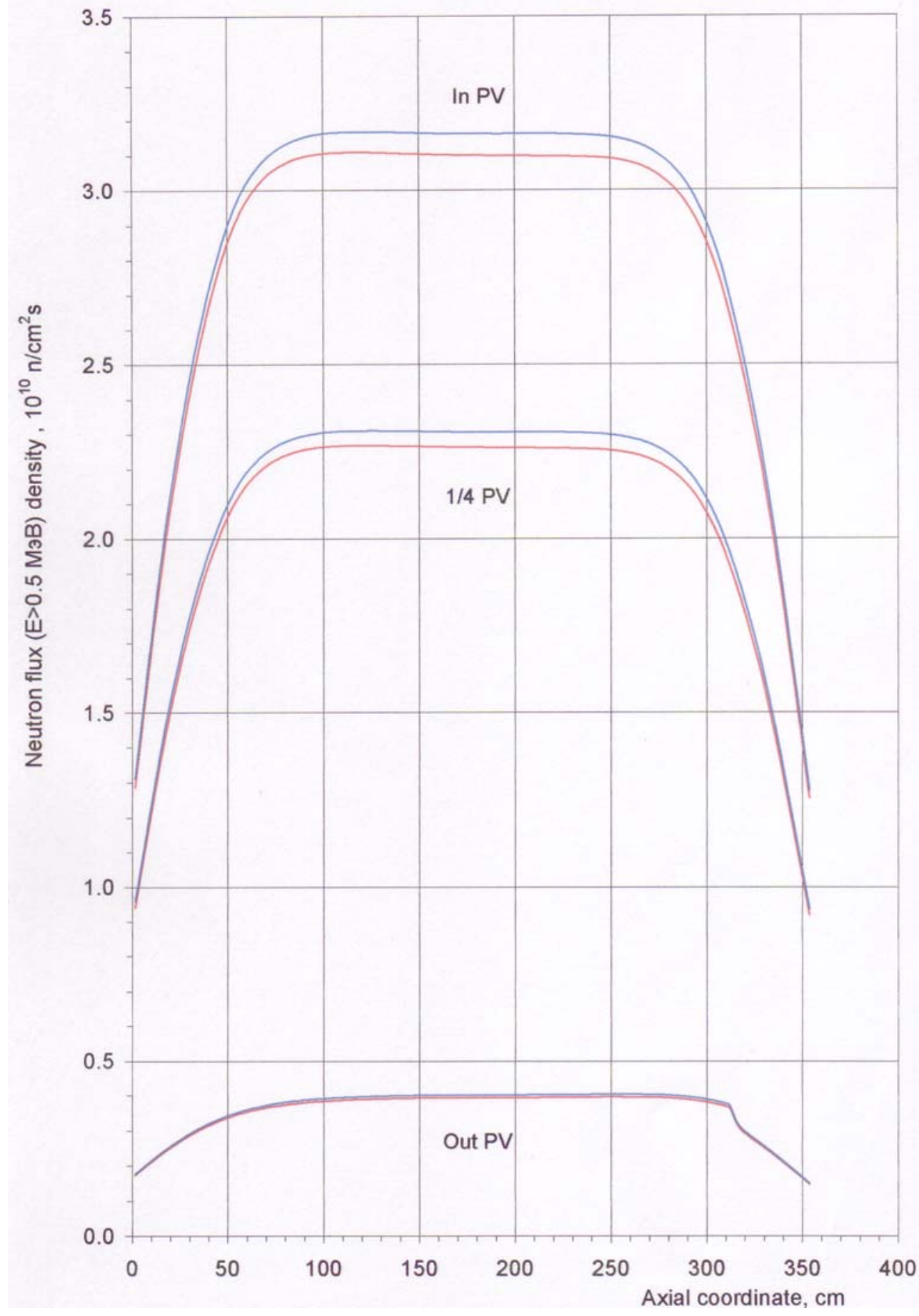

Fig. 3.3 Axial variation in the fast neutron flux at 10.3 degrees (azimuthal maximum) (red line is $\mathrm{UO}_{2}$; blue line is MOX). Source: Ref. 9. 


\section{MOX AND UO 2 THERMOPHYSICAL PROPERTIES}

The thermophysical properties of $\mathrm{MOX}$ and $\mathrm{UO}_{2}$ fuel are similar, but some significant differences were clearly identified and described in detail in Refs. 1 and 2.

\subsection{MOX AND UO 2 PROPERTY DIFFERENCES}

MOX fuel has a lower melting temperature, lower heat of fusion, lower heat capacity (at temperatures above $2000 \mathrm{~K}$ ), and lower thermal conductivity than $\mathrm{UO}_{2}$ fuel. MOX fuel has a higher heat capacity at temperatures below $2000 \mathrm{~K}$ and is a little heavier than $\mathrm{UO}_{2}$ fuel. Other factors like burnup and deviations from stoichiometry change some of the properties very significantly. In particular, melting temperatures and thermal conductivities of both $\mathrm{UO}_{2}$ and $\mathrm{MOX}$ fuel are reduced with increased burnup and/or with deviations from stoichiometry. Deviations from stoichiometry routinely occur as the fuel is irradiated. Before irradiation, the fuel is stoichiometric with two atoms of oxygen for every atom of plutonium or uranium $\left(\mathrm{PuO}_{2}\right.$ or $\left.\mathrm{UO}_{2}\right)$. As the fuel burns, plutonium and/or uranium get converted into other elements, and excess oxygen will be available to combine with the remaining fissionable atoms $\left(\mathrm{PuO}_{2}\right.$ composition changes to $\mathrm{PuO}_{2+\mathrm{x}}$ ). Oxygen can also be converted into other elements by neutron interactions, and oxygen deficit is also possible. Radiation damage also decreases the value of the thermal conductivity at temperatures below $1000 \mathrm{~K}$, temperatures that are lower than most fuel operating temperatures. Figure 4.1 shows melting temperature of fuel as a function of fuel composition. The bottom line between solid and solid + liquid $\left(\mathrm{S}+\mathrm{L}\right.$ ) is the line where melting starts. Note that $7 \% \mathrm{PuO}_{2}$ is considered the upper limit for the fuel composition and that the current core designs have $\mathrm{PuO}_{2}$ contents of about $5 \%$. Figure 4.2 shows fuel melting temperature as a function of composition and burnup.

The coefficients of thermal expansion of both fuels are nearly identical (Refs. 1 and 2 state that they are the same, but Ref. 3 states that the MOX fuel thermal expansion is $1 \%$ higher than $\mathrm{UO}_{2}$ fuel). MOX fuel pellets have a higher creep rate than $\mathrm{UO}_{2}$ pellets ${ }^{3}$. Figure 4.3 shows the coefficients of thermal expansion for $\mathrm{UO}_{2}$ and $\mathrm{PuO}_{2}$ fuels.

Finally, in-homogeneities (due to plutonium-rich clusters) are possible in MOX fuel and can be significant depending on the fabrication process. $\mathrm{UO}_{2}$ fuel is homogeneous.

The property that differs significantly (by about 10\%) between both fuels is the thermal conductivity at temperatures below $2250 \mathrm{~K}$. At temperatures above $2250 \mathrm{~K}$, both fuels have similar thermal conductivities. For the remaining properties, the differences are small.

Values of different thermophysical properties are given in Table 4.1 for $\mathrm{UO}_{2}, \mathrm{PuO}_{2}$, and MOX fuel (with 5\% $\mathrm{PuO}_{2}$ ), and in Fig. 4.1-4.5. Densities are given for fully dense fuels (100\% TD, theoretical density) with zero porosity, and for fuels with 0.05 porosity (or $95 \%$ TD). Porosity, $\mathbf{p}$, varies between 0 (for fully dense fuel, $100 \%$ TD with density $\boldsymbol{\rho}_{\mathbf{T D}}$ ) and 1 (fuel full of voids with zero density). Density, $\boldsymbol{\rho}$, theoretical density, $\boldsymbol{\rho}_{\mathrm{TD}}$, porosity, $\mathbf{p}$, and $\%$ of TD are related by the expression:

$$
\boldsymbol{\rho}_{=} \boldsymbol{\rho}_{\mathrm{TD}}(1-\mathbf{p})=\boldsymbol{\rho}_{\mathrm{TD}}(\% \mathbf{T D} / 100)
$$

Commercial fuel density varies between $94 \%$ and $96 \%$ of the TD prior to irradiation. Irradiation and high temperature change the density, but the changes are similar for both fuels. Burnup is given in Table 4.1 and Fig. 4.5 in units of at \% (5\% at burnup is equivalent to $46.87 \mathrm{MWd} / \mathrm{kg}$ ). 
Figure 4.4 shows the heat capacity as a function of temperature and fuel composition. The differences between $\mathrm{UO}_{2}$ and $\mathrm{MOX}$ (with $5 \% \mathrm{PuO}_{2}$ ) values are very small. Figure 4.5 shows thermal conductivity as a function of temperature, fuel composition, irradiation, and burnup. The differences between $\mathrm{UO}_{2}$ and MOX values are significant, and the effects of burnup and/or irradiation damage are also significant.

All properties have uncertainties that need to be considered in safety calculations. For the melting temperature, the error is $\pm 35 \mathrm{~K}$. The error in the densities is about $1 \%$. The error in the heat of fusion is $\pm 15 \mathrm{~kJ} / \mathrm{kg}$. The error in the heat capacity is $\pm 2 \%$ at temperatures below $1800 \mathrm{~K}$ and $\pm 13 \%$ at temperatures above. For the thermal conductivity, the uncertainties vary from $\pm 10 \%$ below $2000 \mathrm{~K}$ to $\pm 20 \%$ above $2000 \mathrm{~K}$. The values of Table 4.1 or Figs 4.1-4.5 do not consider any of these uncertainties. The uncertainties need to be considered in safety calculations to make sure that the results are conservative. For some accidents, adding the error to a property may be the conservative case, but for others accidents the opposite may be true. Therefore, both bands ( + and - ) of the error must be considered for each property and also a combination of errors (like + for the heat capacity and - for the thermal conductivity).

For instance, the melting temperature of fresh (no burnup) MOX fuel (with $5 \% \mathrm{PuO}_{2}$ ) is $3088 \mathrm{~K}$. When burnup of 5 at $\%$ is considered, this temperature decreases to $3063 \mathrm{~K}$. If the uncertainty of $-35 \mathrm{~K}$ is considered, the temperature is lowered to $3028 \mathrm{~K}\left(2755{ }^{\circ} \mathrm{C}\right)$, which is the conservative (as it melts sooner) value that should be used in safety calculations. For the thermal conductivity, lower values (subtracting the error) are normally conservative as lower thermal conductivities result in higher fuel temperatures.

Table 4.1 Comparison of thermophysical properties of $\mathrm{UO}_{2}, \mathrm{PuO}_{2}$, and $\mathrm{MOX}$ fuel

\begin{tabular}{|c|c|c|c|}
\hline Property & $\mathbf{U O}_{2}$ & $\mathrm{PuO}_{2}$ & $\operatorname{MOX}\left(5 \% \mathrm{PuO}_{2}\right)$ \\
\hline Melting temperature, no burnup (K) & 3120 & 2701 & 3088 \\
\hline with burnup, 5 at $\%$ & 3095 & 2676 & 3063 \\
\hline Density at $273 \mathrm{~K}, 100 \% \mathrm{TD}\left(\mathrm{kg} / \mathrm{m}^{3}\right)$ & 10970 & 11460 & 10994 \\
\hline $95 \% \mathrm{TD}(\mathrm{p}=0.05)$ & 10421 & 10887 & 10444 \\
\hline Heat of fusion $(\mathrm{kJ} / \mathrm{kg})$ & 259.3 & 245.4 & 248 \\
\hline \multicolumn{4}{|l|}{ Thermal conductivity at $1573 \mathrm{~K}(\mathrm{~W} / \mathrm{m} \cdot \mathrm{K})$} \\
\hline stoichiometric, no burnup & 2.32 & & 2.13 \\
\hline stoichiometric, 5 at $\%$ burnup & 2.01 & & 1.8 \\
\hline hypostoichiometric, 5 at $\%$ burnup & 1.8 & & 1.54 \\
\hline
\end{tabular}




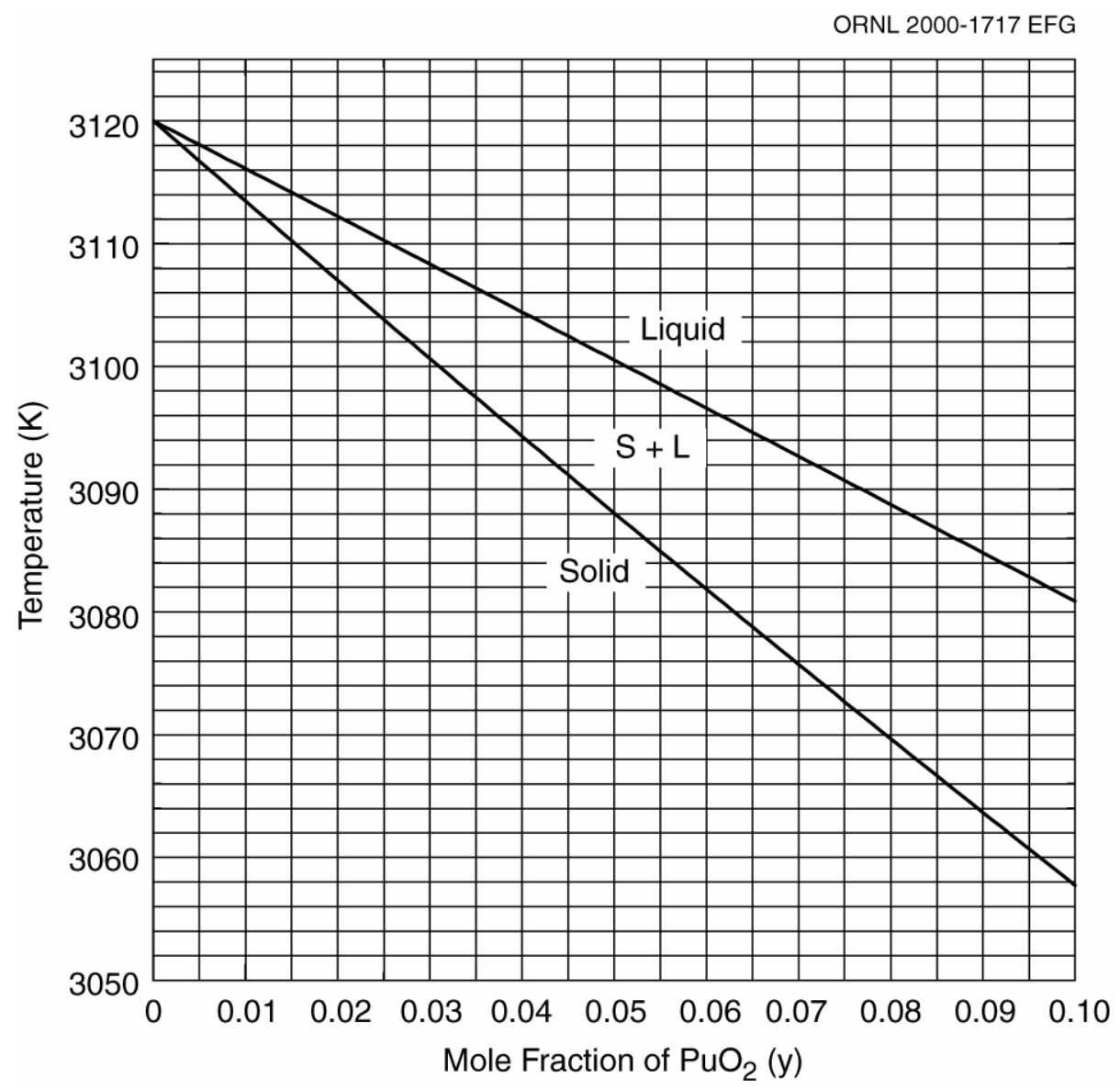

Fig. 4.1. Variation of fuel melting temperature as a function of mole fraction $(\mathrm{y})$ of $\mathrm{PuO}_{2}$. Source: Refs. 1 and 2. 


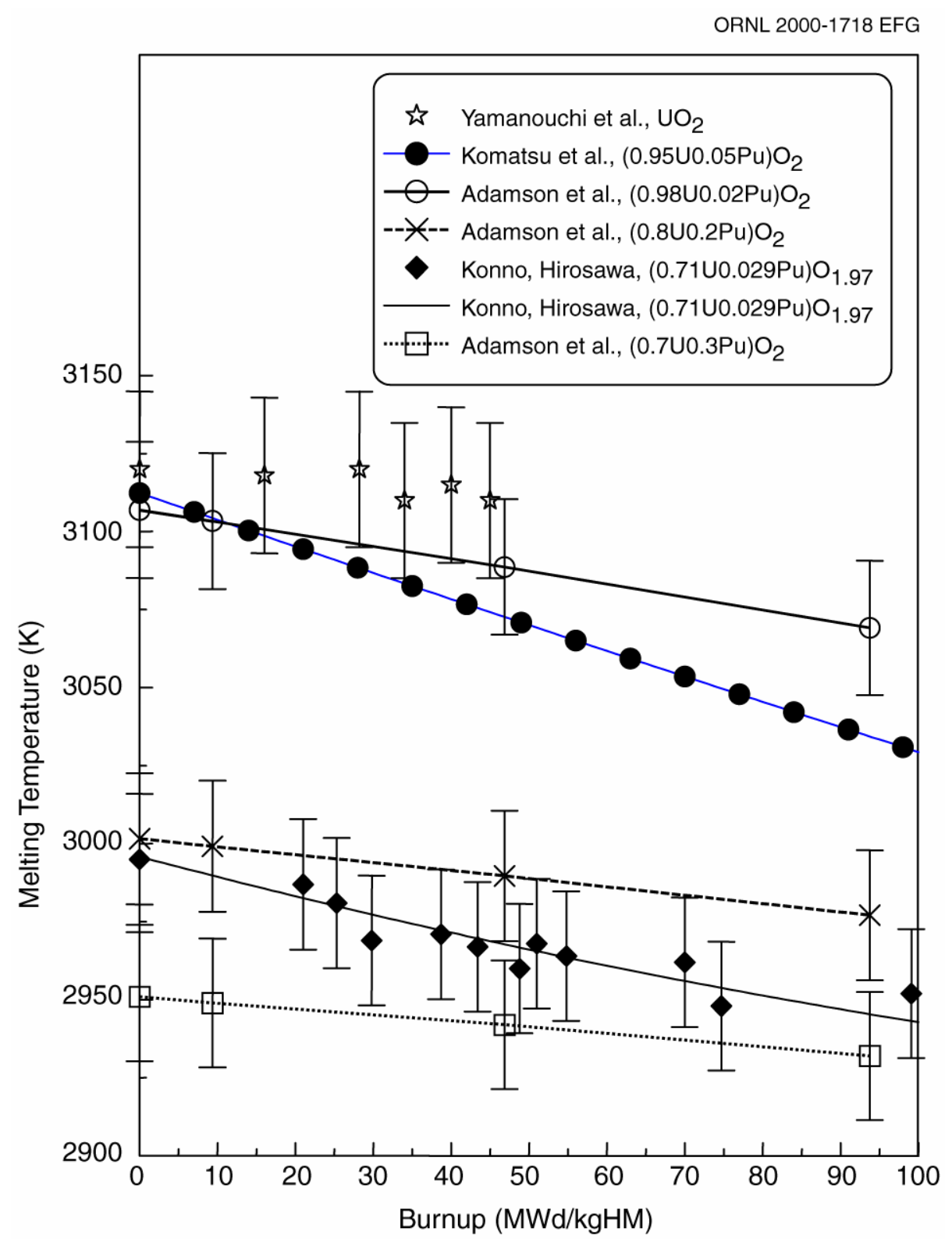

Fig. 4.2 Influence of burnup on fuel melting temperature. Source: Ref. 2. 
ORNL 2000-1719 EFG

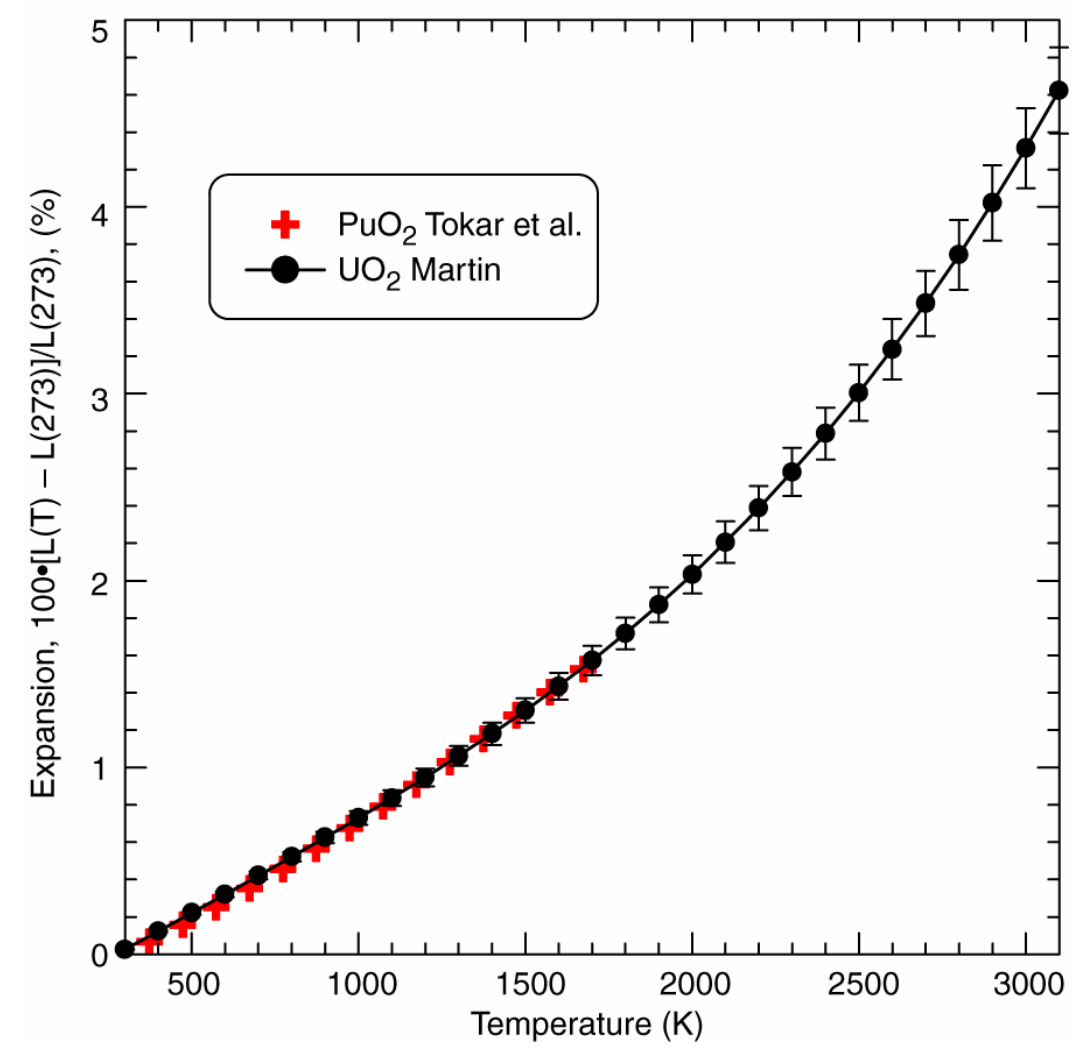

Fig. 4.3 Thermal expansion of $\mathrm{UO}_{2}$ and $\mathrm{PuO}_{2}$ fuels. Source: Ref. 2 .

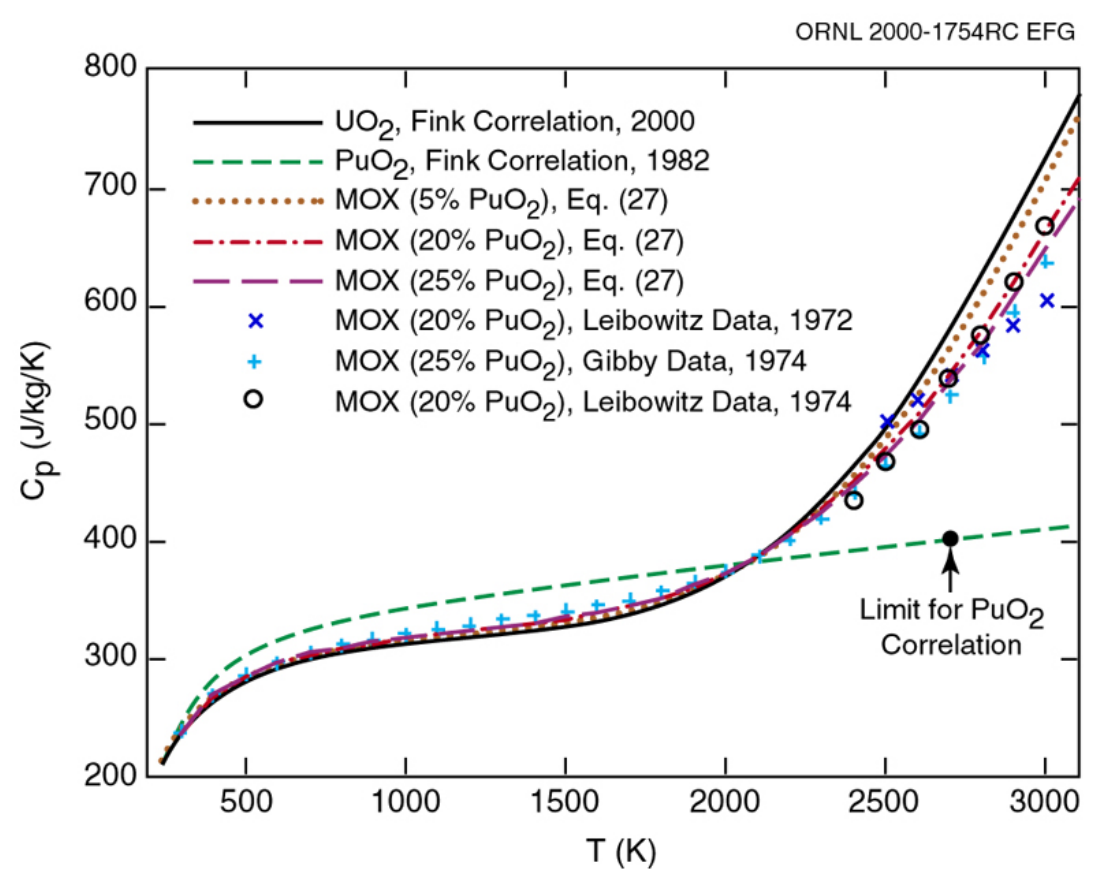

Fig. 4.4 Variation of the heat capacity as a function of temperature and fuel composition.

Source: Ref. 2. 
ORNL 2000-1855RC EFG

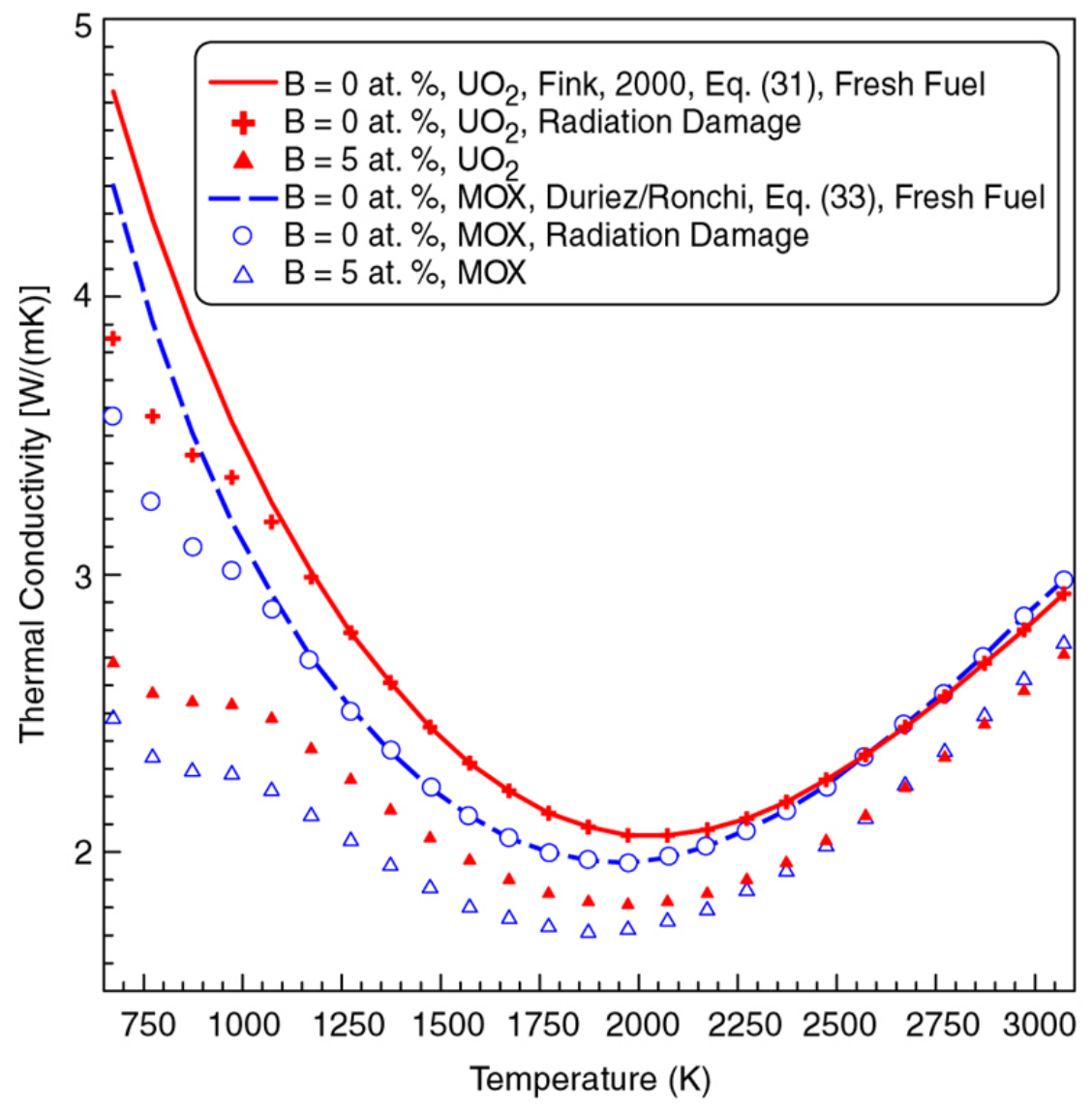

Fig. 4.5 Thermal conductivity of $\mathrm{UO}_{2}$ and MOX fuel for different burnups. Source: Ref. 2 .

\subsection{EFFECTS OF THE DIFFERENT PROPERTIES OF MOX AND UO FUELS $_{2}$}

For the same steady-state power conditions, MOX fuel will result in higher fuel centerline temperatures and in more energy stored (because of the higher temperatures and because of the higher heat capacity below $2000 \mathrm{~K}$ ) than equivalent $\mathrm{UO}_{2}$ fuel. Higher temperatures are the result of the lower thermal conductivity of the MOX fuel. These higher temperatures will result in increased fission product gas releases from the fuel; thus, a larger fission product gap inventory needs to be considered in accidents. This is the most important differential effect.

After a loss-of-coolant accident (LOCA), cooling of the fuel cladding is interrupted, and the temperatures of the fuel and the cladding equalize. The higher initial temperature and energy stored in the MOX fuel will result in a higher peak cladding temperature than the peak cladding temperature of $\mathrm{UO}_{2}$ fuel operating at the same power. Because the three LTAs will be operating at moderate power levels, lower than most of the $\mathrm{UO}_{2}$ assemblies, the peak temperatures of the LTAs will be lower than the temperatures of the $\mathrm{UO}_{2}$ high-power rods and of most $\mathrm{UO}_{2}$ fuel. 
For high MOX loadings of the core (one-third core or 41\%), MOX fuel will have powers comparable to $\mathrm{UO}_{2}$ fuel powers. MOX fuel temperatures will be higher than the temperatures of $\mathrm{UO}_{2}$ fuel operating at the same powers; but in all of the calculations performed, the calculated fuel temperatures are well below the melting temperature of MOX fuel, which is $3028 \mathrm{~K}\left(2755^{\circ} \mathrm{C}\right)$, per Sect. 4.1. Also, after a LOCA, the maximum fuel cladding temperatures calculated are below the limit of $1473 \mathrm{~K}\left(1200{ }^{\circ} \mathrm{C}\right)$ for both MOX and $\mathrm{UO}_{2}$ fuel.

During power increases, the lower specific heat of MOX fuel at temperatures above $2000 \mathrm{~K}$ results in faster and higher temperature increases. However, this difference is very small and should not affect the consequences of any thermal-hydraulic accident.

Irradiation and burnup degrade the thermal conductivity of either fuel. Thus, accidents considered at the end of a fuel cycle are normally more severe than at the beginning of a fuel cycle because of the lower thermal conductivities. This effect is the same for $\mathrm{UO}_{2}$ and MOX fuels and is not a differential factor.

The lower melting temperature and lower heat of fusion of the MOX fuel does not have any effect on design basis accidents, but it is important in severe accidents. MOX fuel will melt sooner than $\mathrm{UO}_{2}$ fuel. Also, the core melt progression and the release of fission products will be different (faster in MOX fuel because the higher fuel temperature, the lower melting temperature, and the lower heat of fusion compared to $\mathrm{UO}_{2}$ fuel of the same power).

The inhomogeneities of the MOX fuel are important in reactivity insertion accidents (RIAs). Because of the inhomogeneities, large fission gas releases may occur during a RIA that may result in cladding rupture. This was the case of the CABRI REP Na7 test ${ }^{4}$, a RIA test with MOX fuel of poor homogeneity that ended in violent cladding rupture. Modern fuel fabrication techniques for MOX fuel will manufacture rather homogeneous fuel; thus, with an appropriate QA process, this problem should not be a significant concern.

The difference in fuel densities (Table 4.1) is $\rho\left(\mathrm{MOX} / \mathrm{UO}_{2}\right)=10444 / 10421=1.0022$ or $0.22 \%$ which is about $1 \mathrm{~kg}$ per assembly, assuming that there are $490 \mathrm{~kg}$ of fuel per assembly and both $\mathrm{MOX}$ and $\mathrm{UO}_{2}$ fuel have the same porosity. If MOX fuel has a larger porosity than $\mathrm{UO}_{2}$ fuel, then the weight of the MOX fuel (or assembly) could be smaller. This is the case of the U.S.-manufactured MOX fuel that will have $1 \%$ more porosity than the $\mathrm{UO}_{2}$ fuel ${ }^{5}$, resulting in a lighter MOX assembly than the $\mathrm{UO}_{2}$ assembly. But this is not necessarily the case with the Russian MOX fuel, where both $\mathrm{MOX}$ and $\mathrm{UO}_{2}$ fuels are in principle, to be manufactured with the same porosity. Furthermore, MOX assemblies have more U-Gd rods (18 in previous designs and between 18 and 27 in future designs) than $\mathrm{UO}_{2}$ assemblies (only 6 in previous designs and between 6 and 18 in future designs). Because the U-Gd rods are lighter than the regular fuel rods, the additional U-Gd rods in the MOX assembly will reduce some of the weight of the MOX assembly, making the overall difference in weight even smaller. Therefore, the MOX assembly is slightly heavier (by about $1 \mathrm{~kg}$ ) than the $\mathrm{UO}_{2}$ assembly, if both fuels have the same porosity. The total weight of one assembly is about $700 \mathrm{~kg}$. Therefore, there should be no impact on fuel lifting equipment.

The thermal expansion coefficient and the creep rate are important in pellet-to-cladding mechanical interaction (PCMI). Because the larger creep rate of MOX fuel compared to $\mathrm{UO}_{2}$ fuel and the similar coefficients of expansion, PCMI in MOX fuel should not be any worse than in $\mathrm{UO}_{2}$ fuel.

The uncertainties in the properties are the same for either fuel; therefore, they are not a differential factor. The uncertainties have larger effects on the property variation than the fuel composition $\left(\mathrm{UO}_{2}\right.$ vs $\mathrm{MOX}$ ). For instead, the thermal conductivity changes about $10 \%$ from $\mathrm{UO}_{2}$ to $\mathrm{MOX}$ fuel, but the uncertainty band is as high as $20 \%$. 


\subsection{SUMMARY AND CONCLUSIONS}

The main property difference between $\mathrm{UO}_{2}$ and MOX fuels is in the thermal conductivity, with reduced values for MOX fuel. The effects of this difference are (a) higher fuel centerline temperature, typically $50-100 \mathrm{~K}$ and, (b) more energy stored in the $\mathrm{MOX}$ fuel as compared to $\mathrm{UO}_{2}$ fuel values. Other differences are more inhomogeneities, a slightly higher density, lower heat of fusion, and lower melting temperature for MOX fuel.

\section{REFERENCES}

1. S. G. Popov, J. J. Carbajo, V. K. Ivanov and G. L. Yoder, Thermophysical Properties of MOX and UO Fuels Including the Effects of Irradiation, ORNL/TM-2000/351, Oak Ridge National Laboratory, November 2000.

2. J. J. Carbajo, G. L. Yoder, S. G. Popov and V. K. Ivanov, "A review of the thermophysical properties of MOX and UO2 fuels,"J. Nucl. Mat. 299, 181-198, (December 2001).

3. "Mixed-Oxide Fuel Use in Commercial Light Water Reactors," attachment to U.S. NRC letter from William D. Travers to Chairman and Commission, April 14, 1999.

4. J. Papin and F. Schmitz, "The status of the CABRI-REP-Na Test Programme: Present Understanding and Still Pending Questions," Proceedings of the $25^{\text {th }}$ Water Reactor Safety Meeting, Bethesda, Maryland, 1997.

5. Correspondence from M. S. Tuckman, Duke Power, to U.S. Nuclear Regulatory Commission transmitting "Proposed Amendments to the Facility Operating License and Technical Specifications to Allow Insertion of Mixed Oxide (MOX) Fuel Lead Assemblies and Request Exemption from Certain Regulations in 10 CFR Part 50," Attachment 3, Description and Technical Justification, page 3-14, February. 27, 2003. 


\section{DECAY HEAT}

\subsection{DECAY HEAT FOR MOX AND UO FUELS $_{2}$}

$\mathrm{MOX}$ and $\mathrm{UO}_{2}$ fuels have different decay heats because of their different isotopic compositions after burnup. Calculations have been performed with the code ORIGEN-S of the SCALE package ${ }^{1}$ for the two fuel types and for two different burnups ( 45 and $50 \mathrm{MWd} / \mathrm{kgHM}$ ). The input data for the fuel assemblies were taken from Ref. 2. The specific power density for either fuel was taken as $42 \mathrm{~W} / \mathrm{g}$. Previous calculations (both Russian and by ORNL) have been reported in Refs. 3 and 4.

The results are shown in Tables 5.1 and 5.2 and in Figures 5.1-5.3. Decay heats are given in watts per kilogram $(\mathrm{W} / \mathrm{kg})$ of heavy metal for the two main classes of contributors: actinides and fission products (FPs). MOX fuel has a larger actinide contribution and a lower fission product contribution than $\mathrm{UO}_{2}$ fuel. For the same burnup level, the total decay heat of MOX fuel is lower than $\mathrm{UO}_{2}$ fuel during the first day after shutdown, but after one day, MOX decay heat is larger than $\mathrm{UO}_{2}$ fuel. Figures 5.2 and 5.3 show this clearly. This difference is less than $4 \%$ (lower for MOX fuel) during the first day of cooling. However, in the long term, MOX fuel can produce $35 \%$ more decay heat at $10,000 \mathrm{~d}$ of cooling.

Total decay heat increases generally with burnup. Therefore, when comparing decay heats of MOX fuel with a lower burnup than $\mathrm{UO}_{2}$ fuel, the decay heat of the MOX fuel will be lower than the $\mathrm{UO}_{2}$ fuel for a longer time, and it could be forever if MOX fuel has a much lower burnup than $\mathrm{UO}_{2}$ fuel. When MOX fuel with $45 \mathrm{MWd} / \mathrm{kgHM}$ burnup is compared with $\mathrm{UO}_{2}$ fuel with $50 \mathrm{MWd} / \mathrm{kgHM}$ burnup (Table 5.1), the total decay heat of MOX fuel is less than the decay heat of $\mathrm{UO}_{2}$ fuel during the first $5 \mathrm{~d}$ of cooling.

The specific power level in the recent power history of a fuel assembly has a large influence on the discharge and near-term decay heat generation. For instance, two $\mathrm{UO}_{2}$ fuel assemblies with the same total discharge burnup but with large differences in the power level at the end of the irradiation, may have greatly different decay heat generation at discharge. The long-term decay heat is generally consistent with the total burnup of the fuel.

\subsection{EFFECTS OF DIFFERENT DECAY HEATS}

The effects of the lower than $\mathrm{UO}_{2}$ decay heat of MOX fuel during the first day after shutdown is to reduce the severity of some accidents because less decay heat is produced after shutdown compared to $\mathrm{UO}_{2}$. This is the case of LOCAs where decay heat is released to the fuel after the coolant is lost. The reduced decay heat of MOX fuel offsets the increased temperature and energy stored due to the reduced thermal conductivity of MOX (covered in Sect. 4). But the difference between $\mathrm{MOX}$ and $\mathrm{UO}_{2}$ fuel decay heats is very small, less than $4 \%$ during the first day of cooling. After this time, the decay heat of MOX is larger than $\mathrm{UO}_{2}$, but the core is expected to be reflooded within minutes. Therefore, long-term cooling for MOX fuel should not be a problem following a LOCA.

The larger than $\mathrm{UO}_{2}$ decay heat in the long term (after 1-5 d) is an important factor in severe accidents, with MOX fuel having faster melting processes and more fission product releases. The larger than $\mathrm{UO}_{2}$ decay heat in the long term (after 1-5 days) needs also to be considered in cooling calculations of MOX spent fuel stored in the spent fuel pool. The difference, for the same $45-\mathrm{MWd} / \mathrm{kg}$ burnup, could be as high as $35 \%$ at 10,000 d after discharge (Table 5.2). However, if MOX fuel has lower burnups than $\mathrm{UO}_{2}$ fuel, the decay heat of MOX fuel may not be much larger than $\mathrm{UO}_{2}$. Typical discharge burnups values for 18-month cycles are $40 \mathrm{MWd} / \mathrm{kg}$ for MOX fuel (2 cycles) and $46 \mathrm{MWd} / \mathrm{kg}$ for $\mathrm{UO}_{2}$ fuel (3 cycles). For this case, and based on previous results, $\mathrm{MOX}$ fuel will have more decay heat than $\mathrm{UO}_{2}$ fuel in the long term by approximately $20 \%$. 


\subsection{SUMMARY AND CONCLUSIONS}

MOX fuel has a lower decay heat in the short term (days) but a larger decay heat in the long term than $\mathrm{UO}_{2}$ fuel. If the MOX fuel has lower burnup than $\mathrm{UO}_{2}$ fuel, then the decay heat of MOX fuel will be lower than $\mathrm{UO}_{2}$ values for longer times. The lower short-term MOX decay heat is beneficial in LOCAs, and the larger long-term MOX decay heat needs to be considered in severe accidents and in cooling the spent fuel in the pool.

\section{REFERENCES}

1. SCALE: A Modular Code System for Performing Standardized Computer Analyses for Licensing Evaluation, NUREG/CR-0200, Rev.6 (ORNL/NUREG/CSD-2/R6), Vols. I, II, and III, May 2000.

2. A.M. Pavlovichev et al, Report on Neutronics Studies on MOX Fuel in VVER: Analysis of alternative in-core fuel core management with increased disposition Pu rate in VVER-1000, Moscow, 2003.

3. Margaret B. Emmett, Calculational Benchmark Problems for VVER-1000 Mixed Oxide Fuel Cycle, ORNL/TM-1999/207, Oak Ridge National Laboratory, March 2000.

4. W. J. Reich et al, Impacts on Reactor Systems, Operations, Equipment, and Facilities from the Use of MOX Fuels, ORNL/MD/LTR-140, Appendix G.2, Oak Ridge National Laboratory, August 1998. 
Table 5.1 MOX and LEU fuel assembly decay heat as a function of discharge burnup

\begin{tabular}{|c|c|c|c|c|c|c|c|c|c|c|c|c|}
\hline \multirow{2}{*}{$\begin{array}{c}\text { Cooling } \\
\text { time } \\
\text { (d) }\end{array}$} & \multicolumn{3}{|c|}{ MOX (45 MWd/kgHM) } & \multicolumn{3}{|c|}{ LEU (45 MWd/kgHM) } & \multicolumn{3}{|c|}{ MOX (50 MWd/kgHM) } & \multicolumn{3}{|c|}{ LEU (50 MWd/kgHM) } \\
\hline & $\begin{array}{l}\text { Actinides } \\
(\mathrm{W} / \mathrm{kg})\end{array}$ & $\begin{array}{c}\text { FPs } \\
(\mathrm{W} / \mathrm{kg})\end{array}$ & $\begin{array}{c}\text { Total } \\
(\mathrm{W} / \mathrm{kg})\end{array}$ & $\begin{array}{c}\text { Actinides } \\
(\mathrm{W} / \mathrm{kg})\end{array}$ & $\begin{array}{c}\text { FPs } \\
(\mathrm{W} / \mathrm{kg})\end{array}$ & $\begin{array}{c}\text { Total } \\
(\mathrm{W} / \mathrm{kg}) \\
\end{array}$ & $\begin{array}{c}\text { Actinides } \\
(\mathrm{W} / \mathrm{kg})\end{array}$ & $\begin{array}{c}\text { FPs } \\
(\mathrm{W} / \mathrm{kg})\end{array}$ & $\begin{array}{c}\text { Total } \\
(\mathrm{W} / \mathrm{kg})\end{array}$ & $\begin{array}{c}\text { Actinides } \\
(\mathrm{W} / \mathrm{kg})\end{array}$ & $\begin{array}{c}\text { FPs } \\
(\mathrm{W} / \mathrm{kg})\end{array}$ & $\begin{array}{c}\text { Total } \\
(\mathrm{W} / \mathrm{kg})\end{array}$ \\
\hline 0.0 & $1.444+2$ & $2.353+3$ & $2.497+3$ & $1.389+2$ & $2.460+3$ & $2.598+3$ & $1.510+2$ & $2.350+3$ & $2.501+3$ & $1.447+2$ & $2.435+3$ & $2.579+3$ \\
\hline $2.0-6$ & $1.444+2$ & $2.312+3$ & $2.456+3$ & $1.389+2$ & $2.416+3$ & $2.554+3$ & $1.509+2$ & $2.309+3$ & $2.459+3$ & $1.447+2$ & $2.392+3$ & $2.536+3$ \\
\hline $1.0-5$ & $1.444+2$ & $2.190+3$ & $2.334+3$ & $1.389+2$ & $2.286+3$ & $2.424+3$ & $1.509+2$ & $2.186+3$ & $2.336+3$ & $1.447+2$ & $2.263+3$ & $2.407+3$ \\
\hline $2.0-3$ & $1.390+2$ & $9.905+2$ & $1.129+3$ & $1.335+2$ & $1.034+3$ & $1.167+3$ & $1.453+2$ & $9.862+2$ & $1.131+3$ & $1.391+2$ & $1.023+3$ & $1.162+3$ \\
\hline $1.0-2$ & $1.211+2$ & $6.998+2$ & $8.209+2$ & $1.157+2$ & $7.328+2$ & $8.485+2$ & $1.270+2$ & $6.970+2$ & $8.240+2$ & $1.207+2$ & $7.256+2$ & $8.463+2$ \\
\hline $2.0-2$ & $1.058+2$ & $5.760+2$ & $6.818+2$ & $1.004+2$ & $6.055+2$ & $7.059+2$ & $1.112+2$ & $5.739+2$ & $6.851+2$ & $1.050+2$ & $5.994+2$ & $7.044+2$ \\
\hline $1.0-1$ & $7.600+1$ & $3.450+2$ & $4.210+2$ & $7.092+1$ & $3.629+2$ & $4.338+2$ & $8.040+1$ & $3.443+2$ & $4.247+2$ & $7.461+1$ & $3.597+2$ & $4.343+2$ \\
\hline $2.0-1$ & $7.241+1$ & $2.834+2$ & $3.558+2$ & $6.773+1$ & $2.953+2$ & $3.630+2$ & $7.655+1$ & $2.832+2$ & $3.597+2$ & $7.122+1$ & $2.934+2$ & $3.646+2$ \\
\hline $1.0+0$ & $5.704+1$ & $1.842+2$ & $2.412+2$ & $5.349+1$ & $1.875+2$ & $2.409+2$ & $6.018+1$ & $1.850+2$ & $2.451+2$ & $5.613+1$ & $1.876+2$ & $2.437+2$ \\
\hline $2.0+0$ & $4.429+1$ & $1.518+2$ & $1.960+2$ & $4.060+1$ & $1.539+2$ & $1.945+2$ & $4.690+1$ & $1.529+2$ & $1.998+2$ & $4.268+1$ & $1.545+2$ & $1.971+2$ \\
\hline $1.0+1$ & $1.201+1$ & $9.250+1$ & $1.045+2$ & $6.693+0$ & $9.388+1$ & $1.005+2$ & $1.358+1$ & $9.404+1$ & $1.076+2$ & $7.523+0$ & $9.493+1$ & $1.024+2$ \\
\hline $2.0+1$ & $8.454+0$ & $7.019+1$ & $7.864+1$ & $2.852+0$ & $7.102+1$ & $7.387+1$ & $9.866+0$ & $7.159+1$ & $8.145+1$ & $3.519+0$ & $7.202+1$ & $7.553+1$ \\
\hline $1.0+2$ & $6.122+0$ & $3.232+1$ & $3.844+1$ & $1.795+0$ & $3.126+1$ & $3.305+1$ & $7.191+0$ & $3.337+1$ & $4.056+1$ & $2.291+0$ & $3.222+1$ & $3.451+1$ \\
\hline $2.0+2$ & $4.331+0$ & $2.136+1$ & $2.569+1$ & $1.298+0$ & $1.962+1$ & $2.091+1$ & $5.112+0$ & $2.229+1$ & $2.740+1$ & $1.668+0$ & $2.057+1$ & $2.228+1$ \\
\hline $1.0+3$ & $1.068+0$ & $4.944+0$ & $6.012+0$ & $3.963-1$ & $4.486+0$ & $4.882+0$ & $1.313+0$ & $5.329+0$ & $6.642+0$ & $5.328-1$ & $4.913+0$ & $5.445+0$ \\
\hline $2.0+3$ & $9.612-1$ & $1.831+0$ & $2.792+0$ & $3.704-1$ & $1.952+0$ & $2.322+0$ & $1.168+0$ & $2.026+0$ & $3.194+0$ & $4.918-1$ & $2.165+0$ & $2.656+0$ \\
\hline $1.0+4$ & $9.275-1$ & $5.749-1$ & $1.502+0$ & $3.733-1$ & $7.432-1$ & $1.116+0$ & $1.030+0$ & $6.356-1$ & $1.665+0$ & $4.537-1$ & $8.126-1$ & $1.266+0$ \\
\hline
\end{tabular}


Table 5.2 Ratio of decay heat - MOX to LEU fuel assemblies

\begin{tabular}{|l|c|c|}
\hline \multirow{2}{*}{$\begin{array}{c}\text { Coolin } \\
\text { g time } \\
(\mathrm{d})\end{array}$} & \multicolumn{2}{|c|}{$\begin{array}{c}\text { Decay heat ratio: } \\
\text { MOX/LEU }\end{array}$} \\
\cline { 2 - 3 } & $\begin{array}{c}45 \mathrm{MWd} / \\
\mathrm{kgHM}\end{array}$ & $\begin{array}{c}50 \mathrm{MWd} / \\
\mathrm{kgHM}\end{array}$ \\
\hline 0.0 & 0.9609 & 0.9630 \\
\hline $2.0-6$ & 0.9614 & 0.9697 \\
\hline $1.0-5$ & 0.9627 & 0.9706 \\
\hline $2.0-3$ & 0.9675 & 0.9737 \\
\hline $1.0-2$ & 0.9675 & 0.9737 \\
\hline $2.0-2$ & 0.9659 & 0.9726 \\
\hline $1.0-1$ & 0.9704 & 0.9779 \\
\hline $2.0-1$ & 0.9801 & 0.9866 \\
\hline $1.0+0$ & 1.0010 & 1.0059 \\
\hline $2.0+0$ & 1.0082 & 1.0133 \\
\hline $1.0+1$ & 1.0392 & 1.0505 \\
\hline $2.0+1$ & 1.0646 & 1.0783 \\
\hline $1.0+2$ & 1.1630 & 1.1753 \\
\hline $2.0+2$ & 1.2282 & 1.2322 \\
\hline $1.0+3$ & 1.2314 & 1.2197 \\
\hline $2.0+3$ & 1.2023 & 1.2022 \\
\hline $1.0+4$ & 1.3456 & 1.3153 \\
\hline
\end{tabular}




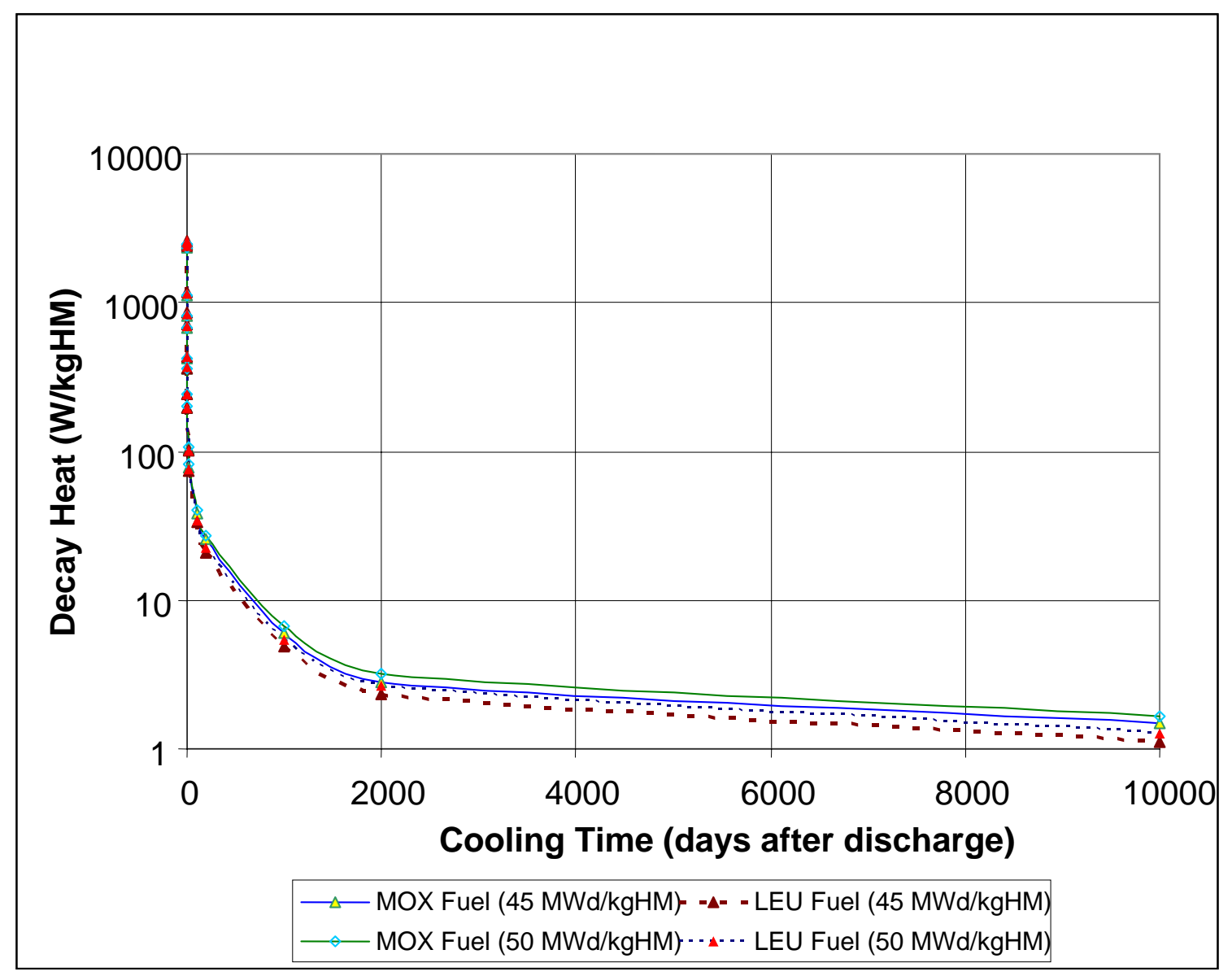

Fig. 5.1 Decay heat vs cooling time for $\mathrm{MOX}$ and $\mathrm{UO}_{2}$ fuel at two burnups 


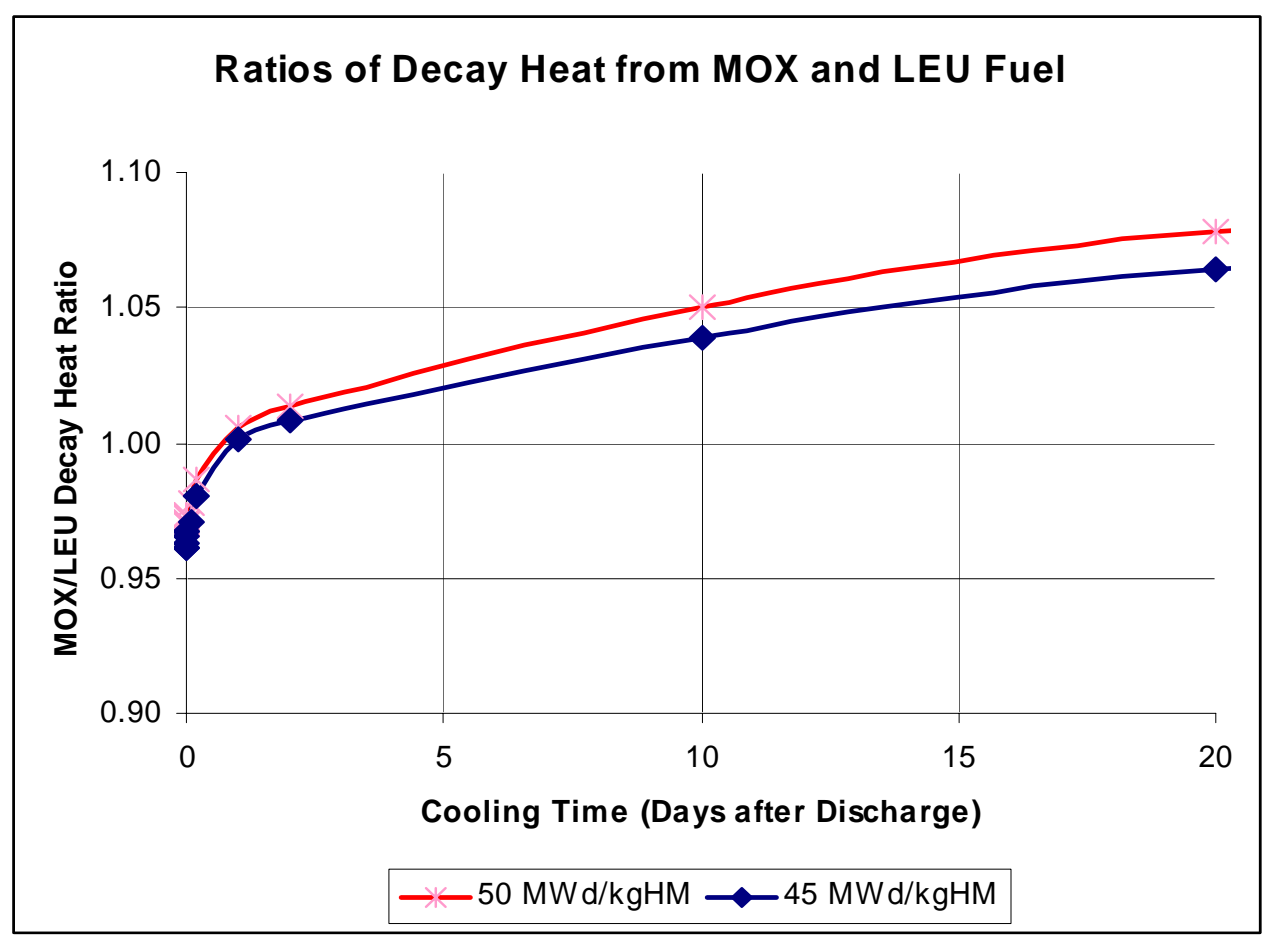

Fig. 5.2 Ratio of MOX and $\mathrm{UO}_{2}$ decay heats during the first $20 \mathrm{~d}$ of cooling time

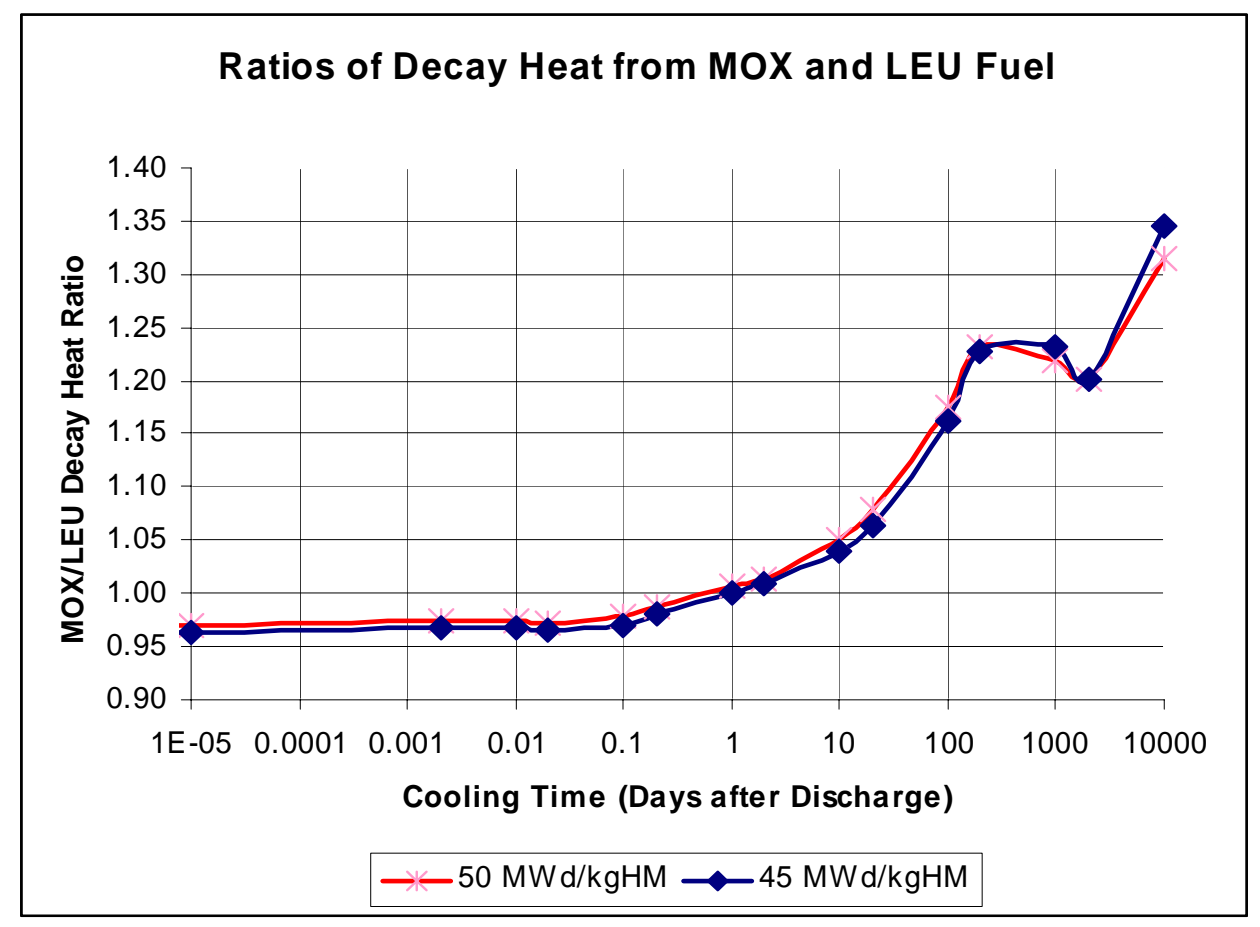

Fig. 5.3 Ratio of MOX and $\mathrm{UO}_{2}$ decay heats up to $10,000 \mathrm{~d}$ cooling time 


\section{RADIOLOGICAL SOURCE TERMS}

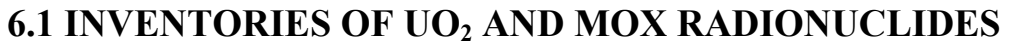

Source terms for $\mathrm{MOX}$ and $\mathrm{UO}_{2}$ fuel are different and depend, like the decay heat, on burnup (irradiation time) and cooling time (time after the end of irradiation). As discussed in Sect. 5, decay heat depends on the built-up inventory of FPs and actinide nuclides. These radionuclides are also the source of the radiation fields from the discharged fuel.

The radioactivity source terms for discharged MOX and LEU fuel are presented in Tables 6.1 and 6.2, obtained from the same ORIGEN-S (Ref. 1) calculations of the decay heat of Sect. 5. The fuel was discharged at a burnup level of $45 \mathrm{MWd} / \mathrm{kgHM}$. The actinide radionuclides are listed in Table 6.1, and the FP radionuclides are tabulated in Table 6.2. The inventory and relative activities of the radionuclides from MOX and LEU fuel are quite different because of the different fission yields for plutonium and uranium fissions and the different nuclide depletion and generation reactions in the characteristic neutron spectra. The radiation fields resulting from the diverse radionuclide inventory for each type of discharged fuel depend on the $\alpha, \beta$, and $\gamma$ emission characteristics for the radionuclide decays.

Neutron doses from the actinides of MOX fuel are larger than from the actinides of $\mathrm{UO}_{2}$ fuel. Also, MOX fuel has larger than $\mathrm{UO}_{2}$ source terms for some important FPs: ${ }^{131} \mathrm{I}$, which is $3.5 \%$ larger; ${ }^{135} \mathrm{Xe}$, $53 \%$ larger, and ${ }^{136} \mathrm{Cs}, 51 \%$ larger than $\mathrm{UO}_{2}$. The inventory of ${ }^{131} \mathrm{I}$ is very important when calculating thyroid doses, which are typically the limiting dose in radiological accident analyses.

Other factors complicate this comparison. The inventory of ${ }^{131} \mathrm{I}$ in MOX fuel increases with plutonium initial concentration and also peaks early during irradiation, specifically, the largest ${ }^{131} \mathrm{I}$ inventory occurs at a burnup of $16.9 \mathrm{MWd} / \mathrm{kg}$. Comparing low-burnup $\mathrm{MOX}$ fuel with high-burnup $\mathrm{UO}_{2}$ fuel, the inventory of ${ }^{131} \mathrm{I}$ in MOX fuel will be $\sim 9 \%$ larger than in $\mathrm{UO}_{2}$ fuel. Source terms and dose calculations were also completed in Refs. 2 and 3.

Overall, the source terms of MOX and LEU fuel are similar, but the doses resulting from MOX fuel are larger than from LEU fuel. The overall gamma doses are similar ${ }^{3}$, but the ${ }^{131}$ I contribution to the dose is larger. The neutron doses from MOX fuel are about 2-3 times larger than from $\mathrm{UO}_{2}$ fuel ${ }^{4}$.

Table 6.1 Actinide activity source terms for discharged MOX and $\mathrm{UO}_{2}$ fuel (Ci/kgHM)

\begin{tabular}{|c|c|c|c|}
\hline \multirow{2}{*}{ Nuclide } & \multicolumn{2}{|c|}{ Specific activity (Ci/kgHM) } & \multirow{2}{*}{$\begin{array}{c}\text { Activity ratio } \\
\text { MOX/UO }\end{array}$} \\
\cline { 2 - 3 } & MOX & $\mathbf{U O}_{\mathbf{2}}$ & 0.75 \\
\hline $\mathrm{Pu}-238$ & $3.22 \mathrm{E}+00$ & $4.29 \mathrm{E}+00$ & 2.26 \\
\hline $\mathrm{Pu}-239$ & $9.92 \mathrm{E}-01$ & $4.38 \mathrm{E}-01$ & 3.11 \\
\hline $\mathrm{Pu}-240$ & $1.78 \mathrm{E}+00$ & $5.72 \mathrm{E}-01$ & 2.96 \\
\hline $\mathrm{Pu}-241$ & $5.71 \mathrm{E}+02$ & $1.93 \mathrm{E}+02$ & 2.51 \\
\hline $\mathrm{Pu}-242$ & $6.83 \mathrm{E}-03$ & $2.72 \mathrm{E}-03$ & 4.48 \\
\hline $\mathrm{Am}-241$ & $8.83 \mathrm{E}-01$ & $1.97 \mathrm{E}-01$ & 3.21 \\
\hline $\mathrm{Am}-242$ & $3.59 \mathrm{E}+02$ & $1.12 \mathrm{E}+02$ & 5.44 \\
\hline $\mathrm{Am}-242 \mathrm{~m}$ & $7.45 \mathrm{E}-02$ & $1.37 \mathrm{E}-02$ & 3.13 \\
\hline $\mathrm{Am}-243$ & $1.05 \mathrm{E}-01$ & $3.35 \mathrm{E}-02$ & 2.80 \\
\hline $\mathrm{Am} 244$ & $5.59 \mathrm{E}+02$ & $2.00 \mathrm{E}+02$ & 3.61 \\
\hline $\mathrm{Cm}-242$ & $2.17 \mathrm{E}+02$ & $6.01 \mathrm{E}+01$ & 4.64 \\
\hline $\mathrm{Cm}-244$ & $1.30 \mathrm{E}-01$ & $2.80 \mathrm{E}-02$ & 4.18 \\
\hline
\end{tabular}


Table 6.2 FP nuclide source terms for discharged $\mathrm{MOX}$ and $\mathrm{UO}_{2}$ fuel

\begin{tabular}{|c|c|c|c|c|c|c|c|c|c|c|c|}
\hline \multirow[t]{2}{*}{ Nuclide } & \multicolumn{2}{|c|}{$\begin{array}{c}\text { Specific activity } \\
\text { (Ci/kgHM) }\end{array}$} & \multirow[t]{2}{*}{$\begin{array}{l}{\mathrm{MOX} / \mathrm{UO}_{2}} \\
\text { ratio }\end{array}$} & \multirow[t]{2}{*}{ Nuclide } & \multicolumn{2}{|c|}{$\begin{array}{c}\text { Specific activity } \\
\text { (Ci/kgHM) }\end{array}$} & \multirow[t]{2}{*}{$\begin{array}{l}{\mathrm{MOX} / \mathrm{UO}_{2}} \\
\text { ratio }\end{array}$} & \multirow[t]{2}{*}{ Nuclide } & \multicolumn{2}{|c|}{$\begin{array}{c}\text { Specific activity } \\
\text { (Ci/kgHM) }\end{array}$} & \multirow[t]{2}{*}{$\begin{array}{l}{\mathrm{MOX} / \mathrm{UO}_{2}}_{2} \\
\text { ratio }\end{array}$} \\
\hline & MOX & UO2 & & & MOX & UO2 & & & MOX & บO2 & \\
\hline $\mathrm{Ag}-111$ & $1.19 \mathrm{E}+02$ & $7.61 \mathrm{E}+01$ & 1.56 & Nb-95m & $1.74 \mathrm{E}+01$ & $2.04 \mathrm{E}+01$ & 0.85 & Sn-123 & $2.67 \mathrm{E}+00$ & $1.83 \mathrm{E}+00$ & 1.46 \\
\hline $\mathrm{Ag}-112$ & $4.87 \mathrm{E}+01$ & $3.27 \mathrm{E}+01$ & 1.49 & Nb-96 & $4.40 \mathrm{E}+00$ & $4.08 \mathrm{E}+00$ & 1.08 & Sn-125 & $1.35 \mathrm{E}+01$ & $1.06 \mathrm{E}+01$ & 1.27 \\
\hline As-77 & $1.86 \mathrm{E}+00$ & $2.23 \mathrm{E}+00$ & 0.83 & $\mathrm{Nb}-97$ & $1.79 \mathrm{E}+03$ & $1.91 \mathrm{E}+03$ & 0.94 & Sr-89 & $5.94 \mathrm{E}+02$ & $9.73 \mathrm{E}+02$ & 0.61 \\
\hline Ba-135m & $5.12 \mathrm{E}-01$ & $4.55 \mathrm{E}-01$ & 1.13 & $\mathrm{Nb}-97 \mathrm{~m}$ & $1.68 \mathrm{E}+03$ & $1.80 \mathrm{E}+03$ & 0.93 & Sr-90 & $5.31 \mathrm{E}+01$ & $1.05 E+02$ & 0.51 \\
\hline Ba-136m & $1.59 \mathrm{E}+01$ & $1.06 \mathrm{E}+01$ & 1.50 & Nd-147 & $7.12 \mathrm{E}+02$ & $7.40 \mathrm{E}+02$ & 0.96 & Sr-91 & $8.54 \mathrm{E}+02$ & $1.25 \mathrm{E}+03$ & 0.68 \\
\hline Ba-137m & $1.39 \mathrm{E}+02$ & $1.38 \mathrm{E}+02$ & 1.01 & Pd-109 & $7.26 \mathrm{E}+02$ & $4.31 \mathrm{E}+02$ & 1.68 & Tb-160 & $3.37 \mathrm{E}+00$ & $1.33 \mathrm{E}+00$ & 2.53 \\
\hline $\mathrm{Ba}-140$ & $1.85 \mathrm{E}+03$ & $1.96 \mathrm{E}+03$ & 0.94 & $\mathrm{Pd}-112$ & $4.85 E+01$ & $3.26 \mathrm{E}+01$ & 1.49 & Tb-161 & $2.34 \mathrm{E}+00$ & $1.42 \mathrm{E}+00$ & 1.65 \\
\hline $\mathrm{Br}-82$ & $4.03 \mathrm{E}+00$ & $4.40 \mathrm{E}+00$ & 0.92 & Pm-147 & $1.86 \mathrm{E}+02$ & $2.03 \mathrm{E}+02$ & 0.92 & Tc-99m & $1.84 \mathrm{E}+03$ & $1.87 \mathrm{E}+03$ & 0.98 \\
\hline Cd-115 & $1.44 \mathrm{E}+01$ & $1.09 \mathrm{E}+01$ & 1.32 & Pm-148 & $2.07 \mathrm{E}+02$ & $2.18 \mathrm{E}+02$ & 0.95 & Te-125m & $3.68 \mathrm{E}+00$ & $2.37 \mathrm{E}+00$ & 1.55 \\
\hline $\mathrm{cd}-115 \mathrm{~m}$ & $7.03 E-01$ & $4.92 \mathrm{E}-01$ & 1.43 & Pm-148m & $7.30 \mathrm{E}+01$ & $5.27 \mathrm{E}+01$ & 1.39 & Te-127 & $1.31 \mathrm{E}+02$ & $1.08 \mathrm{E}+02$ & 1.21 \\
\hline Ce-141 & $1.73 \mathrm{E}+03$ & $1.84 \mathrm{E}+03$ & 0.94 & Pm-149 & $6.59 \mathrm{E}+02$ & $6.92 \mathrm{E}+02$ & 0.95 & Te-127m & $2.30 \mathrm{E}+01$ & $1.82 \mathrm{E}+01$ & 1.26 \\
\hline Ce-143 & $1.51 \mathrm{E}+03$ & $1.70 \mathrm{E}+03$ & 0.89 & Pm-151 & $2.67 \mathrm{E}+02$ & $2.28 \mathrm{E}+02$ & 1.17 & Te-129 & $3.68 \mathrm{E}+02$ & $3.15 E+02$ & 1.17 \\
\hline Ce-144 & $1.23 \mathrm{E}+03$ & $1.50 \mathrm{E}+03$ & 0.82 & Pr-142 & $5.90 \mathrm{E}+01$ & $7.84 \mathrm{E}+01$ & 0.75 & Te-129m & $7.11 \mathrm{E}+01$ & $6.01 \mathrm{E}+01$ & 1.18 \\
\hline Cs-134 & $2.40 \mathrm{E}+02$ & $2.26 \mathrm{E}+02$ & 1.06 & Pr-143 & $1.45 E+03$ & $1.64 \mathrm{E}+03$ & 0.88 & Te-131 & $9.89 \mathrm{E}+02$ & $9.69 \mathrm{E}+02$ & 1.02 \\
\hline Cs-136 & $1.15 E+02$ & $7.61 \mathrm{E}+01$ & 1.51 & Pr-144 & $1.24 \mathrm{E}+03$ & $1.51 \mathrm{E}+03$ & 0.82 & Te-131m & $2.58 \mathrm{E}+02$ & $2.29 \mathrm{E}+02$ & 1.13 \\
\hline Cs-137 & $1.46 \mathrm{E}+02$ & $1.45 \mathrm{E}+02$ & 1.01 & Pr-144m & $1.73 \mathrm{E}+01$ & $2.11 \mathrm{E}+01$ & 0.82 & Te-132 & $1.65 \mathrm{E}+03$ & $1.62 \mathrm{E}+03$ & 1.02 \\
\hline Eu-154 & $1.74 \mathrm{E}+01$ & $9.85 E+00$ & 1.77 & $\mathrm{Rb}-86$ & $1.62 \mathrm{E}+00$ & $2.66 \mathrm{E}+00$ & 0.61 & Xe-131m & $1.69 \mathrm{E}+01$ & $1.56 \mathrm{E}+01$ & 1.08 \\
\hline Eu-155 & $5.67 \mathrm{E}+00$ & $3.78 \mathrm{E}+00$ & 1.50 & Rh-103m & $2.26 \mathrm{E}+03$ & $1.87 \mathrm{E}+03$ & 1.21 & Xe-133 & $2.19 \mathrm{E}+03$ & $2.22 \mathrm{E}+03$ & 0.99 \\
\hline Eu-156 & $3.61 \mathrm{E}+02$ & $3.03 E+02$ & 1.19 & Rh-105 & $1.75 \mathrm{E}+03$ & $1.26 \mathrm{E}+03$ & 1.39 & Xe-133m & $6.95 \mathrm{E}+01$ & $6.83 \mathrm{E}+01$ & 1.02 \\
\hline Eu-157 & $4.21 \mathrm{E}+01$ & $3.29 \mathrm{E}+01$ & 1.28 & Rh-106 & $1.34 \mathrm{E}+03$ & $7.75 \mathrm{E}+02$ & 1.73 & Xe-135 & $9.95 \mathrm{E}+02$ & $6.51 \mathrm{E}+02$ & 1.53 \\
\hline Gd-159 & $1.29 \mathrm{E}+01$ & $7.67 \mathrm{E}+00$ & 1.68 & Ru-103 & $2.27 E+03$ & $1.87 \mathrm{E}+03$ & 1.21 & Y-89m & 7.62E-01 & $1.32 \mathrm{E}+00$ & 0.58 \\
\hline Ge-77 & 8.07E-01 & $8.20 \mathrm{E}-01$ & 0.98 & Ru-106 & $1.27 E+03$ & $7.03 E+02$ & 1.81 & $\mathrm{Y}-90$ & $5.45 \mathrm{E}+01$ & $1.09 E+02$ & 0.50 \\
\hline $1-130$ & $2.77 \mathrm{E}+01$ & $2.38 \mathrm{E}+01$ & 1.16 & Sb-122 & $2.00 E+00$ & $1.31 \mathrm{E}+00$ & 1.53 & $\mathrm{Y}-91$ & $8.60 \mathrm{E}+02$ & $1.29 \mathrm{E}+03$ & 0.67 \\
\hline I-131 & $1.18 \mathrm{E}+03$ & $1.14 E+03$ & 1.04 & Sb-124 & $1.72 \mathrm{E}+00$ & $1.08 \mathrm{E}+00$ & 1.59 & $\mathrm{Y}-91 \mathrm{~m}$ & $4.96 \mathrm{E}+02$ & $7.27 \mathrm{E}+02$ & 0.68 \\
\hline $\mid-132$ & $1.71 \mathrm{E}+03$ & $1.67 \mathrm{E}+03$ & 1.02 & Sb-125 & $1.65 \mathrm{E}+01$ & $1.09 \mathrm{E}+01$ & 1.51 & Y-93 & $1.25 \mathrm{E}+03$ & $1.58 \mathrm{E}+03$ & 0.79 \\
\hline $\mathrm{I}-133$ & $2.29 \mathrm{E}+03$ & $2.32 E+03$ & 0.99 & Sb-127 & $1.31 \mathrm{E}+02$ & $1.09 \mathrm{E}+02$ & 1.20 & Zr-95 & $1.56 \mathrm{E}+03$ & $1.84 \mathrm{E}+03$ & 0.85 \\
\hline In-115m & $1.44 \mathrm{E}+01$ & $1.09 \mathrm{E}+01$ & 1.32 & Sb-128 & $2.04 \mathrm{E}+01$ & $1.71 \mathrm{E}+01$ & 1.19 & Zr-97 & $1.77 \mathrm{E}+03$ & $1.90 \mathrm{E}+03$ & 0.93 \\
\hline Kr-85 & $7.60 \mathrm{E}+00$ & $1.35 \mathrm{E}+01$ & 0.56 & Sm-151 & $1.01 \mathrm{E}+00$ & $6.03 \mathrm{E}-01$ & 1.67 & Total & $5.47 \mathrm{E}+04$ & $5.47 \mathrm{E}+04$ & 1.00 \\
\hline
\end{tabular}




\subsection{GAP RELEASES}

Because of the higher temperature of MOX fuel (due to the lower thermal conductivity), gap releases in MOX fuel are larger than in $\mathrm{UO}_{2}$ fuel for the same power level. Also at high burnups (above 42 $\mathrm{MWd} / \mathrm{kg}$ ), MOX fuel releases appear to be larger than $\mathrm{UO}_{2}$ fuel releases with similar burnup and temperature. Figure 6.1 illustrates this point. This figure shows releases from European MOX and LEU fuels, but more data are needed to confirm this. Because MOX fuel will be irradiated at low burnup (maximum $40 \mathrm{MWd} / \mathrm{kg}$ ), this effect is not applicable. Gap releases need to be considered in the radiological effects of design basis accidents because the rods that fail after some accidents will be releasing the FPs from the gap into the coolant, and eventually, some of the FPs (noble gasses) will reach the environment. Also, the gap releases are important when analyzing spent fuel handling accidents (such as the drop of an assembly with failure of rods and release of the gap source term from failed rods).

\subsection{EFFECTS OF THE DIFFERENT SOURCE TERMS}

The different source terms of irradiated MOX and LEU fuels need to be considered when calculating doses from accidents. MOX fuel has slightly higher source terms that yield larger neutron doses and larger gamma doses (because of the larger inventories of iodine, cesium, and xenon) than comparable $\mathrm{UO}_{2}$ fuel.

The larger MOX gap source terms will result in larger pressures inside the gap. This may increase the probability of failure of MOX rods, change the thermal conductivity of the gap, and the decontamination of FPs after release from the gap. A larger plenum for MOX fuel will eliminate these effects.

When analyzing a core with only three MOX assemblies (the three LTAs), the impact of the source term of only three MOX assemblies in the total of 163 assemblies will be very small. However, in cores with one-third or $41 \% \mathrm{MOX}$, the source term of the MOX fuel assemblies needs to be weighted with the source terms of the $\mathrm{UO}_{2}$ fuel assemblies. This is important when calculating gap releases from failed rods: the failed rods will be equally distributed in the $41 \% \mathrm{MOX}$ and in the $59 \% \mathrm{UO}_{2}$ assembly rods. The source term in the gap of the MOX fuel rods is in general larger than in $\mathrm{UO}_{2}$ fuel rods.

The different source terms of $\mathrm{MOX}$ fuel and $\mathrm{UO}_{2}$ fuel need to be considered in severe accidents and factored into the probabilistic risk analysis (PRA) levels 2 and 3 for a core with MOX fuel.

Source terms for fresh fuel ( $\mathrm{MOX}$ and $\mathrm{UO}_{2}$ ) are also different, with a larger source term and possible larger doses for MOX fuel. This is covered in Sect. 9.

\subsection{SUMMARY AND CONCLUSIONS}

Spent MOX and $\mathrm{UO}_{2}$ fuels have different source terms, with larger MOX actinides and iodine inventories than $\mathrm{UO}_{2}$ fuel. MOX fuel may also have larger gap releases than $\mathrm{UO}_{2}$ fuel that may result in larger pressures inside the gap. This has implications in severe accident and dose calculations, with larger potential consequences and doses for accidents with MOX fuel. Based on this analysis, improved failed fuel element detection and improved plant health monitoring would appear to be appropriate plant modifications to consider. 


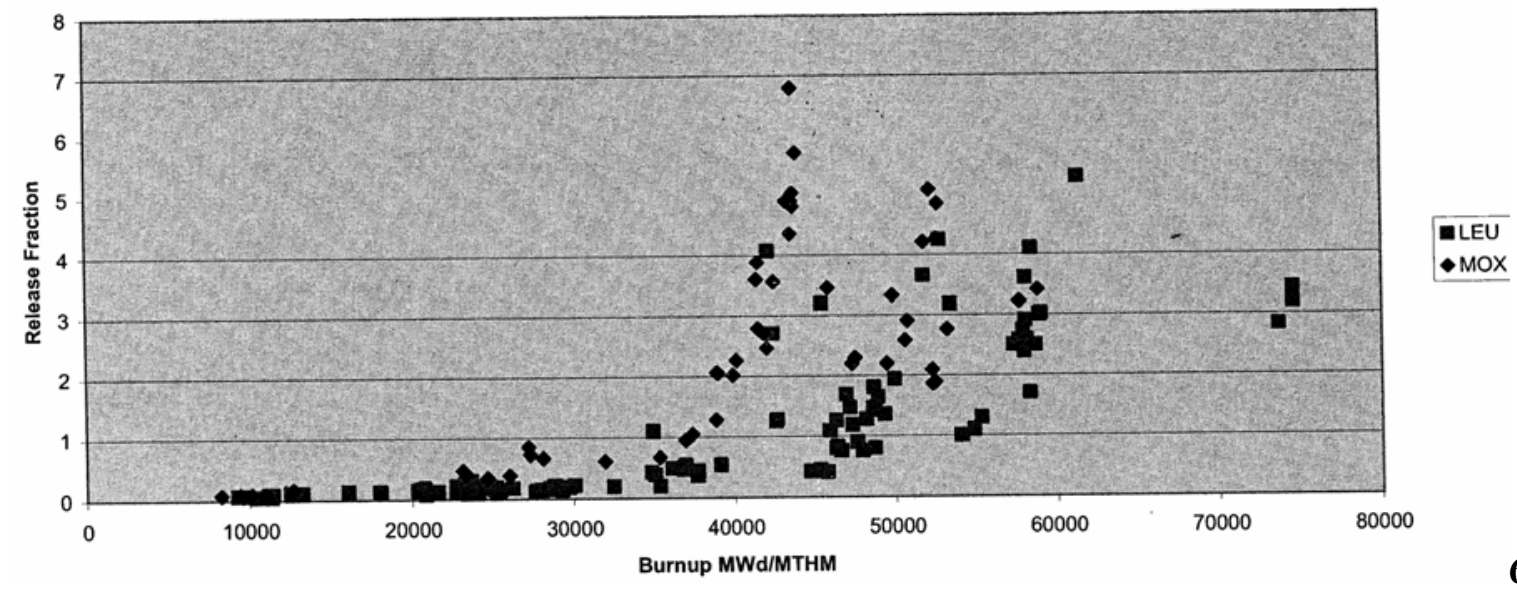

Fig. 6.1 Fission gas releases from European fuels. Source: Framatome Advanced Nuclear Power data.

\section{REFERENCES}

1. SCALE: A Modular Code System for Performing Standardized Computer Analyses for Licensing Evaluation, NUREG/CR-0200, Rev.6 (ORNL/NUREG/CSD-2/R6), Vols. I, II, and III, May 2000.

2. M. B. Emmett, Calculational Benchmark Problems for VVER-1000 Mixed Oxide Fuel Cycle, ORNL/TM-1999/207, Oak Ridge National Laboratory, March 2000.

3. W. J. Reich et al, Impacts on Reactor Systems, Operations, Equipment, and Facilities from the Use of MOX Fuels, ORNL/MD/LTR-140, Appendix G.2, Oak Ridge National Laboratory, August 1998.

4. Duke, COGEMA, Stone \& Webster, Mission Reactors System Modification Plan, Document DCSIS-2001-001, Appendix A, “Assessment of Differences Between MOX Fuel and Conventional Uranium Fuel," Rev. 2, October 1, 2003. 


\section{PROBABILISTIC RISK ANALYSIS (PRA)}

Probabilistic risk analyses (PRAs), also called probabilistic safety analyses (PSAs), in reactors with MOX fuel need to be completed because there will be differences from the PRA performed in the same reactors with only $\mathrm{UO}_{2}$ fuel.

PRA and level 1 will be affected by those accidents involving handling and storing fresh MOX fuel, and refueling, and handling, and storing spent fuel in the spent fuel pool. New accidents are likely to appear for sequences involving MOX fuel handling. The core damage frequency (CDF) during reactor operation should not change, but this needs to be evaluated. The different neutronics of MOX fuel may change the probability of certain accidents.

The PRA level 2 will be affected significantly because the source terms and containment releases will be different when MOX fuel is utilized. The core melt and accident progression will be somewhat different with MOX fuel, because of the different thermophysical properties (lower melting temperature and lower heat of fusion) and different decay heats.

Finally, PRA level 3 will be different because the source terms of $\mathrm{MOX}$ and $\mathrm{UO}_{2}$ fuel are different. PRAs level 3 are not currently required by Russian regulations, but this may change in the future. Some Russian nuclear power plants are already preparing PRA level 3 independent of requirements.

There is a need to know the details of the PRAs (levels 1 and 2) for LEU fuel already completed in Russia, including models, assumptions, and uncertainties. If conservative, high-estimate source terms, and/or conservative frequencies for some accidents were employed, the results of the $\mathrm{PRAs}$ for $\mathrm{UO}_{2}$ may be bounding the results of MOX PRAs when more sophisticated tools, better analytical models, and better data and source terms are employed (a more accurate PRA will be developed for MOX cores with more accurate and realistic results). 


\section{ACCIDENT ANALYSIS}

\subsection{INTRODUCTION}

Analyzing accidents is very important because the overall effects of all the differences between the two different kinds of fuels can be quantified. The combined effects of the differences in the two fuels will be shown in the results of the accidents.

Only design basis accidents have been currently studied. A total of six different design basis accidents have been analyzed:

- trip of the four main primary coolant pumps,

- uncontrolled withdrawal of a regulating control rod,

- control rod ejection,

- LOCA,

- locked rotor of one primary coolant pump, and

- main steam line break (MSLB) accident.

These accidents have been studied at full reactor power, which was assumed to be $104 \%$ of the reactor nominal power. One MSLB accident was also analyzed at zero power. More cases need to be analyzed at hot zero power and cold zero power, in particular, the control rod ejection and other MSLB accidents. Calculations were completed for $\mathrm{UO}_{2}$ and MOX cores. The MOX calculations were performed for three MOX assemblies (three LTAs) and for one-third core MOX. Calculations for future core loadings with up to $41 \%$ MOX will also be required.

The accidents have been analyzed by different organizations: Reactor Research Center Kurchatov Institute (RRC-KI) in Russia, OKB Gidropress (OKB-GP) in Russia, and Oak Ridge National Laboratory (ORNL) in the United States. French organizations have also performed MOX calculations, but these results are not available at the present time.

Different codes were employed for these calculations. The Russian codes DINAMICA-97 and TETCH-M-97 (Ref. 1), which are proprietary codes, are employed by OKB-GP. RELAP5 Mod 3.2 (Ref. 2), RELAP5 Mod 3.3 (Ref. 3), and RELAP5-3D (Ref. 4) are used by ORNL. Finally, RELAP5 Mod 3.2, BIPR8KN (Ref. 5), and a code coupling both are used by RRC-KI. RELAP5 Mod 3.2 and Mod 3.3 are the U. S. Nuclear Regulatory Commission (NRC) codes employed for safety and licensing thermalhydraulic calculations. RELAP5-3D (Ref. 4) code is a three-dimensional (3-D) version of the RELAP5 Mod 3.2 code (Ref. 2) with the 3-D neutron kinetics model based on the NESTLE code (Ref. 6). This code has been developed by Idaho National Engineering and Environmental Laboratory (INEEL) for the Department of Energy (DOE). Finally, BIPR8KN is also a 3-D kinetic code developed by RRC-KI. The code has been coupled to RELAP5 Mod3.2 to perform 3-D kinetic calculations by RRC-KI.

\subsection{ACCIDENT LIMITS}

The limits used in the Russian Federation for safety analyses follow:

1. The maximum temperature of the fuel has to be below melting. For MOX fuel, this temperature is $3028 \mathrm{~K}$ or $2755^{\circ} \mathrm{C}$, and a larger value $(3060 \mathrm{~K})$ can be used for $\mathrm{UO}_{2}$ fuel.

2. The maximum temperature of the cladding is $1473 \mathrm{~K}$ or $1200{ }^{\circ} \mathrm{C}$. 
3. Maximum amount of reacted zirconium from the cladding is $1 \%$ of the total mass.

4. Maximum depth of cladding oxidation is $18 \%$ of the original thickness.

5. Maximum number of rods with defects after accident conditions is $1 \%$ with gap leakage, and $0.1 \%$ with coolant-fuel contact.

6. Radial average fuel enthalpy limit is $586 \mathrm{~kJ} / \mathrm{kg}(140 \mathrm{kcal} / \mathrm{kg})$ for cladding failure. If exceeded, the possibility of cladding damage exists. A second limit of $963 \mathrm{~kJ} / \mathrm{kg}(230$ $\mathrm{kcal} / \mathrm{kg})$ for fresh fuel and $840 \mathrm{~J} / \mathrm{kg}(200 \mathrm{kcal} / \mathrm{kg})$ for irradiated fuel should not be exceeded.

7. Absence of departure from nucleate boiling (DNB) with a confidence level of $95 \%$. DNB occurrence is also an indication of cladding failure.

8. Maximum allowed pressure is $19.4 \mathrm{MPa}$ in primary and $8.63 \mathrm{MPa}$ in secondary systems.

These limits are a combination of the European limits with Russian specific limits, and they are described in detail in Ref. 1. The Russian limits are similar to the U. S. limits with some differences. The U. S. limits are dictated by the U.S. NRC. The limits used in Japan are also slightly different.

Failure of rods is expected after some accidents, like LOCAs, control rod ejection, and locked rotor of a main pump. Similarly, the first enthalpy limit of $586 \mathrm{~J} / \mathrm{kg}$ may be reached during a control rod ejection, and it will be an indication of DNB occurrence and rod failure.

\subsection{RESULTS}

Calculations for VVER-1000 reactor cores with only $\mathrm{UO}_{2}$, three LTAs, and one-third of the core MOX have been completed, and the results of the three cases have been compared. The equilibrium core loading employed for the one-third MOX core consisted of $54 \mathrm{MOX}$ assemblies and $109 \mathrm{UO}_{2}$ assemblies with 12- month refueling cycles. $\mathrm{UO}_{2}$ assemblies have up to $4.2 \%$ enrichment, and MOX assemblies up to $3.62 \%$ plutonium. The fuel design includes $6 \mathrm{U}-\mathrm{Gd}$ poison rods in the $\mathrm{UO}_{2}$ assemblies and $16 \mathrm{U}-\mathrm{Gd}$ poison rods in the MOX assemblies. The control rods employed are different for the one-third core MOX. The control rods for the one-third core MOX are the modified rods containing ${ }^{10} \mathrm{~B}$ enriched to $80 \%$, while the original control rods have ${ }^{10} \mathrm{~B}$ at a concentration of only $19.8 \%$, which is the natural boron concentration. Therefore, the control rods employed in the one-third core MOX calculations have larger neutron absorption capabilities than the original control rods employed for the other cases (only $\mathrm{UO}_{2}$ and three LTAs).

The final design of the MOX core is still being determined ${ }^{7}$. The number of MOX assemblies will be increased up to $41 \%$ of the total core, and the refueling cycle length may be increased to 18 months. MOX assemblies will stay in the core for two cycles, with most of $\mathrm{UO}_{2}$ assemblies staying for three full cycles.

The results of the accidents with one-third core MOX are very similar to the results for three LTAs assemblies or for only $\mathrm{UO}_{2}$ cores, with only small differences in the calculated results. The trip of the four pumps accident, the LOCA, and the locked rotor pump transient yielded very similar results, and the observed differences were not significant. These calculations are documented in Ref. 8-12, performed by RRC-KI and OKB-GP. 
Cladding failures are predicted to occur in the LOCA and in the locked rotor pump transient, but the number of failures is about the same for the three cases $\left(\mathrm{UO}_{2}\right.$, three LTAs and one-third MOX) analyzed. The gap source terms, however, are different for the $\mathrm{MOX}$ and $\mathrm{UO}_{2}$ rods.

Some small differences were found in the control rod ejection accident; in the uncontrolled withdrawal of a regulating rod; and in the MSLB accidents. The differences were due to the different kinetics of the two fuels. In the LOCAs, the larger energy stored in MOX fuel (compared to $\mathrm{UO}_{2}$ fuel at the same power) results in larger peak cladding temperatures (first peak). However, the lower decay heat of MOX fuel results in a slower heating of MOX and a lower second peak cladding temperature than in $\mathrm{UO}_{2}$ fuel.

Calculations for the control rod ejection accident completed at ORNL are presented for a reactor core with one-third core MOX (54 MOX assemblies of the total of 163), for a core with three MOX assemblies (and $160 \mathrm{UO}_{2}$ assemblies), and for a core with only $\mathrm{UO}_{2}$ (all 163 assemblies). The code RELAP5 Mod. 3.2 was employed in these calculations, with point kinetics. The reactor is operating at $104 \%$ nominal power prior to the accident. The accident is started with a control rod ejected at $50 \mathrm{~s}$ into the transient calculation. The worth of the ejected control rod is conservatively assumed to be $0.25 \%$. Reactor power increases after the control rod is ejected, and the calculated peak power is higher in the core with one-third MOX than in the other cores because of the higher reactivity of the MOX fuel (Fig. 8.1). The worth of the ejected control rod in the one-third core MOX is larger than in the other cores because the control rod has enriched ${ }^{10} \mathrm{~B}$, and because the delay neutron fraction in the MOX core is smaller than in the $\mathrm{UO}_{2}$ core. The reactor power increases and decreases faster in the one-third core MOX because of the larger MOX reactivity coefficients. The peak power for MOX fuel is larger than for $\mathrm{UO}_{2}$ fuel, but the total energy deposited in the fuel (integral of the curves of Fig. 8.1) is lower for MOX fuel.

The power increases for the core with three $\mathrm{MOX}$ assemblies and for the only $\mathrm{UO}_{2}$ core are virtually the same as the effects of three MOX assemblies in a core with a total of 163 assemblies is very small. The shutdown control rods are inserted at $51 \mathrm{~s}$. Because of the stronger control rods of the one-third MOX core, the effect of the control rods is more pronounced in this core. Figure 8.2 shows results obtained by OKB-Gidropress for one-third core MOX and 3 LTAs (Ref. 11). The results are similar to the ones of Figure 8.1.

Some high-power fuel rods (hot rods) near the ejected control rod experience high-power increases with fuel and cladding temperature increases. DNB occurs in these fuel rods. Cladding temperatures calculated for the hottest $\mathrm{MOX}$ and $\mathrm{UO}_{2}$ fuel rods are shown in Fig. 8.3, and they are comparable. The height of the rod is divided in the model into ten axial nodes. The hottest temperature nodes are near the top, at levels 7 and 8 (starting from the bottom). All of the calculated parameters are within allowed safety limits: no melting occurs in the fuel (MOX melting temperature is $3028 \mathrm{~K}$ or $2755^{\circ} \mathrm{C}$ ), cladding temperature is below $1473 \mathrm{~K}$, and average fuel enthalpy is below $840 \mathrm{~J} / \mathrm{kg}$. Cladding failures are likely to occur in the rods with DNB occurrence (hottest fuel rods) that happens in rods with cladding temperature excursions or in rods with average fuel enthalpy above $586 \mathrm{~kJ} / \mathrm{kg}$. These rod failures will release FPs from the gap. About the same number of rods failed in the only $\mathrm{UO}_{2}$ core and in the core with one-third MOX. RELAP5 models cannot calculate the number of failed fuel rods, but the numbers should be similar for both fuels, based on temperature and enthalpy results. RELAP5 cannot calculate gap releases either; a severe accident code is needed for this. The gap source terms of the MOX and $\mathrm{UO}_{2}$ rods are different and need to be considered when calculating releases from the failed rods and in the dose calculations.

Additional calculations with 3-D kinetics are needed for this accident because this accident together with $\mathrm{MSLB}^{13}$ are space-dependent transients that are better analyzed with 3-D codes. Also calculations at hot zero power need to be performed. 
The uncontrolled withdrawal of a regulating group accident resulted in a slower power increase for the one-third core MOX due to the lower worth of the regulating $\operatorname{rod}^{10,11}$. Scram occurred later $(2 \mathrm{~s})$ in the one-third core $\mathrm{MOX}$ than in the $\mathrm{UO}_{2}$ only core, but the maximum power is the same in both cases. The power decreases after the scram faster in the one-third core MOX because of the stronger control rods.

MSLB accidents were analyzed at ORNL and documented in Ref. 13, assuming that the reactor was operating at $104 \%$ of the nominal power (3,000 MWth). It was also assumed that a high worth central control rod is stuck out of the reactor and is not available for control rod insertion. The line break is a double-sided break, upstream of the steam generator isolation valve. Calculations were performed for only $\mathrm{UO}_{2}$ cores and for cores with one-third MOX. RELAP5/MOD3.2 (Ref. 2) and RELAP5-3D (Ref. 4) were employed to perform point kinetics and 3-D kinetic calculations.

Point kinetics and 3-D kinetics RELAP5-3D calculations for both $\mathrm{UO}_{2}$ and $\mathrm{MOX}$ cores yielded very similar results. None of the calculations resulted in power increases. After the MSLB accident is initiated, the reactor is rapidly shutdown by a low-pressure signal in the secondary, followed by a trip of the main circulating pump of the loop with the affected steam generator (SG), and by the isolation of the broken SG by closing the SG isolation valve and the feedwater valve. All these system trips protect the reactor from this accident. By the time the cold primary coolant reaches the reactor core, the reactor is already shutdown. MSLB accident calculations performed from an initial hot zero power condition did not result in return to power (recriticality). There was no need to inject borated water from the high-pressure safety injection system (HPSIS). In fact, the primary system pressure never decreased enough to reach the set point for the HPSIS to inject water.

MSLB calculations for the VVER-1000 were repeated, assuming that the trip by low pressure in the secondary system fails. In this case, the reactor will be shutdown by either high power or by low pressure in the primary system. This calculation resulted in a power increase of $7 \%$ over the initial value before reactor shutdown, but no recriticality was calculated to occur after reactor shutdown. The increase was slighter larger and faster for the core with one-third MOX. For all the cases, there was no need to inject borated water.

Recriticality could occur if the broken SG is not isolated (keeping the SG valve open and continuing the feedwater flow). This results in extended cooling of the primary system with possible reactor power increases. For these cases the injection of borated water may be necessary. However, these conditions are very unlikely to occur because multiple failures will be required. These calculations do not appear to warrant the need to upgrade the boron injection system.

\subsection{SUMMARY AND CONCLUSIONS}

These calculations show that the one-third core MOX results are comparable to the ones for a core with all $\mathrm{UO}_{2}$ fuel or with only three LTAs. Some differences have been observed; however, the differences are not important. Doses from the source terms released from the gap will be different with MOX fuel (larger). It is important to mention that the control rods employed in the one-third core MOX calculations are modified control rods with ${ }^{10} \mathrm{~B}$ enriched to $80 \%$. The cases run with $\mathrm{UO}_{2}$ fuel or with only three LTAs employed the original, unmodified control rods, using natural boron.

Calculations for a core with $41 \%$ MOX and additional accidents are planned to be analyzed in the future. These additional accidents are control rod ejection at zero power, uncontrolled withdrawal of regulating group at different powers, MSLBs at different powers, start-up of an inactive loop, dilution of the boron concentration in the coolant, and feedwater temperature decrease. These studies will bring more 
insights into the effects of the MOX fuel (compared to $\mathrm{UO}_{2}$ fuel). In particular, they will study the boron injection system, and they will be instrumental in deciding if this system needs to be upgraded.

Severe accidents need to be analyzed also and their differential effects quantified. Because the source terms of $\mathrm{MOX}$ and $\mathrm{UO}_{2}$ fuel are different, it is expected that some differences will be seen in the results. Improved instrumentation that aids in the detection or control of accident scenarios may be warranted.

\section{REFERENCES}

1. International Atomic Energy Agency, Guidelines for Accident Analysis of WWER Nuclear Power Plants, IAEA-EBP-WWER-01, 1995.

2. Idaho National Engineering and Environmental Laboratory, RELAP5 Code Development Team, RELAP5/MOD3.2 Code Manual, NUREG/CR-5535, (INEL-95/0174), 1995.

3. Information Systems Laboratory, Inc, Nuclear Safety Analysis Division, RELAP5/MOD3.3 Code Manual” NUREG/CR-5535, Rev. 1, January 2002

4. Idaho National Engineering and Environmental Laboratory, RELAP5-3D Code Development Team, RELAP5-3D Code Manual, INEEL-EXT-98-00834, Rev. 2.0, July 2002.

5. V. K. Ivanov et al, "Results of Coupled Dynamic Calculations of Neutron Physics and Thermal hydraulics of a VVER, with 3-Dimension Core Representation" Proceedings of the $12^{\text {th }}$ Symposium of AER, 543, Sunny Beach, Bulgaria, 2002.

6. R. M. Al-Chalabi et al, "NESTLE, A Nodal Kinetics Code," Trans. Am. Nucl. Soc., 68, 1993.

7. A.M. Pavlovichev et al., Report on Neutronics Studies on MOX Fuel in VVER: Analysis of alternative in-core fuel core management with increased disposition Pu rate in VVER-1000, Moscow, 2003.

8. V. K. Ivanov, Transient Analyses for the Balakovo Plant. Joint Report, RRC-KI and OKBGidropress, Moscow 2000.

9. V. K. Ivanov et al, The Analysis Transient for Balakovo Plant (with LTA) using RELAP Model and Russian Licensing Codes, RRC-KI and OKB-Gidropress, Moscow 2001.

10. V. K. Ivanov, Calculation Analysis of Selected Transients for LTA with MOX fuel in a Core Balakovo Unit 4 by the Design Codes, OKB-Gidropress Report, Moscow, August 2001.

11. OKB-Gidropress, Preliminary analyis of unsteady conditions using code DINAMIKA-97 for 1/3 FA core loading with MOX fuel, Report 440-PR-017, October 2001.

12. V.K. Ivanov, Perform preliminary RELAP transient analysis with $1 / 2 \mathrm{MOX}$ loaded core design, RRC-KI Report, May 2003.

13. J. J. Carbajo et al., "Main-Steam-Line-Break Accident Analyses in a VVER-1000 Reactor," Trans. Am. Nucl. Soc., 85, 124 (2001) 


\section{CONTROL ROD EJECTION AT $50 \mathrm{sec}$}

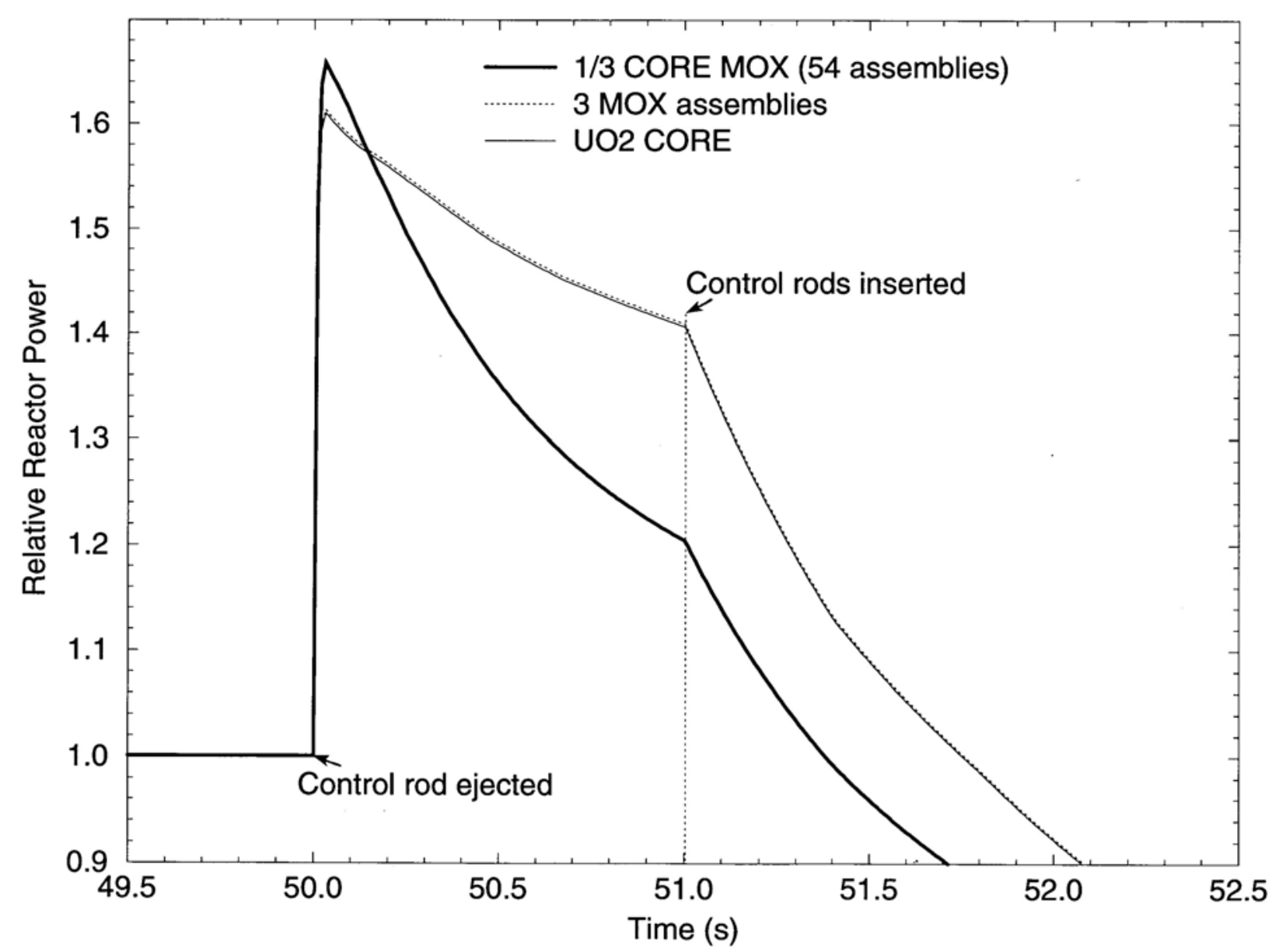

Fig. 8.1 Relative power calculated for the control rod ejection with three different cores (one-third MOX, three LTAs, and $\mathrm{UO}_{2}$ ). 


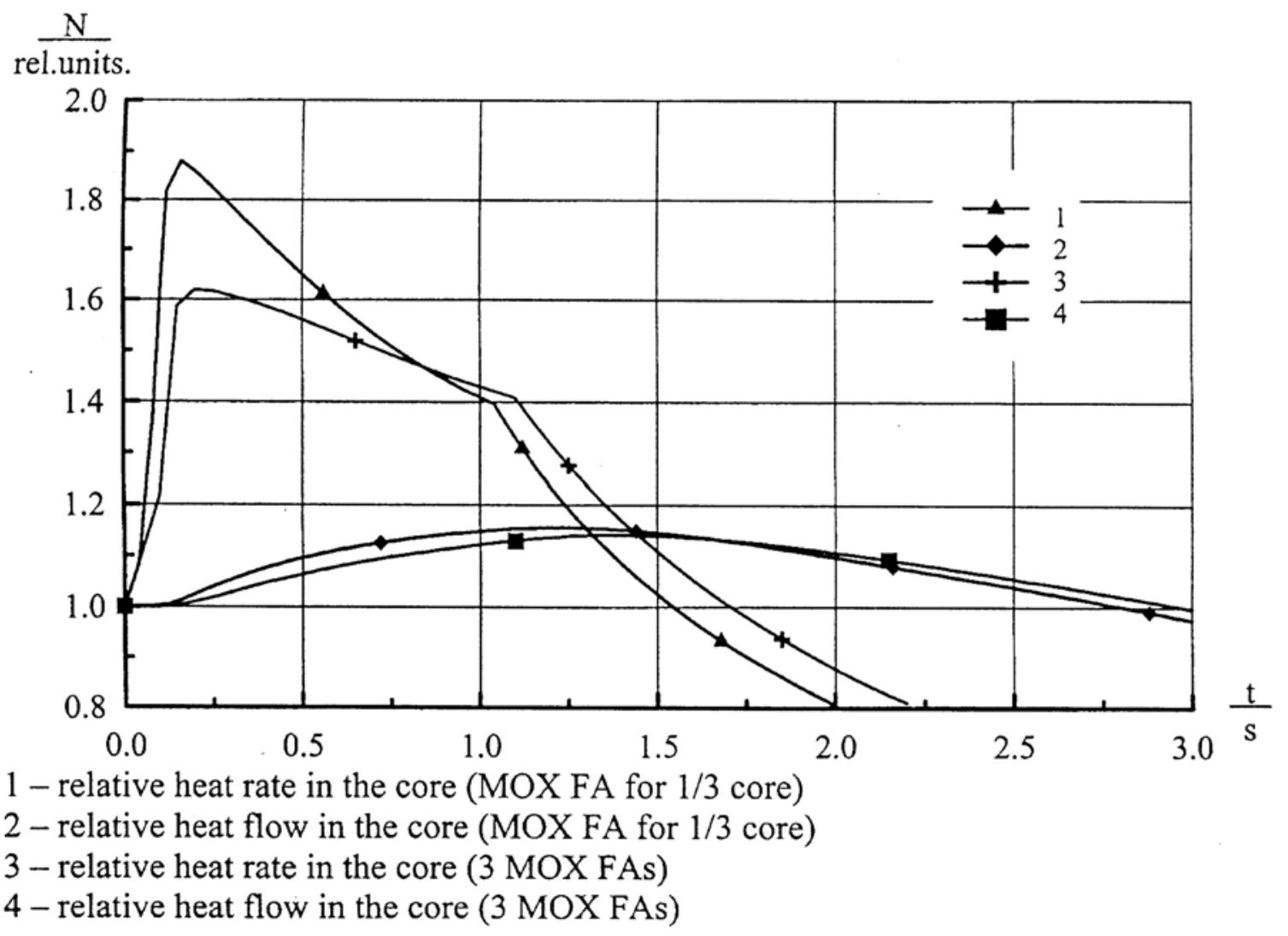

Fig. 8.2. Relative power calculated by OKB-Gidropress for the control rod ejection. 


\section{CONTROL ROD EJECTION AT $50 \mathrm{sec}$}

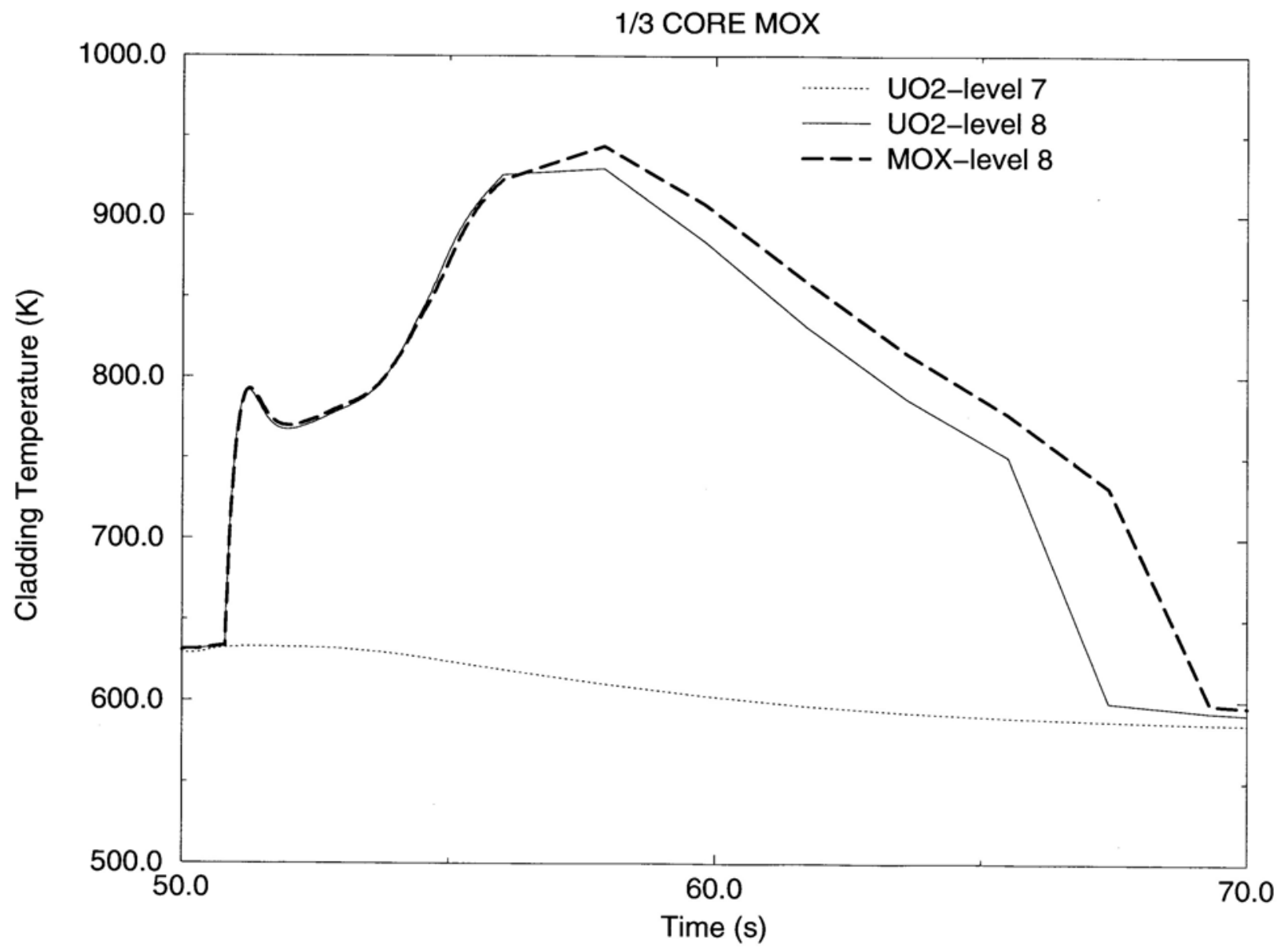

Fig. 8.3 Cladding temperatures calculated for the one-third core MOX after control rod ejection. 


\section{FRESH FUEL CRITICALITY AND DOSE PROPERTIES}

The transportation and handling of fresh assemblies involve hazards related to the criticality, dose, and radiotoxicity of the fuel materials. In the VVER-1000 reactors, the transportation of the fuel is performed in package sets on railway cars, storage of the fresh fuel at the power plant, and moving the assemblies within the reactor power plant to the cooling pool. A description of these activities is provided in Ref 1. The different nuclear properties of $\mathrm{UO}_{2}$ and $\mathrm{MOX}$ fuel have a potential impact on these operations because of different criticality conditions and dose rates from the fuel. Therefore a basic comparison of the multiplication factors and the dose rates of $\mathrm{MOX}$ and $\mathrm{UO}_{2}$ fuel assemblies (FAs) will provide a basis to assess the issues involved in the handling and transportation of the assemblies. In addition to the dose rates issues, plutonium is more radiotoxic than uranium because the plutonium isotopes are alpha emitters and therefore result in an increased inhalation hazard. Each of these issues is discussed in the following sections.

\subsection{FRESH FUEL CRITICALITY}

As shown in Table 3.1, the nuclear properties of plutonium (cross sections, neutrons per fission, etc.) are significantly different than those of uranium. Therefore the criticality of unirradiated MOX FAs must be considered for transportation, handling, and storage.

\subsubsection{Criticality of $\mathrm{UO}_{2}$ and MOX Assemblies in Package Sets}

The MOX FA is designed to have reactivity vs burnup profiles that provide an overall fuel cycle length that is similar to the $\mathrm{UO}_{2}$-only core designs (see Sect. 3.2). Therefore, the initial reactivity of the MOX FAs is not significantly different than that of the $\mathrm{UO}_{2} \mathrm{FAs}$, and generally is lower. However, in the case of dry assemblies, the reactivity of the MOX FAs can be higher than $\mathrm{UO}_{2}$ because of the larger number of neutrons per fission and the larger fission cross sections at higher neutron energies. Therefore, the criticality must be calculated for the particular package set used for transportation.

The fresh FAs are transported from the fuel fabrication plant to the nuclear power plant by means of rail in package sets. These package sets consist of two steel tubes that are interconnected and sealed on both ends. The FAs are placed in wooden containers and then placed in the tubes ${ }^{1}$. These package sets are typically arranged on the rail car in a stack that is three-high and two-wide ${ }^{2}$. Figure 9.1 shows a crosssectional view of a single package set.

Calculations were performed for a $4.4 \%$-enriched $\mathrm{UO}_{2} \mathrm{FA}$ and a uniform $4.2 \% \mathrm{Pu}_{\mathrm{fis}} \mathrm{MOX}$ FA that are representative of the actual assemblies that will be used in the LTA and mission fuel irradiations ${ }^{3}$. The multiplication factors for the normal case of a dry package set and an accidental case with cold water (without boron) both inside and outside the package set are presented in Table 9.1.

Table 9.1 Multiplication factors in infinite grid of package set cells with $\mathrm{UO}_{2}$ and MOX FA

\begin{tabular}{|l|c|c|}
\hline \multicolumn{1}{|c|}{ Case } & UO $_{2}$ FA & MOX FA \\
\hline Dry package set & 0.83 & 0.86 \\
\hline Cold water inside and outside package set & 0.84 & 0.85 \\
\hline
\end{tabular}

Source: Ref. 3. 


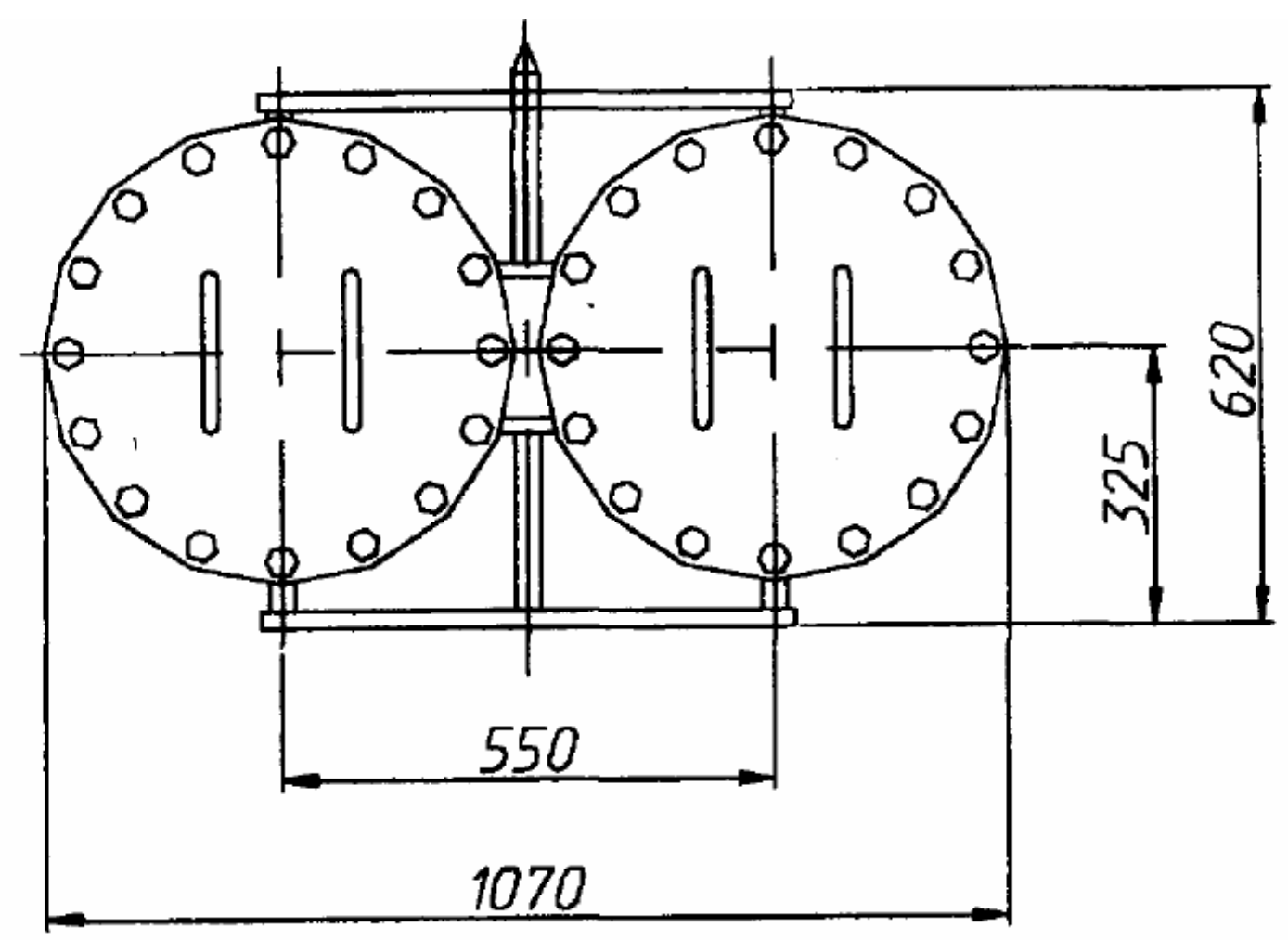

Fig. 9.1 Cross-sectional view of a package set for VVER-1000 FA transportation (dimensions in mm). Source: Ref. 1.

Additional calculations were performed for the case of an infinite grid of package sets where the cold water is only inside the set and not outside. This results in the effective multiplication factor of 1.06 and 1.07 for $\mathrm{UO}_{2}$ and $\mathrm{MOX}$ fuel assemblies. In this case, a multiplication factor less than the limiting value (0.95) is obtained for a specific arrangement of package sets that are four rows deep and infinite in width.

Therefore in terms of criticality of the package sets, there is little difference between $\mathrm{UO}_{2}$ and MOX fuel. In general, the conditions to ensure subcriticality of the $\mathrm{UO}_{2}$ assemblies will provide almost the same margin for the MOX assemblies.

\subsubsection{Criticality of $\mathrm{UO}_{2}$ and MOX Assemblies in Fresh Fuel Depository}

The assemblies are moved from the railcar to the fresh fuel depository in the package sets used for transportation. The $\mathrm{UO}_{2}$ assemblies are typically removed from the package sets and stored in decks in fresh fuel covers. The MOX fuel storage, however, is expected to be performed only in the package sets to reduce the dose rates to those working in the building ${ }^{1}$. Therefore, the criticality issues are similar to those analyzed in Sect. 9.1.1 for the fuel package sets. 


\subsubsection{Criticality of $\mathrm{UO}_{2}$ and MOX Assemblies in Pool Storage}

Before placing the FAs into the reactor core, they are stored in the cooling pool. There are two possible FA configurations in the storage pool, compact and noncompact as shown
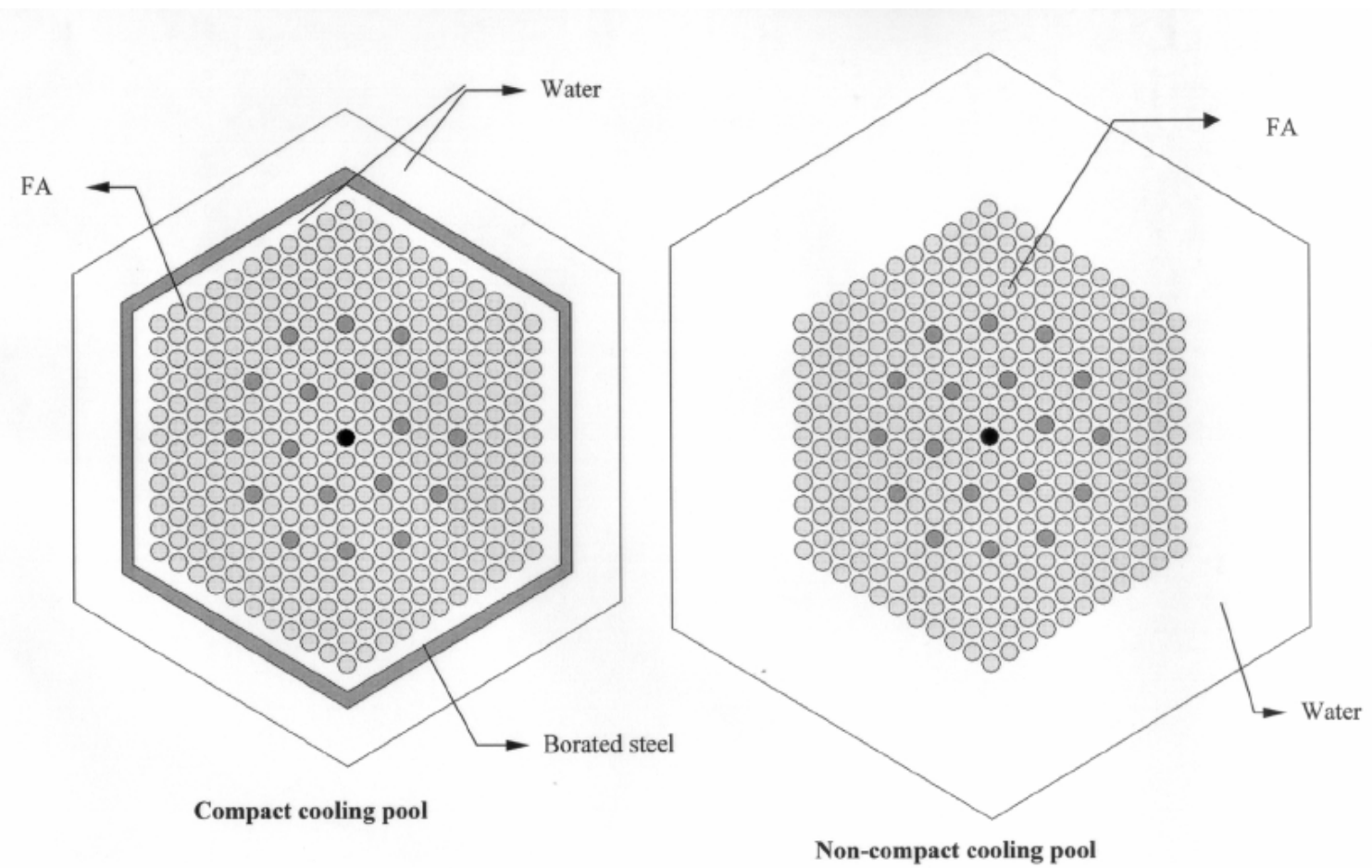

Fig 9.2 Single assembly models used for calculational analysis of compact and noncompact cooling pool arrangements. Source: Ref. 1.

in Figure 9.2 In the case of the noncompact configuration, the assemblies are simply placed in the pool with adequate spacing between assemblies to ensure subcriticality. The compact configuration uses a borated steel container to allow the assemblies to be placed in a tighter arrangement, thereby requiring less storage space. The cell dimensions for the compact and noncompact configurations are typically 300 and $400 \mathrm{~mm}$, respectively.

Calculations of the criticality of these configurations have been performed in accordance with conservative safety rules for determination of the maximal design capacity of the storage area based on assumptions of the assemblies being infinite in the axial direction, room temperature conditions, and no boric acid in the cooling water ${ }^{3}$. Calculations of the multiplication factor as a function of pitch are shown in Fig. 9.3. These results show that the multiplication factors of the $\mathrm{UO}_{2}$ and $\mathrm{MOX}$ assemblies are similar for all pitch values and less than 0.95 for the standard pitch dimensions.

In consideration of accident conditions in which there is a decrease in water density, additional calculations have been performed to obtain the multiplication factor as a function of water density. The results are presented in Fig. 9.4 for $\mathrm{MOX}$ and $\mathrm{UO}_{2}$ assemblies. The dotted lines correspond to a noncompact cooling pool with and without axial neutron leakage with $\mathrm{UO}_{2}$ fuel. Corresponding values are included for MOX fuel without axial leakage (square symbols). The results show that for both $\mathrm{UO}_{2}$ and MOX, an effective multiplication factor of less than 0.95 is obtained for water densities below 0.1 $\mathrm{g} / \mathrm{cm}^{3}$ and above about $0.5 \mathrm{~g} / \mathrm{cm}^{3}$ with little difference between $\mathrm{UO}_{2}$ and $\mathrm{MOX}$. 
The solid curves in Fig. 9.4 correspond to the compact configuration with the water density for the entire pool (upper curve) and inside the borated-steel container (lower curve) for $\mathrm{UO}_{2}$ fuel.

Corresponding points are included for MOX FAs. The results show that the multiplication factor is always below 0.95

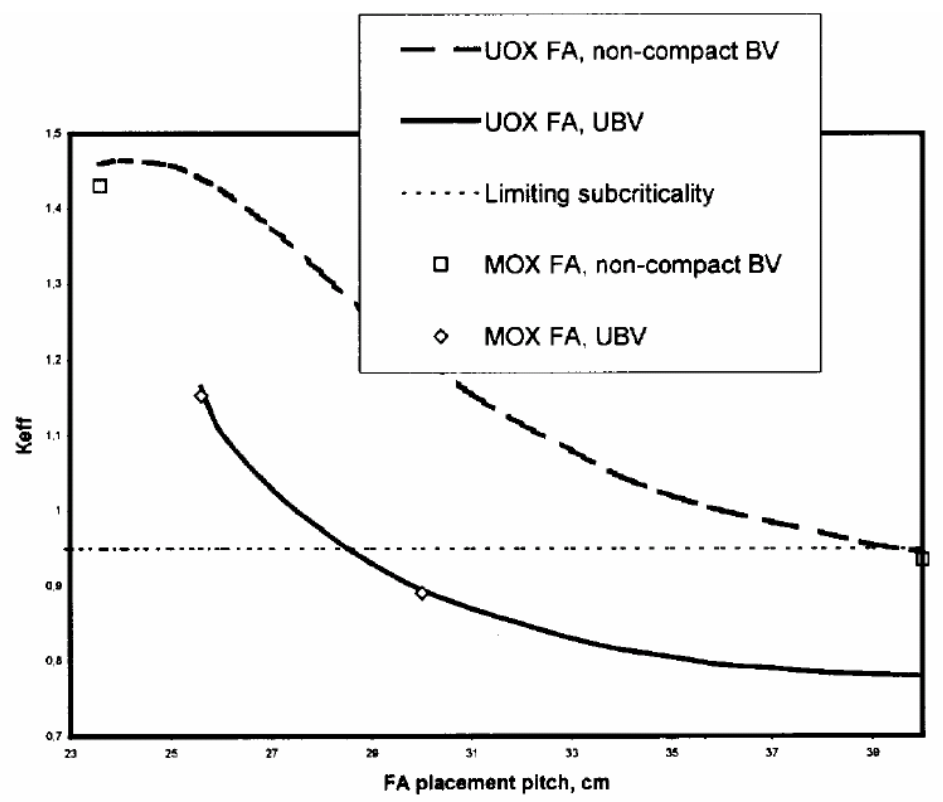

Fig. 9.3 Dependency of the effective multiplication factor on FA placement pitch in compact and noncompact cooling pools. Source: Ref 3.

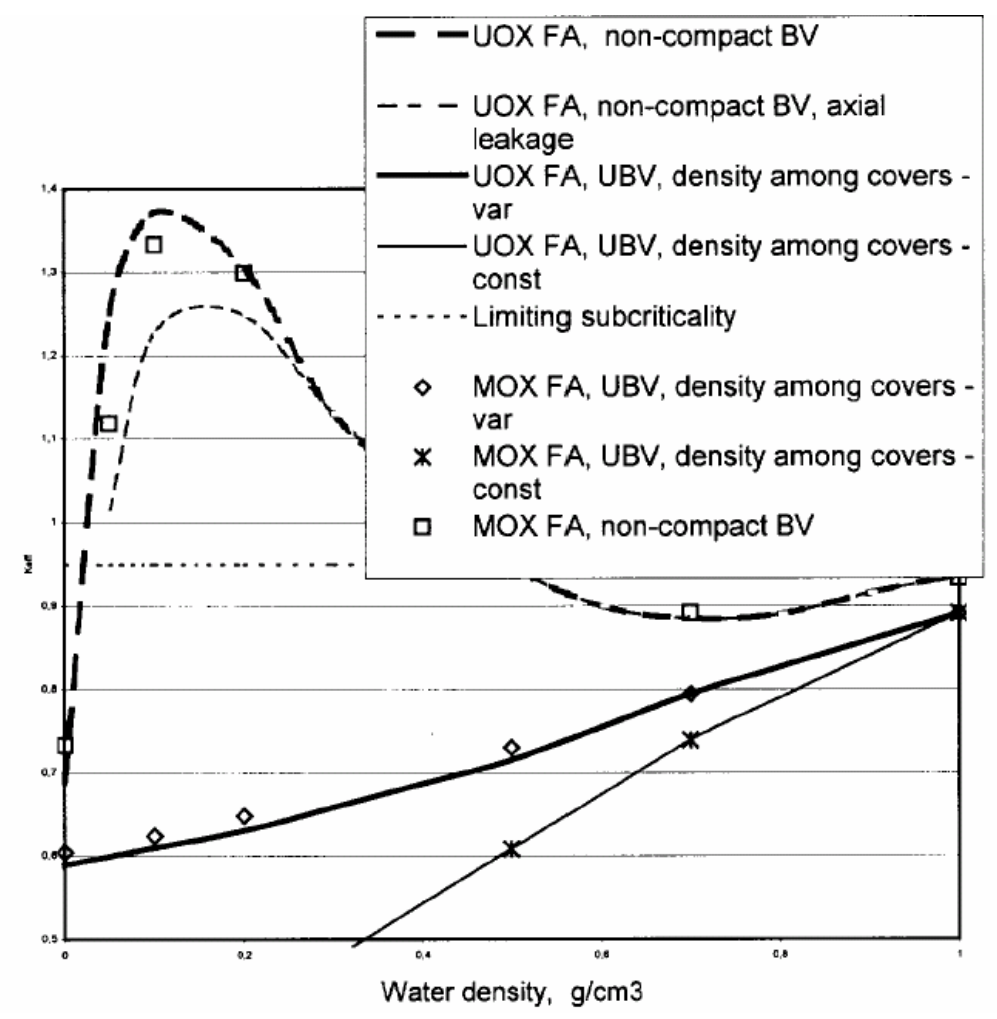

Fig. 9.4 Dependency of the effective multiplication factor on water density in FA for compact and noncompact cooling pools. Source: Ref. 3. 
for all water densities, and like the noncompact case, there is little difference between $\mathrm{UO}_{2}$ and $\mathrm{MOX}$.

The storage of fresh MOX fuel assemblies in the cooling pool before insertion into the reactor has criticality conditions that are nearly identical to $\mathrm{UO}_{2}$ fuel. This applies to both compact and noncompact storage pools.

\subsubsection{Criticality of $\mathrm{UO}_{2}$ and MOX Assemblies in Fuel Transfer Container}

The fresh FAs are transferred from the fresh fuel receiving building (depository) to the cooling pool using a cover to protect the assemblies. The cover can contain a total of 18 FAs with a pitch of $400 \mathrm{~mm}$ as shown in Fig. 9.5. This configuration conservatively corresponds to the case of the FAs in the noncompact storage pool presented above. Therefore, subcriticality (multiplication factor less than 0.95 ) is ensured for water densities less than $0.1 \mathrm{~g} / \mathrm{cm}^{3}$ and greater than $0.5 \mathrm{~g} / \mathrm{cm}^{3}$. Removing levels of conservatism can expand the range of water density for subcriticality, which has been confirmed by calculations performed at $\mathrm{ORNL}^{2}$. Similar to the conclusion for the non-compact cooling pool, there is little difference between the $\mathrm{UO}_{2}$ and MOX FAs in terms of subcriticality.

\subsubsection{Conclusions on Criticality of Fresh MOX Fuel}

Several configurations during the fuel transportation, transfer, and storage have been analyzed with both $\mathrm{UO}_{2}$ and $\mathrm{MOX}$ fuel. In all cases, there are few differences between $\mathrm{MOX}$ and $\mathrm{UO}_{2}$ fuels.

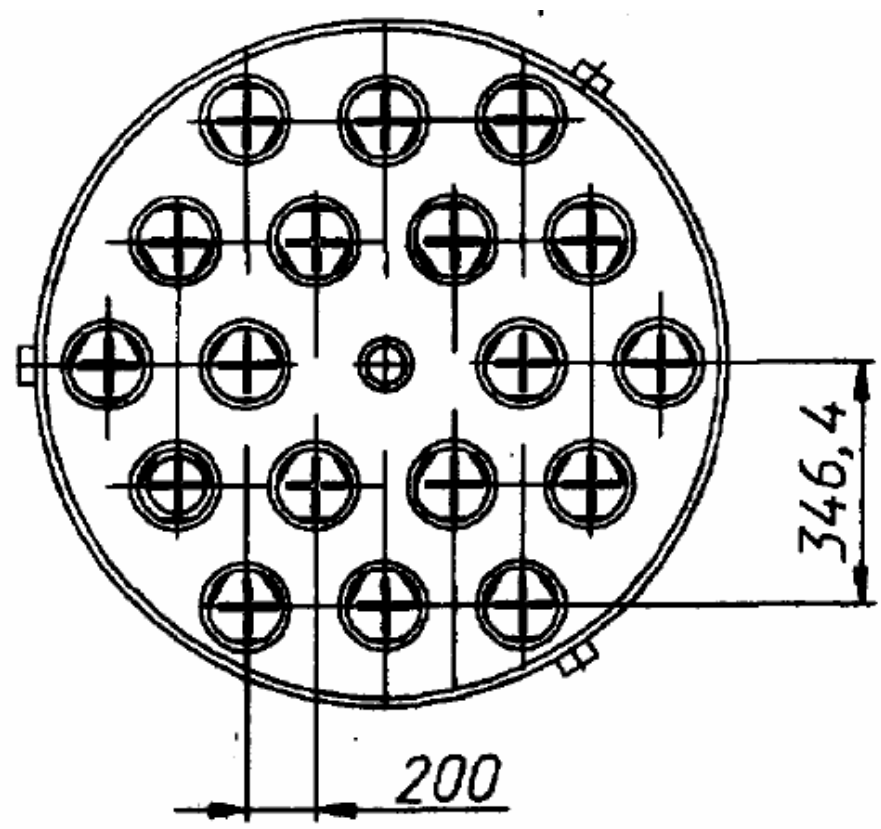

Fig 9.5. Cross-sectional view of fuel transfer container (dimensions in $\mathbf{m m}$ ). Source: Ref. 1. 


\subsection{FRESH FUEL DOSE RATES}

The dose rates of $\mathrm{UO}_{2}$ and MOX fuels are significantly different because of the shorter half-lives of the plutonium isotopes present in the MOX fuel. In the following sections, the dose rates from fresh MOX fuel are compared to those of fresh $\mathrm{UO}_{2}$ fuel. Comparisons are presented for both WG and RG MOX to provide a comparison of the dose rates and to allow consideration of the issues in handling WG MOX fuel vs those of handling RG MOX as performed in several locations throughout the world. The results are based on several analyses performed in Russia, Europe, and the United States ${ }^{3-5}$.

\subsubsection{Neutron and Gamma Sources in Fresh Fuel}

Neutron sources are present in fresh fuel from spontaneous fission and $(\alpha, n)$ reactions with oxygen. Because the plutonium isotopes have a higher spontaneous fission rate and alpha decay activity, the neutron source for MOX fuel is larger than that of $\mathrm{UO}_{2}$ fuel. Table 9.2 shows the neutron sources for $\mathrm{UO}_{2}$, WG MOX and RG MOX FAs in relative units. As this table shows, the neutron source is approximately 350 times larger in WG MOX fuel than $\mathrm{UO}_{2}$ fuel, but about 10 times lower than for RG MOX.

Table 9.2 Comparison of the neutron and gamma sources (relative units) for fresh $\mathrm{UO}_{2}$, WG MOX, and RG MOX

\begin{tabular}{|l|c|c|c|}
\hline & UO $_{2}$ & WG MOX & RG MOX \\
\hline Neutron source (1/s) & $5.8 \mathrm{E}+3$ & $2.0 \mathrm{E}+6$ & $1.9 \mathrm{E}+7$ \\
\hline Gamma source $(1 / \mathrm{s})$ & $1.0 \mathrm{E}+10$ & $3.7 \mathrm{E}+12$ & $1.1 \mathrm{E}+14$ \\
\hline
\end{tabular}

Source: Ref. 4.

Gamma radiation sources are also present in fresh fuel from the decay of the radionuclides that are present either by direct gamma emission or by Bremsstralung from energetic beta particles. In $\mathrm{UO}_{2}$ fuel, the primary source of gammas is from daughter products of ${ }^{238} \mathrm{U}$, particularly ${ }^{234 \mathrm{~m}} \mathrm{~Pa}$. The decay of ${ }^{234 \mathrm{~m}} \mathrm{~Pa}$ is in equilibrium with that of ${ }^{238} \mathrm{U}$, and therefore the dose rate does not vary with time or enrichment. In MOX fuel, in addition to the ${ }^{234 \mathrm{~m}} \mathrm{~Pa}$ source, several of the plutonium isotopes emit gamma rays on decay. A significant source, however, is from the decay of ${ }^{241} \mathrm{Am}$, which is produced from the decay of ${ }^{241} \mathrm{Pu}$. As a result, the gamma source in MOX fuel increases with time from the buildup of ${ }^{241} \mathrm{Am}$. The total gamma source in $\mathrm{UO}_{2}$, WG MOX, and RG MOX, including all of these contributions, is also given in Table 9.2 in relative units. The gamma source in WG MOX is 370 times larger than $\mathrm{UO}_{2}$ fuel and 30 times lower than RG MOX.

\subsubsection{Single Assembly Dose Rates}

Dose rates have been computed for $\mathrm{UO}_{2}$ and MOX FAs for comparison purposes ${ }^{4}$. The results are presented in Table 9.3 for the neutron and gamma dose rates on the FA surface as well as the total dose rate at different distances from the assembly. These results show that the total dose rate at the FA surface and as a function of distance from the MOX is about eight times larger than the dose rates of a $\mathrm{UO}_{2} \mathrm{FA}$. In comparison to RG MOX, the WG MOX total dose rates are about six times lower with the neutron dose being much smaller.

The larger dose rates at the fuel assembly surface may require additional controls in the handling and inspection of the MOX fuel assemblies to minimize the overall dose obtained in these operations. 
Table 9.3 Neutron and gamma dose rates at FA surface and total dose as a function of distance from the FA.

\begin{tabular}{|l|c|c|c|}
\hline \multirow{2}{*}{} & \multicolumn{3}{|c|}{ Dose rate (mrem/h) } \\
\cline { 2 - 4 } & UO $_{\mathbf{2}}$ & WG MOX & RG MOX \\
\hline Neutron dose, FA surface & 0.0 & 13.2 & 128.0 \\
\hline Gamma dose, FA surface & 3.5 & 13.0 & 34.0 \\
\hline Total dose, $0 \mathrm{~m}$ & 3.5 & 26.2 & 162 \\
\hline Total dose, $0.5 \mathrm{~m}$ & 0.5 & 3.7 & 24.1 \\
\hline Total dose, $1.0 \mathrm{~m}$ & 0.2 & 1.9 & 12.1 \\
\hline Total dose, $2.0 \mathrm{~m}$ & 0.1 & 0.8 & 5.0 \\
\hline
\end{tabular}

Source Ref. 4.

\subsubsection{Conclusions on Fresh Fuel Dose Rates}

The neutron and gamma sources are significantly higher for MOX fuel than for $\mathrm{UO}_{2}$. In particular, MOX fuel has a significant level of neutron production that must be considered in the evaluation of the doses. Overall, the dose rate from a fresh fuel assembly is approximately eight times larger than $\mathrm{UO}_{2}$ fuel and is about $25 \mathrm{mrem} / \mathrm{h}$ on the surface. This increase in sources and dose rate will require consideration in the transportation and handling of the fuel to minimize exposure. While these dose rates do not necessarily require remote handling, additional controls may be necessary for MOX fuel that are not required for $\mathrm{UO}_{2}$ fuel for the direct handling of the assemblies.

\subsection{RADIOTOXICITY}

The radiotoxicity of MOX fuel is significantly higher than that of $\mathrm{UO}_{2}$ fuel because almost all of the plutonium isotopes are alpha emitters. Therefore, unlike uranium, plutonium has significant inhalation and ingestion hazard. A comparison of the activities of the major contributors computed with ORIGEN-S (Ref. 6) is given in Table 9.4 for $\mathrm{UO}_{2}$, WG MOX, and RG MOX VVER-1000 assemblies by nuclide. For $\mathrm{UO}_{2}$, the activity of the alpha emitters is approximately $1 \mathrm{Ci}$ and is sufficiently low that there are no issues in the fuel manufacturing process or handling of the fuel assemblies. The WG MOX assembly has a significantly higher alpha activity of nearly $5,000 \mathrm{Ci}$, which is predominately from the short-lived ${ }^{241} \mathrm{Pu}$. The RG MOX assembly has an even higher alpha activity of nearly 30,000 Ci, again predominately from ${ }^{241} \mathrm{Pu}$.

The larger radiotoxicity of MOX fuel must be considered in the fuel manufacturing process, in which plutonium dioxide powder is mixed with uranium dioxide powder, sintered into fuel pellets, and then sealed into fuel rods. Under normal circumstances, once the pellets are sintered and placed into sealed rods, the alpha emitters will be contained in the rods and will not represent a contamination hazard. The primary source of concern is if damage to the fuel cladding were to occur during transportation or handling. Accelerometers on the transport vehicle can be used to provide an indication of possible fuel damage and thereby potentially avoid moving damaged fuel into the nuclear power plant fuel receiving area. In the event of a dropped FA, alpha monitoring equipment and personnel protective equipment may be necessary. 
Table 9.4 Activities of fresh $\mathrm{UO}_{2}$, WG MOX, and RG MOX FAs.

\begin{tabular}{|l|c|c|c|c|c|}
\hline & & & \multicolumn{3}{|c|}{ Activity (Ci per assembly) } \\
\hline \multicolumn{1}{|c|}{ Nuclide } & Half-life & Decay mode & UO $_{2}$ & WG MOX & RG MOX \\
\hline Th-231 & $25.2 \mathrm{~h}$ & $\beta$ & 0.04 & 0.0 & 0.0 \\
\hline Th-234 & $24.1 \mathrm{~d}$ & $\beta$ & 0.13 & 0.1 & 0.1 \\
\hline $\mathrm{Pa}-234 \mathrm{~m}$ & $1.2 \mathrm{~m}$ & $\beta$ & 0.13 & 0.1 & 0.1 \\
\hline $\mathrm{U}-234$ & $2.45 \mathrm{E}+5 \mathrm{y}$ & $\alpha$ & 1.0 & 0.0 & 0.0 \\
\hline $\mathrm{U}-235$ & $7.04 \mathrm{E}+8 \mathrm{y}$ & $\alpha$ & 0.04 & 0.0 & 0.0 \\
\hline $\mathrm{U}-238$ & $4.47 \mathrm{E}+9 \mathrm{y}$ & $\alpha$ & 0.13 & 0.1 & 0.1 \\
\hline $\mathrm{Pu}-238$ & $87.7 \mathrm{y}$ & $\alpha$ & - & 63.1 & 68.8 \\
\hline $\mathrm{Pu}-239$ & $2411 \mathrm{y}$ & $\alpha$ & - & 1076 & 963 \\
\hline $\mathrm{Pu}-240$ & $6560 \mathrm{y}$ & $\alpha$ & - & 244 & 1496 \\
\hline $\mathrm{Pu}-241$ & $14.35 \mathrm{y}$ & $\beta$ & - & 3422 & 26,510 \\
\hline $\mathrm{Pu}-242$ & $3.76 \mathrm{E}+5 \mathrm{y}$ & $\alpha$ & - & 0.0 & 5.4 \\
\hline Am-241 & $432 \mathrm{y}$ & $\beta$ & - & 12.7 & 120 \\
\hline Total & - & - & $\mathbf{1 . 4 6}$ & $\mathbf{4 8 1 8}$ & $\mathbf{2 9 , 2 0 0}$ \\
\hline
\end{tabular}

\subsection{SUMMARY AND CONCLUSIONS}

The results presented in this chapter, which are based on actual analysis, compare the criticality, dose, radiotoxicity in the transportation, handling, and storage of fresh $\mathrm{MOX}$ fuel to that of $\mathrm{UO}_{2}$ fuel. The results indicate the following:

- There is no significant difference in the criticality of $\mathrm{MOX}$ and $\mathrm{UO}_{2}$ fuel in transportation, handling, and storage.

- WG MOX has significantly higher gamma and neutron dose rates than $\mathrm{UO}_{2}$ fuel. These higher dose rates must be considered in the suitability of existing transportation package sets, which may require modifications. The higher dose rates must also be considered in handling and storage, but are sufficiently low that modifications to the plant may not be required.

- MOX has a significantly higher alpha activity than $\mathrm{UO}_{2}$ fuel. The cladding is sufficient to contain this activity and protect the fuel handlers for intact and undamaged fuel. However, additional monitoring and storage will be required for damaged fuel 


\section{REFERENCES}

1. A. M. Pavlovitchev et al., Description of Fresh and Spent Fuel Storage at Balakovo NPP Definitions for Safety Calculations, Russian Research Center "Kurchatov Institute," ORNL/SUB/00-85B99398V-2, Oak Ridge National Laboratory, 2001.

2. S. Goluoglu, Criticality Calculations of Fresh LEU and MOX Assemblies for Transport and Storage at the Balakovo Nuclear Power Plant, ORNL/TM- $\quad$ 2000/286, Oak Ridge National Laboratory, 2000.

3. A. M Pavlovitchev et al., Shipping Cask Studies with MOX Fuel, Russian Research Center "Kurchatov Institute," ORNL/SUB/00-85B99398V-3, Oak Ridge National Laboratory, 2001.

4. A. G. Kalashnikov et al., "Calculations in Radiation Characteristics of Fresh and Spent SA with Uranium Fuel and Fuel on the Basis of Weapons-Grade and Civil Plutonium of VVER-1000 Reactor," ATALANTE 2000: Int. Conf. on the Back-End of the Fuel Cycle for the $21^{\text {st }}$ Century, Avignon France, October 24-26, 2000.

5. M. B. Emmett, Calculational Benchmark Problems for VVER-1000 Mixed Oxide Fuel Cycle, ORNL/TM-1999/207,Oak Ridge National Laboratory, 2000.

6. SCALE: A Modular Code System for Performing Standardized Computer Analyses for Licensing Evaluation, NUREG/CR-0200, Rev. 6 (ORNL/NUREG/CSD-2/R6), Vols. I, II, and III, May 2000. 


\section{SPENT FUEL CRITICALITY AND DOSE PROPERTIES}

Spent MOX fuel has different properties than that of spent $\mathrm{UO}_{2}$ fuel in terms of decay heat, radionuclide inventories, criticality, and dose rates. The decay heat was discussed in Chap. 5, and the radionuclide inventories were discussed in Chap. 6. In this chapter the issues of spent fuel criticality and dose rate will be considered.

\subsection{SPENT FUEL CRITICALITY}

The criticality of spent fuel must be considered in the storage pool where there is a potential for a large array of assemblies to form a critical configuration. Because at full burnup the multiplication factor for the spent fuel is very low (0.8-0.9), the probability of a criticality accident is much smaller than that of fresh fuel. The criticality of the spent fuel pool can be bounded by the very conservative assumption that the fuel is fresh and stored in the compact and noncompact configurations used for fresh fuel (see Chap. 9). The results for the fresh fuel indicate very little difference in criticality between the MOX and $\mathrm{UO}_{2}$ fuels.

\subsection{SPENT FUEL DOSE RATES}

\subsubsection{Single Assembly Dose Rates}

During refueling the spent FAs are moved from the reactor core to the spent fuel pool under water to provide cooling and shielding for the personnel. The assemblies are stored in the spent fuel pool to allow the assemblies to cool until the decay heat is sufficiently low to allow transfer to the spent fuel cask. Calculations of the spent fuel dose rates for $\mathrm{UO}_{2}$ and MOX assemblies were performed for $17 \mathrm{x} 17 \mathrm{PWR}$ assemblies ${ }^{1}$. These results are comparable to the dose rates from VVER-1000 FAs at similar burnups. Figure 10.1 shows a comparison of the neutron dose rate as a function of decay time at one meter from the midplane of MOX and $\mathrm{UO}_{2} \mathrm{FAs}$ at a burnup of $45 \mathrm{MWd} / \mathrm{kg}$. The neutron dose rate is significantly higher (approximately three times larger) for the MOX assembly than the $\mathrm{UO}_{2}$ assembly. The difference between MOX and $\mathrm{UO}_{2}$ is the result of the larger actinide content in the MOX fuel. At shorter decay times, the majority of the neutron production is from spontaneous fission of ${ }^{244} \mathrm{Cm}$, and at long decay times the neutrons are produced by $(\alpha, n)$ reactions. Because MOX fuel has a significantly larger amount of ${ }^{244} \mathrm{Cm}$ and alpha emitters than $\mathrm{UO}_{2}$ fuel, its neutron dose is significantly larger. The gamma dose rate $1-\mathrm{m}$ from the midplane of spent $\mathrm{MOX}$ and $\mathrm{UO}_{2} \mathrm{FAs}$ is shown in Fig. 10.2. The gamma dose rate from the MOX assembly is comparable to that of the $\mathrm{UO}_{2}$ assembly. This is expected because both fuels produce a similar amount of FPs, which are the primary gamma emitters. Note also, that the gamma dose rate is much larger than the neutron dose rates.

\subsubsection{Shipping Cask Dose Rates}

The spent FAs are transported in the TK-13 container, which is shown in Fig 10.3. This shipping cask holds 12 spent FAs and has a thick steel container to provide shielding. The same container was used to analyze the dose rates from spent $\mathrm{MOX}$ and $\mathrm{UO}_{2} \mathrm{FAs}$; however, this assembly has not been approved for transportation of spent MOX fuel. Dose rates were calculated for FAs with burnups of 60 $\mathrm{MWd} / \mathrm{kg}$ after a 3-year cooling time (both conservative assumptions). Table 10.1 provides the neutron and gamma sources for the 12 assemblies for $\mathrm{UO}_{2}$, WG-MOX, and RG-MOX. These results show that the spent MOX fuel has a significantly higher neutron source and comparable gamma source as the $\mathrm{UO}_{2}$ fuel. 


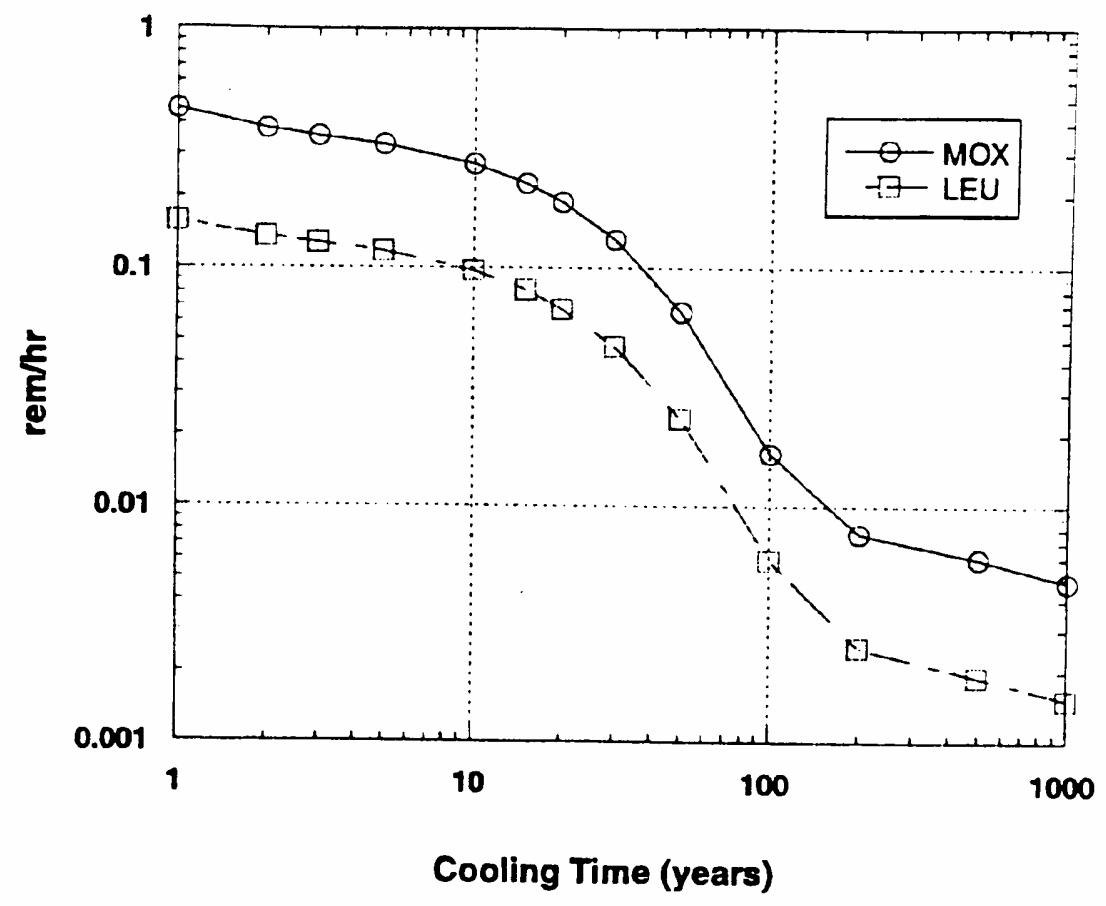

Fig. 10.1 Neutron dose rates at $1 \mathrm{~m}$ from $\mathrm{MOX}$ and $\mathrm{UO}_{2}$ assemblies. Source: Ref. 1.

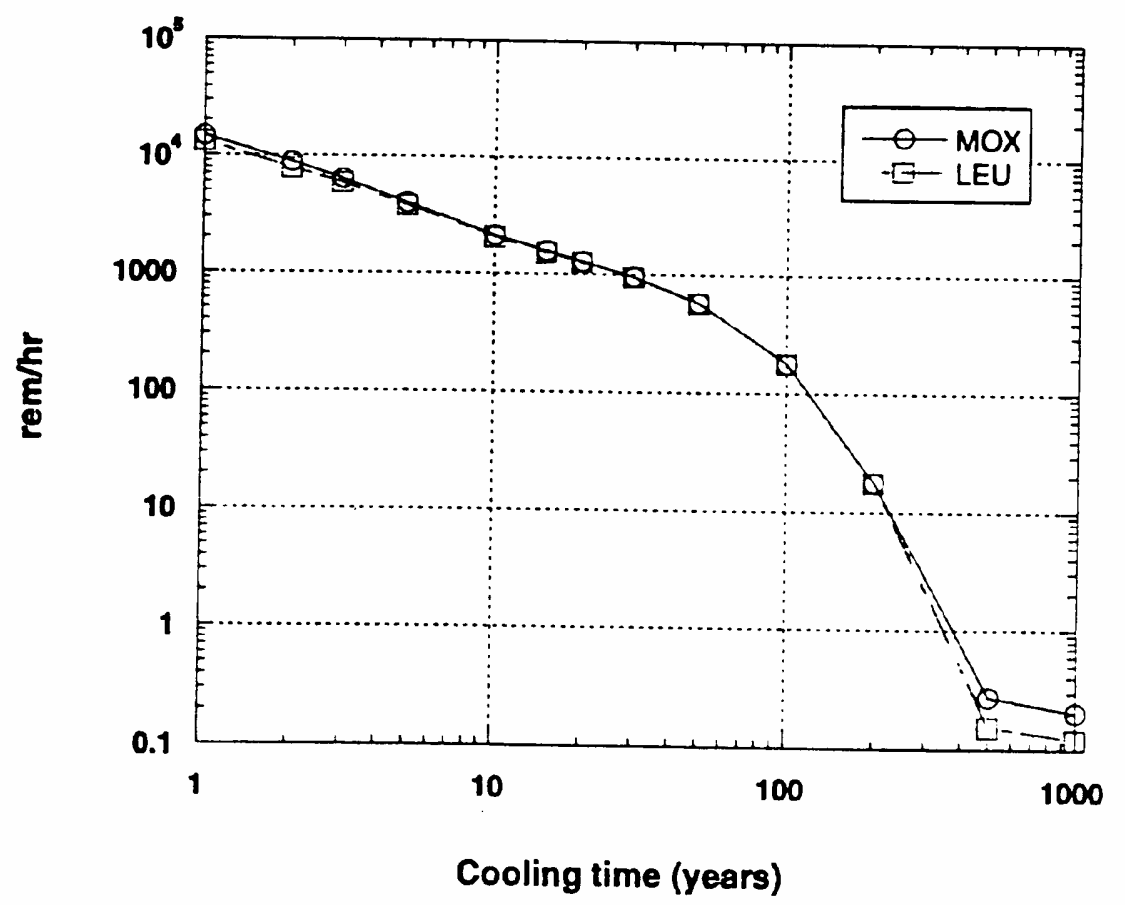

Fig. 10.2 Gamma dose rates at $1 \mathrm{~m}$ from $\mathrm{MOX}$ and $\mathrm{UO}_{2}$ assemblies. Source: Ref. 1. 


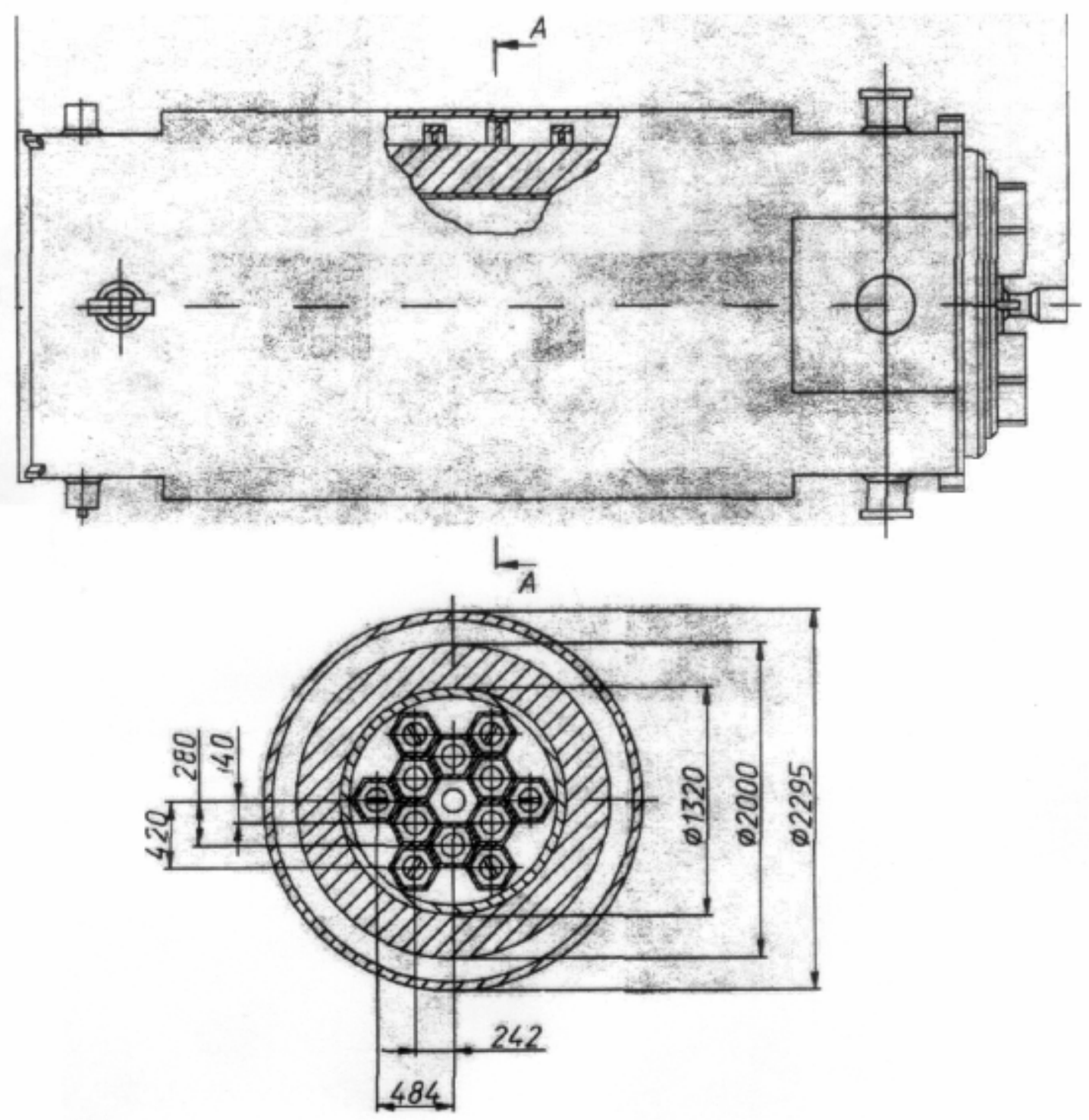

Fig. 10.3 Diagram of TK-13 spent fuel container. Source: Ref. 2. 
Table 10.1 Comparison of the neutron and gamma sources for spent $\mathrm{UO}_{2}$, WG MOX, and RG MOX (burnup of $60 \mathrm{MWd} / \mathrm{kg}$, 3-year cooling time)

\begin{tabular}{|l|c|c|c|}
\hline & $\mathbf{U O}_{2}$ & WG-MOX & RG-MOX \\
\hline Neutron source (1/s) & $9.40 \mathrm{E}+09$ & $2.87 \mathrm{E}+10$ & $1.04 \mathrm{E}+11$ \\
\hline Gamma source (1/s) & $1.02 \mathrm{E}+17$ & $1.21 \mathrm{E}+17$ & $1.16 \mathrm{E}+17$ \\
\hline
\end{tabular}

Source: Ref. 3

Table 10.2 Neutron and gamma dose rates at transportation cask surface and total dose as a function of distance from the cask

\begin{tabular}{|l|c|c|c|}
\hline \multirow{2}{*}{} & \multicolumn{3}{|c|}{ Dose rate (mrem/h) } \\
\cline { 2 - 4 } & UO $_{\mathbf{2}}$ & WG-MOX & RG-MOX \\
\hline Neutron dose, FA surface & 4.8 & 15.0 & 54.4 \\
\hline Gamma dose, FA surface & 28.4 & 79.0 & 280 \\
\hline Total dose, $0 \mathrm{~m}$ & 33.2 & 94.0 & 334 \\
\hline Total dose, $0.5 \mathrm{~m}$ & 17.7 & 49.5 & 176 \\
\hline Total dose, $1.0 \mathrm{~m}$ & 11.4 & 32.6 & 115 \\
\hline Total dose, $2.0 \mathrm{~m}$ & 6.0 & 16.4 & 57.6 \\
\hline
\end{tabular}

Source: Ref. 3

The dose rate at the cask surface and as a function of distance from the cask is given in Table 10.2. The WG-MOX dose rates are approximately three times larger than that of the $\mathrm{UO}_{2}$ dose rates. Note that the gamma dose rates are three times larger even though the gamma source in the fuel is nearly the same. The increased gamma dose rate is the result of capture gammas from the larger neutron source in the MOX fuel.

\subsection{SUMMARY AND CONCLUSIONS}

The criticality of spent MOX fuel is generally the same as for spent $\mathrm{UO}_{2}$ fuel and is generally bounded in safety calculations by the assumption of fresh, unburned fuel. As demonstrated in Chap. 9, fresh $\mathrm{MOX}$ and $\mathrm{UO}_{2}$ fuel was shown to have nearly the same criticality properties.

Spent MOX fuel has a significantly larger neutron source and a comparable gamma source in comparison to spent $\mathrm{UO}_{2}$ fuel. For unshielded assemblies, the larger neutron source is of little concern because the dose rate is dominated by the gamma dose. However, for the spent fuel cask, this higher neutron source results in a factor of 3 increase in the shipping cask external dose rate. Therefore, additional neutron shielding will be required to maintain the same dose rate as for $\mathrm{UO}_{2}$ fuel.

Alternatively, mixed loadings of the TK-13 cask should be considered in which the interior assemblies are $\mathrm{MOX}$ and the exterior assemblies are $\mathrm{UO}_{2}$. This configuration would provide the additional shielding required. 


\section{REFERENCES}

1. W. J. Reich et al, Impacts on Reactor Systems, Operations, Equipment, and Facilities from the Use of MOX Fuels, Appendix G.2, ORNL/MD/LTR-140, Oak Ridge National Laboratory, August 1998.

2. A.M. Pavlovitchev et al., Description of Fresh and Spent Fuel Storage at Balakovo NPP Definitions for Safety Calculations, Russian Research Center "Kurchatov Institute," ORNL/SUB/00-85B99398V-2, Oak Ridge National Laboratory, 2001.

3. A. G. Kalashnikov et al., "Calculations in Radiation Characteristics of Fresh and Spent SA with Uranium Fuel and Fuel on the Basis of Weapons-Grade and Civil Plutonium of VVER-1000 Reactor," ATALANTE 2000: Int. Conf. on the Back-End of the Fuel Cycle for the $21^{\text {st }}$ Century, Avignon France, October 24-26, 2000. 


\section{SECURITY AND MATERIAL PROTECTION CONTROL AND ACCOUNTABILITY (MPC\&A)}

\subsection{GENERAL}

MOX fuel contains WG plutonium that can be diverted to unauthorized weapons use. The WG plutonium in the MOX fuel can be reconverted again into its original weapons source. In contrast, LEU fuel contains less than $5 \%{ }^{235} \mathrm{U}$ and cannot be diverted to weapons use. Therefore, security and material protection requirements for MOX fuel need to be more stringent that with LEU fuel. This applies primarily to fresh MOX fuel; irradiated MOX fuel is very similar to irradiated LEU fuel because their high radiation fields act as "irradiation-barriers" that self-protect both irradiated fuels from diversion.

The additional security measures needed for MOX fuel are to be defined by the Russian authorities and to be agreed by the overall Fissile Material Disposition Program and the International Atomic Energy Agency (IAEA). The Government of the Russian Federation has agreed with the IAEA in a note verbale dated December 1, 1997, to follow IAEA guidelines for the management of plutonium to be used in peaceful nuclear activities. This information is provided in Ref. 1 and is described here. Basically, the Government of the Russia Federation together with the Government of the United States and the IAEA intend to take appropriate measures concerning safeguards and verification of plutonium inventories that have been designated as no longer required for defense purposes. According to Ref. 2, the amount of plutonium in this MOX program (which is more than $2 \mathrm{~kg}$ and unirradiated) categorizes it as Category I, and the guidelines for the management of plutonium in this category are described in the following sections.

\subsection{NONPROLIFERATION AND INTERNATIONAL SAFEGUARDS}

The obligations under the Treaty of the Nonproliferation of Nuclear Weapons (NPT) and its Safeguards Agreement will be followed by the Russian Federation regarding the handling of plutonium in this program. This treaty was adopted at the NPT Review and Extension Conference that took place in New York in May 1995.

\subsection{RESPONSIBLE HANDLING}

Plutonium will be handled in accordance with current internationally recognized standards for radiological protection and nuclear safety (IAEA standards are a recommended option) as accepted by the Government of the Russian Federation and its other relevant international commitments, at all stages of production, separation, processing, fabrication, use, transport, storage and disposal. Special care should be taken to protect the environment, workers, and public.

\subsection{PHYSICAL PROTECTION}

The information of Ref. 2 applies for Category I material. The levels of physical protection to be ensured during the use, storage, and transport of plutonium should be

1. Use and storage in a highly protected area, surrounded by physical barriers with limited points of entry, and under constant surveillance by guards in close communication with appropriate response forces. Access to this protected area should be tightly controlled, restricted to persons whose trustworthiness has been determined.

2. Transport under special precautions, including prior arrangements among sender, recipient, and carrier and under constant surveillance by escorts that assure close communication with appropriate response forces. It requires special armored and secured transport trucks equivalent to 
the U.S. tractor-trailers known as Safeguards Transports (SGTs) or the enclosed safe and secure trailers (SSTs).

3. In the case of an international transfer, the supplier, together with the recipient and the carriers should take the steps necessary to confirm that the different agencies or authorities having responsibility in the transfer ensure the prescribed levels of physical protection and to coordinate recovery and response operations in the event of unauthorized handling or use of plutonium. The national agencies should consult and cooperate as appropriate to secure the safe completion of the transfer.

4. Until they are used or disposed of, holdings of separated plutonium in excess of $15 \mathrm{~g}$ will only be stored at reprocessing plants, fabrication plants, or at sites authorized by the Government of the Russian Federation for that purpose. It is desirable to minimize the number of sites where this material could be held.

\subsection{MATERIAL ACCOUNTABILITY AND CONTROL}

Plutonium inventories will follow an effective system of nuclear material accountability and control, based on a system of material balance areas ${ }^{3}$. Such a system requires keeping for each material accounting records of regular physical inventories and the measurement techniques used in determining them, all inventory changes, in such detail as to permit the book inventory to be determined at any time, and any adjustments and corrections made in respect to physical inventories and book inventories. It will also make provisions for

1. a measurement system for the determination of the quantities of plutonium received, produced, shipped, lost, or otherwise removed from inventory and the total quantities on inventory. This system will either conform to the latest international standards or be equivalent in quality to such standards;

2. the evaluation of the precision, the accuracy of measurements, and the estimation of measurement uncertainty;

3. procedures for identifying, reviewing and evaluating differences in shipper/receiver measurements;

4. procedures for taking a physical inventory;

5. procedures for the evaluation of accumulations of unmeasured inventory and unmeasured losses;

6. a system of records and reports showing, for each material balance area, the inventory of plutonium and the changes in that inventory including receipts into transfers out of the material balance area;

7. assurance that accounting procedures are being operated correctly; and

8. regular verification of accountability records.

\subsection{PUBLICATION OF INFORMATION}

The following information should be published by the Russian Federation to promote transparency and public understanding of how the plutonium to be used in peaceful activities is managed:

1. occasional brief statements explaining the national strategy for nuclear power and for the nuclear fuel cycle, and against this background, the general plans for managing the national holdings of plutonium;

2. annual statements of the holdings of plutonium subject to these guidelines; and

3. annual statements with estimates of the total plutonium contained in the spent civil reactor fuel. 


\subsection{SUMMARY}

The guidelines for the management of plutonium per IAEA information circulars have been described. These guidelines describe the nonproliferation and international safeguards, handling, physical protection, material accountability and control, and publication of information. Detailed guidelines for international transfers have not been included. They are available in IAEA Information Circulars.

\section{REFERENCES}

1. International Atomic Energy Agency (IAEA) Information Circular INFCIR/549, "Communication Received from Certain Member States Concerning their Policies Regarding the Management of Plutonium," Vienna, 16 March 1998.

2. International Atomic Energy Agency (IAEA) Information Circular INFCIRC/225/Rev.4, "The Physical Protection of Nuclear Material and Nuclear Facilities," Vienna, 1998.

3. International Atomic Energy Agency (IAEA) Information Circular INFCIRC/153, "The Structure and Content of Agreements between the Agency and States required in connection with the Treaty on the Non-Proliferation of Nuclear Weapons", 1995. 


\section{CONCLUSIONS AND RECOMMENDATIONS}

\subsection{SUMMARY OF ISSUES}

In this report the significant differences between $\mathrm{MOX}$ and $\mathrm{UO}_{2}$ fuel as used in VVER-1000 reactors was discussed. A summary of the key issues follows:

\section{Assembly and Core Designs (Chap. 2)}

- Suitable assembly and core designs can be obtained for the current 12-month fuel cycle as well as for the 18-month, increased disposition rate cores.

- The validation data available for certification of design codes is sufficient for insertion of LTAs. Additional data to validate data and codes for absorber reactivity worth, reactivity coefficients, and isotopic composition are needed.

Neutronics Properties (Chap. 3)

- $\quad{ }^{239} \mathrm{Pu}$ has significantly different nuclear properties than ${ }^{235} \mathrm{U}$ that impact the neutronic behavior of the reactor core.

- The assembly reactivity vs burnup is different for MOX fuel than $\mathrm{UO}_{2}$ fuel; but with proper design, this difference does not affect the operation of the core in terms of fuel cycle length.

- The neutron spectrum resulting from MOX fuel is harder than that from $\mathrm{UO}_{2}$ fuel. This harder spectrum reduces the worth of the soluble boron and control rod absorbers.

- The worth of absorber materials (boron and gadolinium) used in the soluble boron, burnable absorbers, and control rods is lower in MOX cores. This results in the increase in the soluble boron concentration, increased use of burnable absorbers, and a modification to the control rods to use enriched boron.

- The power distribution and linear heating rates in MOX cores are comparable to that of $\mathrm{UO}_{2}$ cores.

- The delayed neutron fraction and prompt neutron lifetime are smaller in MOX cores and will require analysis to determine any impacts on the reactor safety analysis.

- The moderator temperature coefficient of reactivity is more negative in MOX cores, particularly at $\mathrm{BOC}$, than $\mathrm{UO}_{2}$ cores. The Doppler coefficient of reactivity is also slightly more negative.

- The fast flux at the pressure vessel is not significantly increased in MOX cores if a low-leakage loading pattern with $\mathrm{UO}_{2}$ assemblies on the core periphery is used.

\section{$\underline{\mathrm{MOX} \text { and } \mathrm{UO}_{2}}$ Thermophysical Properties (Chap. 4)}

- The difference in thermal conductivity (lower in MOX fuel) results in a higher MOX fuel temperature (about 50-100 K centerline) and energy stored as compared to $\mathrm{UO}_{2}$ fuel at the same power levels. 
- This higher temperature increases the release of fission products into the gap of MOX fuel.

- MOX fuel has more inhomogeneities, lower heat of fusion, and lower melting temperature than $\mathrm{UO}_{2}$ fuel.

\section{Decay Heat (Chap. 5)}

- Decay heat from MOX fuel is lower during the first day or days after irradiation and larger after that than $\mathrm{UO}_{2}$ fuel.

- The lower decay heat of MOX fuel in the short term is beneficial when compared to $\mathrm{UO}_{2}$ fuel for accidents like LOCAs.

- MOX fuel decay heat is larger than $\mathrm{UO}_{2}$ decay heat in the long term (days) and this may be detrimental in severe accidents and in cooling spent fuel when compared to $\mathrm{UO}_{2}$ fuel.

Source Terms (Chap. 6)

- Irradiated $\mathrm{MOX}$ and $\mathrm{UO}_{2}$ fuels have comparable total fission product activities with variations being nuclide dependent based on the differing fission production yields. MOX source term has more actinides and more iodines which may result in higher neutron and gamma doses from MOX fuel. Gap source terms may be larger for MOX fuel, depending on operating temperatures.

- Irradiated MOX fuel has a significantly larger inventory of actinides, which will be significant at long decay times when actinides dominate the source term.

- Severe accidents consequences (and doses) may be different and possibly worse (higher) for MOX fuel.

\section{Probability Risk Assessment (Chap. 7)}

- PRA levels 1, 2, and 3 need to be revised/upgraded for cores with MOX fuel.

\section{Accident Analysis (Chap. 8)}

- The results of the design basis accidents completed have shown that MOX fuel can be safely burned in VVER-1000 reactors without significant differences compared to $\mathrm{UO}_{2}$ fuel. Cores with up to $1 / 3 \mathrm{MOX}$ were used in these calculations and only the control rods were upgraded.

- Other accidents and calculations for cores with $41 \%$ MOX need to be completed to investigate the need for other reactor modifications. Severe accidents need to be evaluated also, to assess the difference in source term releases and doses when compared to $\mathrm{UO}_{2}$ fuel.

Fresh Fuel Criticality and Dose Properties (Chap. 9)

- There is no significant difference in the criticality of $\mathrm{MOX}$ and $\mathrm{UO}_{2}$ fuel in transportation, handling and storage.

- Weapons-grade MOX has significantly higher gamma and neutron dose rates than $\mathrm{UO}_{2}$ fuel. These higher dose rates must be considered in the suitability of existing transportation package 
sets, which may require modifications. The higher dose rates must also be considered in handling and storage, but are sufficiently low that modifications to the plant may not be required.

- MOX has a significantly higher alpha activity than $\mathrm{UO}_{2}$ fuel. The cladding is sufficient to contain this activity and protect the fuel handlers for intact and undamaged fuel. However, additional monitoring and storage will be required for damaged fuel.

Spent Fuel Criticality and Dose Properties (Chap. 10)

- The criticality of spent MOX fuel is generally the same as for spent $\mathrm{UO}_{2}$ fuel and is bounded in safety calculations by the assumption of fresh, unburned fuel.

- Spent MOX fuel has a significantly larger neutron source and a comparable gamma source in comparison to spent $\mathrm{UO}_{2}$ fuel.

- For the spent fuel cask, the higher neutron source results in a factor of 3 increase in the shipping cask external dose rate. Therefore, additional neutron shielding will be required to maintain the same dose rate as for $\mathrm{UO}_{2}$ fuel.

- Alternatively, mixed loadings of the TK-13 cask should be considered in which the interior assemblies are $\mathrm{MOX}$ and the exterior assemblies are $\mathrm{UO}_{2}$. This configuration would provide the additional shielding required.

$\underline{\text { Security and MPC\&A (Chap. 11) }}$

- Because MOX fuel contains WG plutonium that can diverted to weapons use, additional security and control accountability measures must implemented with MOX fuel.

\subsection{IMPLICATIONS FOR PLANT MODIFICATIONS}

The issues identified in this report and summaries in Sect. 12.1 provide a basis for evaluating the modifications proposed for the Balakovo nuclear power station. Several of the proposed upgrades are important to improve the safety of the plant and apply to both $\mathrm{MOX}$ and $\mathrm{UO}_{2}$ fuel. The following modifications merit consideration:

1. Reactor Protection and Control Absorber Assemblies. The reduced worth of the control rod absorber materials in the partial MOX core affects the scram system and shutdown margin. Changes in the physical design of the control elements to increase their reactivity worth should be considered. The control rod absorber material dimensions can be increased, and the boron can be enriched to increase the reactivity worth. Plans to increase the ${ }^{10} \mathrm{~B}$ concentration to $80 \%$ are already under consideration.

2. Fresh Fuel Transportation, Storage, and Handling Modifications. The radiation field from fresh MOX fuel results in significantly higher doses from MOX fuel than $\mathrm{UO}_{2}$ fuel, particularly the neutron dose. Therefore, modifications to the fresh fuel shipping package may be necessary to meet surface dose requirements. Storage and handling at the nuclear power plant must also consider the increased dose rates and consider necessary changes to minimize dose to personnel. Modifications to the refueling machine may be required to increase reliability to minimize the 
probability of dropped and damaged fuel. An additional facility to contain damaged fresh fuel may be necessary.

3. Failed Fuel Element Detection. MOX fuel provides a different actinide and FP source term than $\mathrm{UO}_{2}$ fuel. The gap release source term in particular is larger in $\mathrm{MOX}$ than in $\mathrm{UO}_{2}$ fuel. This difference in source term merits consideration of improved failed fuel element detection to monitor radionuclide releases.

4. Health Monitoring System. Fresh MOX fuel has a significantly higher radiotoxicity than $\mathrm{UO}_{2}$ fuel, and the irradiated MOX fuel has a significantly different radionuclide inventory than $\mathrm{UO}_{2}$. Fresh fuel handling accidents may result in alpha contamination. Therefore, improvements in the health monitoring system should be considered to protect personnel from exposure to radioactive materials.

5. Spent Fuel Storage. Irradiated $\mathrm{MOX}$ fuel has a larger amount of decay heat than irradiated $\mathrm{UO}_{2}$, which must be considered in the storage in the spent fuel pool and also in the length of the cooling time necessary before transportation. Modifications to the storage pool cooling and configuration may be necessary.

6. Spent Fuel Transportation. Irradiated MOX fuel has a larger neutron and gamma dose rate than irradiated $\mathrm{UO}_{2}$ fuel. Modifications to the spent fuel transfer cask design may be necessary to accommodate the increased dose rate.

7. Reactivity Monitoring System. The insertion of MOX changes the worth of absorbers and the delayed neutron parameters. Therefore, monitoring of the core reactivity may be necessary to ensure that these changes do not have a significant impact on the safety of the core.

8. Soluble Boron and Boron Injection System. The reactivity worth of boron is reduced in MOX cores, and therefore the concentration of the soluble boron to maintain the same reactivity control will increase. For reactivity control during steady-state operation, the boron concentrations are expected to be in an acceptable range with natural boron. However, there may be a need to consider enriched boron to provide acceptable reactivity control and reduce the load on the chemical and volume control system. In addition, the need for modifications to the boron injection system has not been evaluated.

9. Security and Safeguards Modifications. The handling of unirradiated WG plutonium will require additional security and monitoring during transportation and handling at the plant to meet IAEA and Russian governmental requirements. Modifications to provide additional level of protection and monitoring will be required. 
ORNL/TM-2004/233

1-2 B.B. Bevard

3. R.J. Belles

4-8. J.J. Carbajo

9. B.S. Cowell

10-14. R.J. Ellis

15-19 J.C. Gehin

20. M.D. Hogan

21. D.L. Moses

22. L.J. Ott

23. C.V. Parks

24. E.L. Popov

25. D.J. Spellman

26. G.L. Yoder

27. ORNL Laboratory Records, RC

\section{INTERNAL DISTRIBUTION}

\section{EXTERNAL DISTRIBUTION}

28. R. N. Boudreau, Office of Fissile Material Disposition, U.S. DOE, NA-26, 1000 Independence Avenue, SW.,Washington, DC 20585

29. N. D. Fletcher, Office of Fissile Material Disposition, U.S. DOE, NA-26, 1000 Independence Avenue, SW.,Washington, DC 20585

30. V. K. Ivanov, Russian Research Center Kurchatov Insititute, Institute of Nuclear Reactor, VVER Division, 123182 Kurchatov Square 1, Moscow, Russia

31. E. J. Siskin, Office of Fissile Material Disposition, U.S. DOE, NA-26, 1000 Independence Avenue. SW., Washington, DC 20585

32. Y. A. Styrine, Russian Research Center Kurchatov Insititute, Institute of Nuclear Reactor, VVER Division, 123182 Kurchatov Square 1, Moscow, Russia 